\title{
D_A DITMARS
}

\section{NATIONAL BUREAU OF STANDARDS REPORT}

$$
9905
$$

\author{
PRELIMINARY REPORT \\ ON THE THERMODYNAMIC PROPERTIES OF \\ SELECTED LIGHT-ELEMENT AND \\ SOME RELATED COMPOUNDS
}

(The previous semiannual reports in this series have the NBS Report Nos.6297, 6484, 6645,6928, 7093, 7192, 7437, 7587, $7796,8033,8186,8504,8628,8919,9028,9389,9500,9601$, and 9803.$)$

\section{NBS}

$+1$

U.S. DEPARTMENT OF COMMERCE

NATIONAL BUREAU OF STANDARDS 


\section{NATIONAL BUREAU OF STANDARDS}

The National Bureau of Standards ${ }^{1}$ was established by an act of Congress March 3, 1901. Today, in addition to serving as the Nation's central measurement laboratory, the Bureau is a principal focal point in the Federal Government for assuring maximum application of the physical and engineering sciences to the advancement of technology in industry and commerce. To this end the Bureau conducts research and provides central national services in three broad program areas and provides central national services in a fourth. These are: (1) basic measurements and standards, (2) materials measurements and standards, (3) technological measurements and standards, and (4) transfer of technology.

The Bureau comprises the Institute for Basic Standards, the Institute for Materials Research, the Institute for Applied Technology, and the Center for Radiation Research.

THE INSTITUTE FOR BASIC STANDARDS provides the central basis within the United States of a complete and consistent system of physical measurement, coordinates that system with the measurement systems of other nations, and furnishes essential services leading to accurate and uniform physical measurements throughout the Nation's scientific community, industry, and commerce. The Institute consists of an Office of Standard Reference Data and a group of divisions organized by the following areas of science and engineering:

Applied Mathematics-Electricity-Metrology-Mechanics-Heat-Atomic Physics-Cryogenics ${ }^{2}$ - Radio Physics ${ }^{2}$-Radio Engineering ${ }^{2}$ - Astrophysics ${ }^{2}$ - Time and Frequency. ${ }^{2}$

THE INSTITUTE FOR MATERIALS RESEARCH conducts materials research leading to methods, standards of measurement, and data needed by industry, commerce, educational institutions, and government. The Institute also provides advisory and research services to other government agencies. The Institute consists of an Office of Standard Reference Materials and a group of divisions organized by the following areas of materials research:

Analytical Chemistry-Polymers-Metallurgy — Inorganic Materials — Physical Chemistry.

THE INSTITUTE FOR APPLIED TECHNOLOGY provides for the creation of appropriate opportunities for the use and application of technology within the Federal Government and within the civilian sector of American industry. The primary functions of the Institute may be broadly classified as programs relating to technological measurements and standards and techniques for the transfer of technology. The Institute consists of a Clearinghouse for Scientific and Technical Information, ${ }^{3}$ a Center for Computer Sciences and Technology, and a group of technical divisions and offices organized by the following fields of technology:

Building Research-Electronic Instrumentation - Technical Analysis - Product

Evaluation-Invention and Innovation-Weights and Measures - Engineering

Standards-Vehicle Systems Research.

THE CENTER FOR RADIATION RESEARCH engages in research, measurement, and application of radiation to the solution of Bureau mission problems and the problems of other agencies and institutions. The Center for Radiation Research consists of the following divisions:

Reactor Radiation-Linac Radiation-Applied Radiation-Nuclear Radiation.

1 Headquarters and Laboratories at Gaithersburg, Maryland, unless otherwise noted; mailing address Washington, D. C. 20234.

2 Located at Boulder, Colorado 80302.

${ }^{3}$ Located at 5285 Port Royal Road, Springfield, Virginia 22151. 


\section{NATIONAL BUREAU OF STANDARDS REPORT}

\section{NBS PROJEEI}

NBS REPORT
$221-0404$
$221-0405$
$221-0426$
$222-0423$
$313-0430$
$316-0426$
$316-0513$

I July 1968

9905

\section{PRELIMINARY REPORT \\ ON THE THERMODYNAMIC PROPERTIES OF \\ SELECTED LIGHT--ELEMENT AND \\ SOME RELATED COMPOUNDS}

(The previous semiannual reports in this series have the NBS Report Nos.6297,6484,6645,6928, 7093, 7192, 7437, 7587, $7796,8033,8186,8504,8628,8919,9028,9389,9500,9601$, and 9803.)

Technical Summary Report

on the Thermodynamic Properties

of Light-Element Compounds

Reference: U.S. Air Force, Office of Scientific Research, Order No. ISSA 67-6

\section{IMPORTANT NOTICE}

NATIONAL BUREAU OF STA for use within the Government. B and review. For this reason, the whole or in part, is not authoriz Bureau of Standards, Washington the Report has been speciticaliy $p$
Approved for public release by the Director of the National Institute of Standards and Technology (NIST) on October 9, 2015 accounting documents intended Jbjected to additional evaluation isting of this Report, either in Office of the Director, National the Government agency for which ies for its own use.

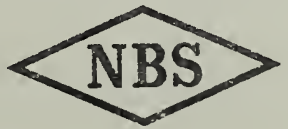

\section{U.S. DEPARTMENT OF COMMERCE}

NATIONAL BUREAU OF STANDARDS 

Thermodynamic and related properties of substances important in current high-temperature research and development activities are being investigated under contract with the U. S. Air Force Office of Scientific Research (USAF Order No. ISSA 67-6) and the Advanced Research Projects Agency (ARPA Order No. 20). This research program is a direct contribution to the Interagency Chemical Rocket Propulsion Group (Working Group on Thermochemistry) and, simultaneously, to other organizations oriented toward acquiring the basic information needed to solve not only the technical problems in propulsion but also those associated with ballistics, reentry, and high-strength high-temperature materials. For given substances this needed basic information comprises an ensemble of closely related properties being determined by an extensive array of techniques. Some of these techniques, by relating thermodynamic properties to molecular or crystal structure, make it possible to tabulate these properties over far wider ranges of temperature and pressure than those actually employed in the basic investigations.

This report presents in detail the methods, results, and interpretation of six recent NBS experimental investigations of thermodynamic and related properties. Measurements of the heats of reaction with hydrogen of chlorine trifluoride and its two free elements gave on preliminary calculation $\Delta \mathrm{Hf}_{303}^{\circ}\left({\mathrm{C} \ell \mathrm{F}_{3}}_{3}\right)=-38.61 \mathrm{kcal} / \mathrm{mol}$, which agrees with two published values and disproves a formerly credited value that is $10 \mathrm{kcal} / \mathrm{mol}$ less exothermic. Precise measurements of the heat capacity of sintered beryllium oxide gave generally lower heat capacities (by up to $30 \%$ at $55 \mathrm{~K}$ ) and an appreciably lower entropy $\left(S_{298.15}^{\circ}=3.291 \pm 0.004 \mathrm{cal} / \mathrm{K} \mathrm{mol}\right)$ than 
previousiy accepted. A new millisecond apparatus for measuririg simultaneously the heat capacity, electrical resistivity, and hemispherical total emittance of electrical conductors is described (respective estimated errors: $1.5 \%, 0.6 \%$, and $3 \%$ at $2500 \mathrm{~K}$; less at $1800 \mathrm{~K})$. Preliminary results are given for molybdenum $(1800-2800 \mathrm{~K})$. The reaction between beryllium metal and aluminum oxide was studied mass-spectrometrically (1511-1743 K). The resulting second-I aw and third-law heats of four reactions involving the gas species $\mathrm{Be}, \mathrm{Al}, \mathrm{O}, \mathrm{Al}_{2} \mathrm{O}$, and $\mathrm{AlO}$ are compared. From a continuation of the spectroscopic investigation of the alkali-hydroxide molecules, the high-temperature microwave spectra of $\mathrm{RbOH}$ and the matrix-isolation infrared spectra of $\mathrm{RbOH}$ and $\mathrm{NaOH}$ (plus the deuteroxides in 2.17 cases) were observed, and are analyzed to give bond lengths, frequency fundamentals, nuclear quadrupole coupling constants, and vibration-rotation interaction constants. The essentially linear shapes and unusual bonding potentials of these molecules are very similar to those found earlier for $\mathrm{CsOH}$, and suggest a similar behavior of all the alkali hydroxides.
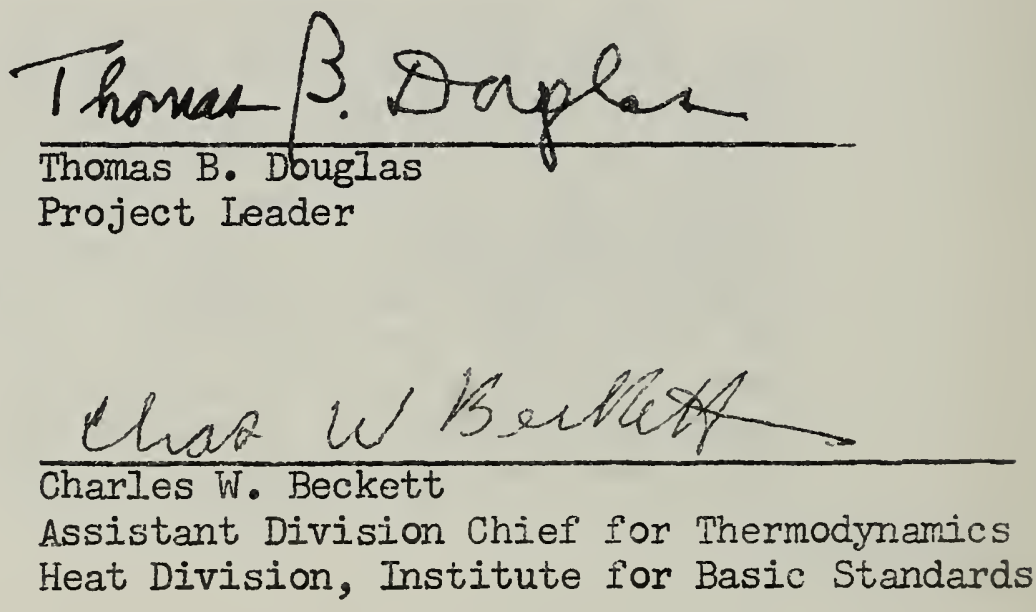
Page

Abstract . . . . . . . . . . . . i

Chap. 1. FLUORINE FLAME CAIORIMETRY III. THE HEAT

OF FORMATION OF CHUORINE TRIFLUORIDE

(by R. C. King and G. T. Armstrong) . . . . . 1

1. Introduction . . . . . . . . . . . I

2. Experimental Apparatus and Procedures . . . 2

2.I The Reaction Vessel and Flow System . . 2

Fig. 1. Assembly of Reaction

Vessel • • • • • 3

Fig. 2. Combustion Chamber and

Primary Solution Vessel . 4

Fig. 3. The Oxidizer Flow Iine • 5

2.2 Water Removal from the Reaction Vessel • 6

Table 1. Water Changes in

Reaction Vessel . . . 7

2.4 The Samples • • • • • . . • . 8

Table 2. Analyses of Oxidizer

3. Calibration of the Calorimeter . . . . 11

Table 3. Calibration of the

Calorimeter.

The $\mathrm{O}_{2}-\mathrm{H}_{2}$ Reaction • 12

4. The Completeness of the Reactions : : : 13

Table 4. The Completeness of the

$\mathrm{C} \mathrm{F}_{3}-\mathrm{H}_{2}-\mathrm{H}_{2} \mathrm{O}$ Reaction . . 14

5. Reaction Heat Measurements . . . . 15

Table 5. The Completeness of the

$\mathrm{C} \ell_{2}-\mathrm{H}_{2}-\mathrm{H}_{2} \mathrm{O}$ and

$\mathrm{C}_{2}-\mathrm{H}_{2}-\mathrm{HF}$ aq Reactions - 17

Table 6. The $\mathrm{ClF}_{3}-\mathrm{H}_{2}-\mathrm{H}_{2} \mathrm{O}$ Reaction:

Typical Reaction

Quantities . . . . 18

Table 7. The $\mathrm{ClF}_{3}-\mathrm{H}_{2}-\mathrm{H}_{2} \mathrm{O}$ Reaction: Typical Heat Measurements 19

Table 8. The Heat of the

$\mathrm{C} \ell \mathrm{F}_{3}-\mathrm{H}_{2}-\mathrm{H}_{2} \mathrm{O}$ Reaction

$\left(303^{\circ} \mathrm{K}\right)$ • . . 20 
$\underline{\text { Page }}$

Table 9. The $\mathrm{Cl}_{2}-\mathrm{H}_{2}-\mathrm{H}_{2} \mathrm{O}$ and

$\mathrm{Cl}_{2}-\mathrm{H}_{2}-\mathrm{HF}_{\mathrm{aq}}$ Typical.

Reaction Quantities . . $2 I$

iable 10. The $\mathrm{Cl}_{2}-\mathrm{H}_{2}-\mathrm{H}_{2} \mathrm{O}$ and

$\mathrm{Cl}_{2}-\mathrm{H}_{2}-\mathrm{HF}_{\text {aq }}$ Reactions :

Typical Heat Measurements . 22

Table 11. The Heats of the

$\mathrm{Cl}_{2}-\mathrm{H}_{2}-\mathrm{H}_{2} \mathrm{O}$ and

$\mathrm{Cl}_{2}-\mathrm{H}_{2}-\mathrm{HF}_{\mathrm{aq}}$ Reactions

$\left(303^{\circ} \mathrm{K}\right) \cdot . .23$

Table 12. The $\mathrm{F}_{2}-\mathrm{H}_{2}-\dot{H C}_{\mathrm{aq}}$ Reaction:

Typical Heat Measurements . 24

Table 13. The Heat of the

$\mathrm{F}_{2}-\mathrm{H}_{2}-\mathrm{HCl}$ aq Reaction

$\left(303.6{ }^{\circ} \mathrm{K}\right)$. . . . 25

Table 14. Preliminary Calculation

of the Heat of Formation

of Chlorine Trifluoride 26

References • • • • • • • • • • 27

Chap. 2. HEAT CAPACITY AND THERMODYNAMIC PROPERTIES OF

BERYLIIUM OXIDE, BeO, FROM 15 TO $370 \mathrm{~K}$

(by George T. Furukawa and Mariin I. Reilly) . . . 28

Abstract . . . . . . . . . . . 28

I. Introduction . . . . . . . . . 28

II. Sample . . • . . . . . . . . 30

III. Apparatus and Method . . . . . . . $3 I$

IV. Results • • • • • • • • • • . 33

Table 1. Spectrochemical Analysis

of the Sintered Beryllium

axide (BeO) Pellet . . 37

Table 2. Thermodynamic Functions for Beryllium Oxide (BeO), Solid Phase • . . . 38

Table 3. Comparison of Enthalpy

Values of Table 2 with

the Experimental Relative

Enthalpy Data of Victor and Douglas.. .39

References • • • • • • • • • • . 40

Fig. 1. Percentage Deviation of

the Empty Sample Vessel

Heat Capacities . . . 43 


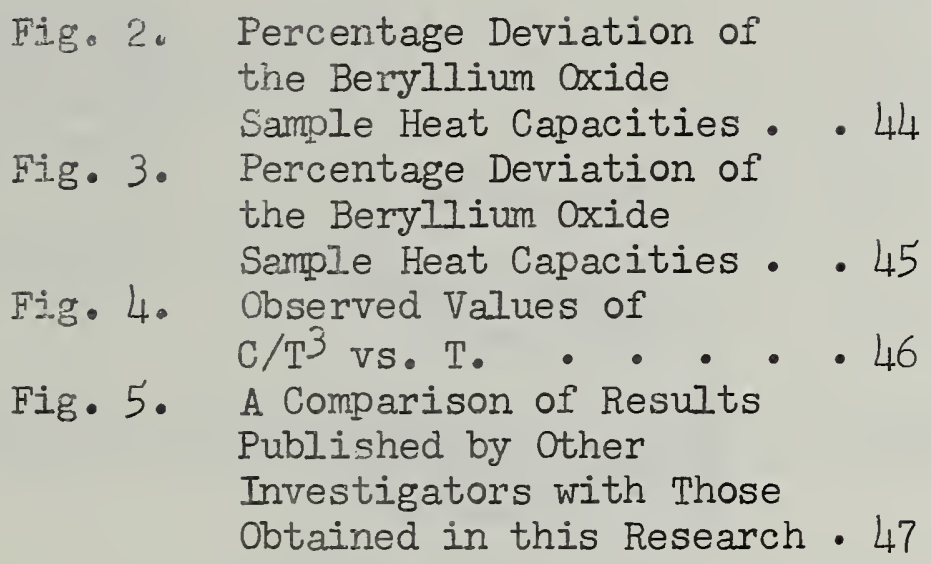

Chap. 3. DYNAMIC MEASUREMENT OF HEAT CAPACITY,

EIECTRICAL RESISTIVITY AND HEMTSPHERICAL

TOTAL EMITTAINCE OF MOLYBDENUM IN THE

RANGE 1800-2800 $\overline{\mathrm{K}}$

(by A. Cezairliyan, M. S. Morse, H. A. Berman,

G. M. Foley, and C.W. Beckett) . . . . . 48

Abstract . . . . . . . . . . 48

I. Introduction . . . . . . . . 49

II. Description of the Method . . . . . . 51

a. Heating Period . . . . . . . 52

b. Cooling Period . . . . . . . 53

c. Relations for Properties . . . . . 53

III. Description of the System . . . . . . 54

a. Specimen and Test Cell . . . . 54

Fig. 1. Functional Diagram of

Millisecond Thermodynamic

Measurements System • . 55

b. Rest of Main Circuit . . . . . 56

c. High-Speed Pyrometer . . . . . 56

d. High-Speed Digital Data Acquisition

System - . . . . . . . 57

Fig. 2. Functional Diagram of

High-Speed Digital Data

Acquisition System . . 59

IV. Experimental Results

Fig. 3. Heat Capacity of

Molybdenum as a Function

of Temperature . . . 61

Fig. 4. Flectrical Resistivity of

Molybdenum as a Function

of Temperature . . . 62 
Fig. 5. Hemispherical Total Emititance of Molybderium as a Function of Temperature . .63

V. Discussion . . . . . . . . . 64 Acknowledgment ........ . . 66 References . . . . . . . . 67

Chap. 4. MASS SPECTROMETRIC STUDY OF THE BERYLIIUMALUMINA REACTION

(by J. Efimenko) . . . . . . . . . 69

Introduction . . . . . . . . . . .69

Experimental . . . . . . . . . . 69

Results

Discussion

Table i. Data: Ion Intensities: 70

Table 2. Auxiliary Data . . . 73

Table 3. Reaction Enthalpies . . 74

Table 4. Partial Pressures . . . 75

Fig. 1. A van't Hoff plot for the reaction

$\mathrm{Be}(\mathrm{g})+\mathrm{Al}_{2} \mathrm{O}_{3}(\mathrm{~s})$

$=\mathrm{BeO}(\mathrm{s})+2 \mathrm{Al}(\mathrm{g})+20(\mathrm{~g}) \cdot 76$

Fig. 2. A van't Hoff plot for the reaction

$2 \mathrm{Al}(\mathrm{g})+\mathrm{O}(\mathrm{g})=\mathrm{Al} \mathrm{O}(\mathrm{g}) \cdot .77$

Fig. 3. A van't Hoff plot for

the reaction

$\mathrm{Be}(\mathrm{g})+\mathrm{Al}_{2} \mathrm{O}(\mathrm{g})$

$=\mathrm{BeO}(\mathrm{s})+2 \mathrm{Al}(\mathrm{g}) \cdot .78$

Fig. 4. A van't Hoff plot for the reaction

$\mathrm{Be}(\mathrm{g})+\mathrm{Al}_{2} \mathrm{O}_{3}(\mathrm{~s})$

$=\mathrm{BeO}(\mathrm{s})+2 \mathrm{AlO}(\mathrm{g}) \cdot .79$

Chap. 5. STRUCTURE OF THE AIKALI HYDROXIDES. III.

MICROWAVE SPECTRA OF RBOH AND RBOD

(by Chi Matsumura and David $\bar{h}_{\text {. Lide, }} \mathrm{Jr}_{\bullet}$ ) . . 80

Abstract • . • . . . . . . . 80

Introduction . . . . . . . . . . . . .8I

Experimental . . . . . . . . . . .81

Analysis of Spectrum . . . . . . . . 83 
$\underline{\text { Page }}$

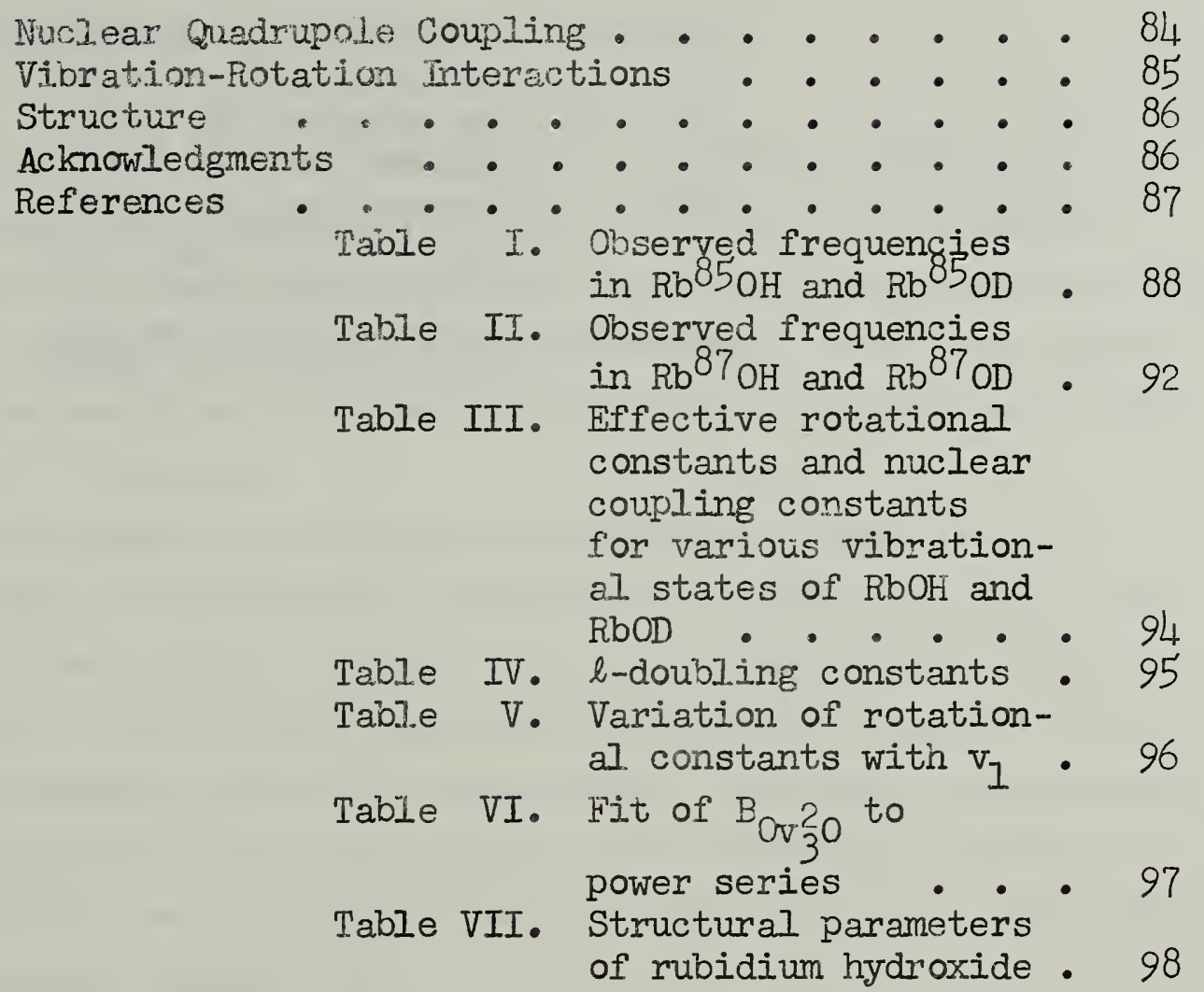

Chap. 6. STRUCTURE OF THE ALKALI HYDROXIDES. IV. THE

INFRARED SPECTRA OF MATRIX ISOLATED RBOH,

$\mathrm{RbOD}$ AND $\mathrm{NaOH}, \mathrm{NaOD}$

(by N. Acquista and Stanley Abramowitz) . . . 99

Abstract

Introduction

Experimental

Experimental Results

References $\quad \begin{aligned} & \text { Table 1. Observed Bands for } \\ & \text { Monomeric Alkali } \\ & \text { Metal Hydroxides . . . } 105\end{aligned}$ 
TABIE OF CONTENTS (Continued)

$\underline{\text { Page }}$

Fig. 2. The spectra of matrix isolated $\mathrm{NaOH}$ in argon . 108

Fig. 3. The spectrum of matrix isolated $\mathrm{NaOH}$ in argon . 109

Fig. 4. The spectrum of matrix isolated $\mathrm{NaOH}$ (and that of $\mathrm{NaOD}$ ) in argon . . . 110

Fig. 5. The spectrum of matrix isolated $\mathrm{NaOD}$ in argon . . 171 
Chapter 1

FLUORINE FLAME CALORIMETRY III.

THE HEAT OF FORMATION OF CHLORINE TRIFLUORIDE

R. C. King and G. T. Armstrong

\section{INTRODUCTION}

A study of the heat of formation of chlorine trifluoride has been conducted using flame calorimetry. Chlorine trifluoride is an extremely reactive compound, which reacts spontaneously with many substances leading to multiple reaction products. For this reason there are few reactions which are suitable for a well-defined study of its heat of formation.

For this study the chlorine trifluoride was reacted with hydrogen, using an experimental approach and procedures similar to those used in an earlier study on the heat of formation of oxygen difluoride [1]. The product acids were dissolved in water to form an aqueous solution inside the calorimeter. The heats of the auxiliary reactions of chlorine and fluorine with hydrogen to form the aqueous solutions of the mixed acids were also measured. The equations for the reactions studied are:

$$
\begin{aligned}
& \mathrm{C} \mathrm{F}_{3}(\mathrm{~g})+2 \mathrm{H}_{2}(\mathrm{~g})+100 \mathrm{H}_{2} \mathrm{O}(\mathrm{l}) \rightarrow\left[\mathrm{HC} 1 \cdot 3 \mathrm{HF} \cdot 100 \mathrm{H}_{2} 0\right](1) \\
& \frac{1}{2} \mathrm{Cl}_{2}(\mathrm{~g})+\frac{1}{2} \mathrm{H}_{2}(\mathrm{~g})+\left[3 \mathrm{HF} \cdot 100 \mathrm{H}_{2} \mathrm{O}\right](1) \rightarrow\left[\mathrm{HC} 1 \cdot 3 \mathrm{HF} \cdot 100 \mathrm{H}_{2} \mathrm{O}\right](\mathrm{l}) \\
& \frac{3}{2} \mathrm{~F}_{2}(\mathrm{~g})+\frac{3}{2} \mathrm{H}_{2}(\mathrm{~g})+\left[\mathrm{HC} 1 \cdot 100 \mathrm{H}_{2} \mathrm{O}\right](\mathrm{l}) \rightarrow\left[\mathrm{HC} 1 \cdot 3 \mathrm{HF} \cdot 100 \mathrm{H}_{2} 0\right](1)
\end{aligned}
$$

Retaining the product acids inside of the calorimeter in a known thermodynamic state has several advantages which have already been discussed [1]. It is believed that the systematic errors in the heats of reactions (2) and (3) are similar to those in reaction (1), and that most of the systematic errors will cancel in the calculation of the heat of formation of chlorine trifluoride, leading to a more accurate value. The agreement between the heats of reactions (2) and (3) and the heats of formation of the aqueous solutions of the respective acids can be used is an indication of the overall validity of the procedures used in this study.

This report presents a brief description of the experiments and some preliminary results on the heats of the reactions and the calculated heat of formation of chlorine trifluoride. 
2. Experimental Apparatus and Procedures

2.1 The Reaction Vesse1 and F1ow System

The overall design of the reaction vessel is illustrated in figure 1. It is similar to the one used and described earlier [1]. The main modification is the use of a secondary solution vessel of larger volume (more like the primary solution vesse1).

The mixture of hydrogen chloride and hydrogen fluoride formed in the chlorine trifluoride-hydrogen reaction was observed to be extremely corrosive. To lessen loss of the acid by corrosion, a removable platinum liner (0.002 in. thick) was placed in the combustion chamber (A). (See figure 2) For the chlorine-hydrogen reactions, a platinum Iiner was placed on the underside of the lid to the combustion chamber. Platinum in this position was found to be very unsuitable for the chlorine-trifluoride experiments, In these experiments the liner on the lid would vaporize, leading a soot-like deposit on the walls of the combustion chamber. A spectrochemical analysis of this deposit revealed it to be platinum.

The undersides of the Monel lids $(J)$ to the solution chambers were coated with Teflon. For an experiment each solution vessel contains $100 \mathrm{~cm}^{3}$ of water. Additional details of the reaction vessel and the procedures for using it have already been described [1].

The overall design of the flow system is similar to that used earlier. The major modification was introduced in the oxidizer flow 1ine. Previously, a Pyrex float-type flowmeter was used to indicate the rate of flow of the oxidizer. Because of the extreme reactivity of chlorine trifluoride, a mass flowmeter was inserted in the oxidizer flow 1 ine to be used in addition to the float-type flowmeter. This modification is shown in figure 3. For the chlorinetrifluoride-hydrogen reactions, the Pyrex flowmeter was replaced with a stand-in Monel tube. However, the Pyrex flowmeter was used satisfactorily for the $\mathrm{O}_{2}-\mathrm{H}_{2}, \mathrm{Cl}_{2}-\mathrm{H}_{2}$, and $\mathrm{F}_{2}-\mathrm{H}_{2}$ reactions and was found very useful for monitoring the $\mathrm{O}_{2}-\mathrm{H}_{2}$ and $\mathrm{Cl}_{2}-\mathrm{H}_{2}$ flames. 


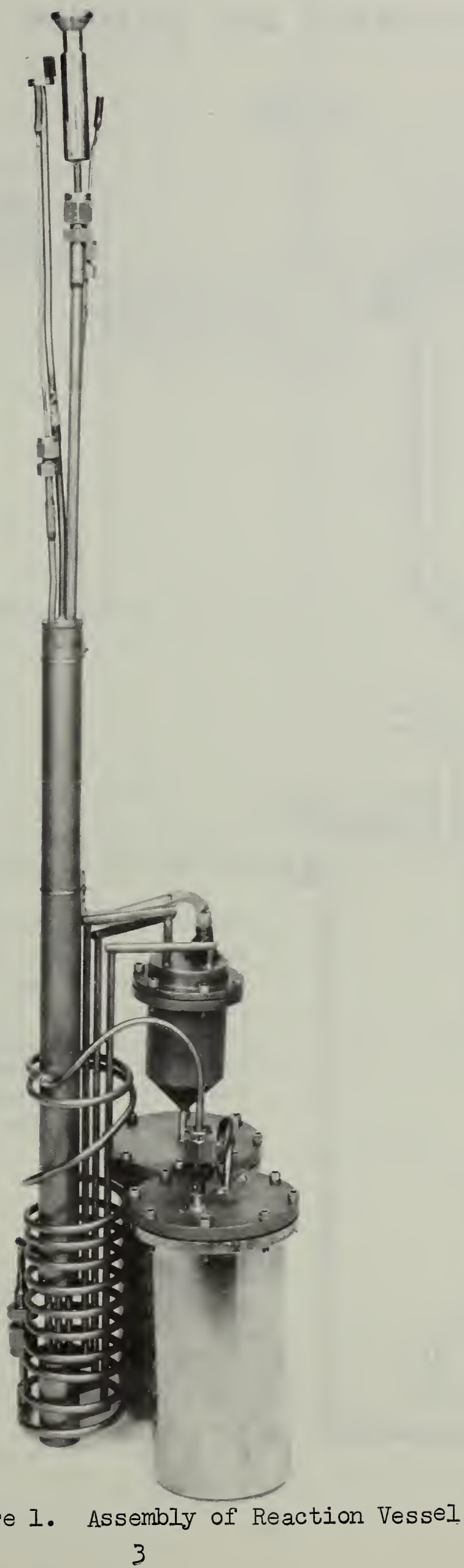



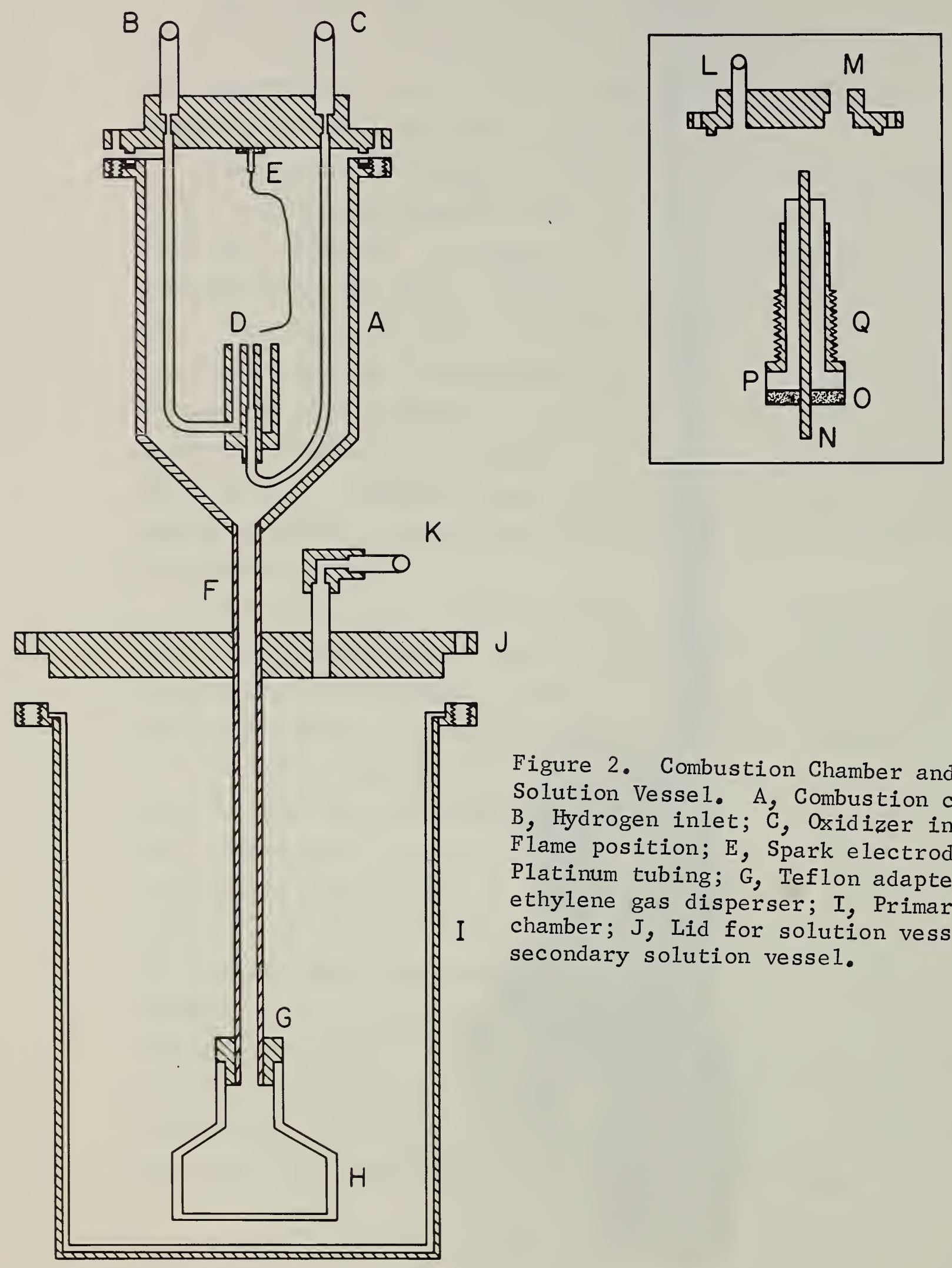

Figure 2. Combustion Chamber and Primary Solution Vesse1. A, Combustion chamber; $B$, Hydrogen inlet; C, Oxidizer inlet; $D$, Flame position; E, Spark electrode; F, Platinum tubing; G, Teflon adapter; H, Polyethylene gas disperser; I, Primary solution chamber; J, Lid for solution vesse1; $\mathrm{K}$, To secondary solution vessel. 

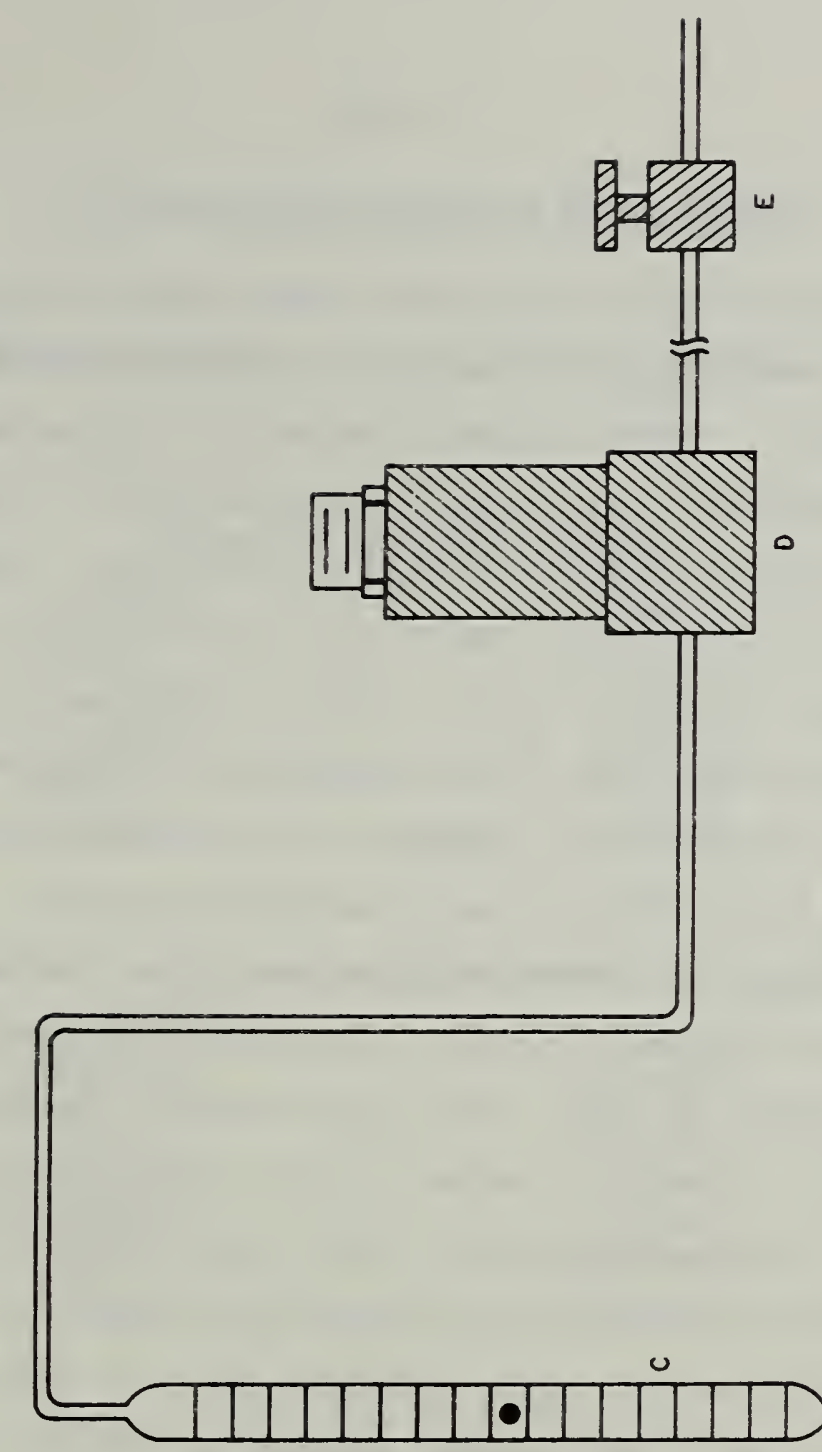

is in 1 14 - 10 ฮ ठ ज 5 D

उ.

० न थ

I I क 0

(1) $m^{\infty}$ it

Uै $\oplus$

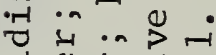

-

.

\&

स 00 है

0 4

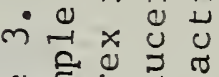

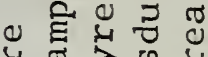

วิ ले से है

- $\rightarrow$ की

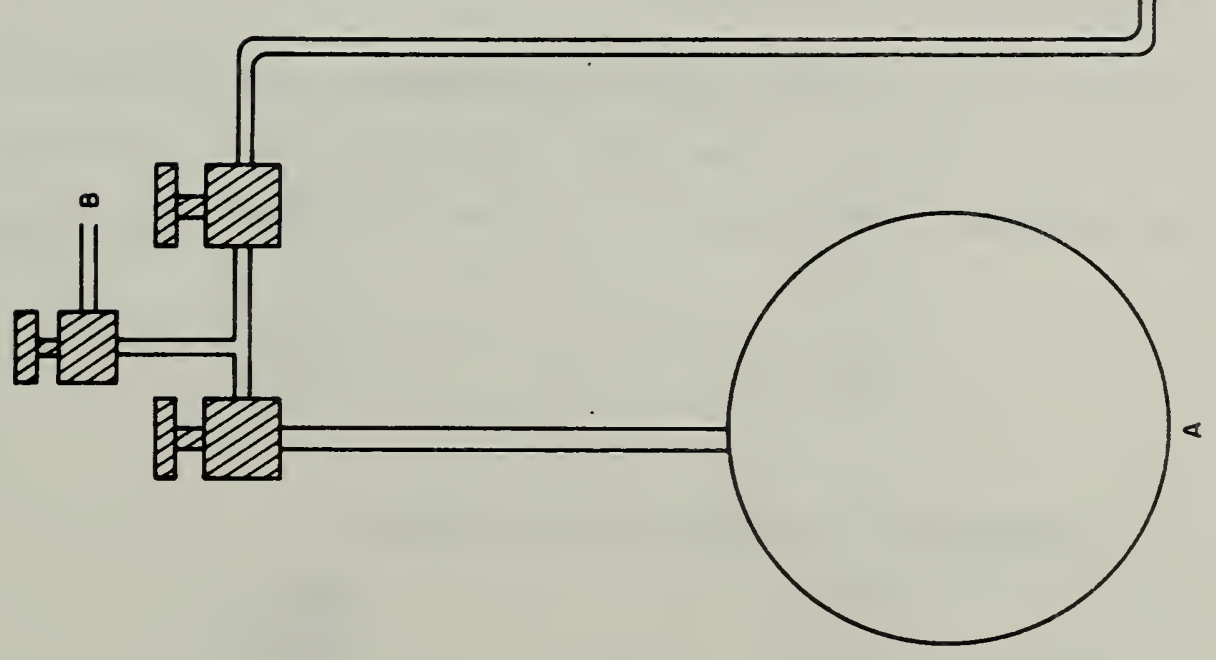




\subsection{Water Removal from the Reaction Vessel}

The water changes in the reaction vessel were checked by weighing the saturators and aborber (magesium perchlorate) before and after each experiment. These water changes are compared in Table 1. It is generally observed that there is consistency in the water changes in the reaction vessel for a given reaction. The addition of water by the hydrogen which enters into reaction can account for the increase in water for the $\mathrm{O}_{2}-\mathrm{H}_{2}, \mathrm{C}_{1} \mathrm{~F}_{3}-\mathrm{H}_{2}-\mathrm{H}_{2} \mathrm{O}$, and $\mathrm{Cl}_{2}-\mathrm{H}_{2}-\mathrm{H}_{2} \mathrm{O}$ reactions. The reactions for these experiments extended over periods ranging from 15 to 20 minutes, whereas the reaction periods for the $\mathrm{Cl}_{2}-\mathrm{H}_{2}-\mathrm{H}_{\mathrm{aq}}$ and $\mathrm{F}_{2}-\mathrm{H}_{2}-\mathrm{HCl}$ aq reactions were shorter, ranging from eight to twelve minutes. Therefore, in the latter experiments less hydrogen was reacted and as a result, less water was added, yielding an overall net removal of water from the reaction vesse1. It is assumed that the net change in water in the reaction vessel is averaged over the entire experiment, which lasts for about 65 minutes. We assume also that the heat effect associated with the net change in water in the reaction vessel is a constant part of the drift of the calorimeter temperature. Therefore, no correction is applied to the temperature rise of the calorimeter, except for the condensation of water carried in by the part of the hydrogen that reacts.

\subsection{Experimental Procedures}

The procedures for conducting an experiment, the ignition system, and methods for calculations have been described [1]. For each reaction, the oxidizer was reacted in excess hydrogen $-n_{H_{E}} / n$ oxidizer $=2$. 
Water Changes in Reaction Vesse 1

Expt

No.
Water Removed

g
Water
in
$\mathrm{g}$
Increase

g

Oxygen-Hydrogen Reaction
0.7634
0.8615
0.0981
0.8477
0.8574
0.0097
1.0371
1.0635
1.0463
0.9446
0.7795
0.8828
$-0.0264$
$-0.1017$
0.1033
0.7060
0.7508
$+0.0448$

Chlorine Trifluoride-Hydrogen-Water Reaction
0.5458
0.5975
$+0.0517$
0.5959
0.5781
0.0178
0.7055
0.7589
$-0.0534$
0.5679
0.6636
0.0957
0.6038
0.6484
$+0.0446$
0.7337
0.7408
0.0071
0.6448
0.7184
0.0186

Chlorine-Hydrogen-Water-Reaction
0.3229
0.6809
0.3016
0.5931
$+0.3580$
0.5554
0.8235
0.8892
1.4887
0.2915
0.2681
0.5995

Chlorine-Hydrogen-HF aq - Reaction
0.8163
0.7222
$-0.0941$
0.9960
0.8689
$-0.1271$
0.8010
0.7147
0.7313
0.6777
0.6136
0.8135
0.7377
$+0.0166$
$-0.0641$
$-0.0758$

Fluorine-Hydrogen-HClaq - Reaction
0.7667
0.8284
0.9450
1.0401

0.7328

$-0.0429$

0.7703

$-0.0581$

0.8921

$-0.0529$

0.8510

$-0.1891$ 
2.4 The Samples

a. biydrogen

A commerclal grade of high-puxity hydrogen was used directly from the cylinder. The aralysis of the sample has already been presented [1].

\section{b. The Oxidizer Gases}

Each sample of the oxidizer gases was obtained commercially. The high-purity oxygen was obtained in a $200 \mathrm{cu} . \mathrm{ft}$. cylinder and was transferred to a weighable spherical bulb for the calibration experiments. The pressure in the sample bulb was $17 \mathrm{~atm}$. The analysis of the sample has already been presented [1].

Chlorine Trifluoride. A large sample $(80 \mathrm{~g})$ of the chlorine trifluoride was transferred to a $250 \mathrm{~cm}^{3}$ weighable bulb for the reactions. The sampling procedure consisted of evacuating and conditioning the bulb and then filling with chlorine trifluoride by condensation with dry ice. The chlorine trifluoride was passed over activated $\mathrm{NaF}$ to remove the $\mathrm{HF}$ in the sample.

The chlorine trifluoride sample was contained as a liquid under its vapor pressure of about 0.4 atm gauge at room temperature. So that the gas and liquid phases of the sample would have similar concentrations of the impurities, a smaller container would have been more desirable. In preliminary experiments, a smaller cylindrical container was used and found to be less satisfactory because of difficulties in controlling the flame. Therefore, the $250 \mathrm{~cm}^{3}$ bulbs were used and were immersed in a beaker of water $\left(30^{\circ} \mathrm{C}\right.$ ) to maintain the pressure of chlorine trifluoride. 
After removal of the hydrogen fluoride, the remaining impurities are more volatile than the chlorine trifluoride. It is possible that the sample becomes purer in chlorine trifluoride as a series of experiments is completed. To check this point, duplicate analyses were performed on the sample at different times. The results showed the sample to contain 0.47 and 0.45 mole \% impurities.

No one method is available which can provide a complete and accurate analysis of the chlorine trifluoride sample. For this study, a combination of the mercury absorption, mass spectrometric and infrared methods are being used. The limitation of the mercury absorption method is that other reactive fluorides are absorbed with the chlorine trifluoride. The C1-0-F compounds are possible impurities in the chlorine trifluoride sample. These gases would be absorbed by the mercury, causing an error in the overall mole percent of the $\mathrm{ClF}_{3}$, and the absorption of these gases may liberate oxygen, causing an error in the analysis for free oxygen in the sample. Because of the unavalability of a better method for a complete analysis of the gas, mercury absorption was used and the residual gas was analyzed by mass spectrometry. The general procedures for these methods have been described [1]. An improvement in the mercury absorption introduced for these analyses was first to condition the mercury and container and then re-evacuate prior to filling to the final pressure of one atm. The results of the analyses are given in Table 2 . Additional analyses on the chlorine trifluoride sample using other methods including infrared analysis are planned.

Chlorine. The chlorine was a commercial research grade sample and no attempt was made to purify it. The chlorine was determined by mercury absorption and the impurities were measured by mass spectrometry. In the mercury-absorption, it was necessary to heat the 
Table 2

Analyses of Oxidizer Gases

Constituent

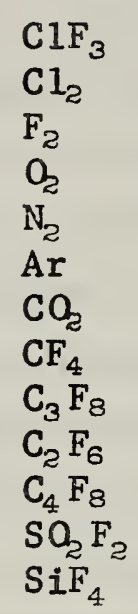

Sample

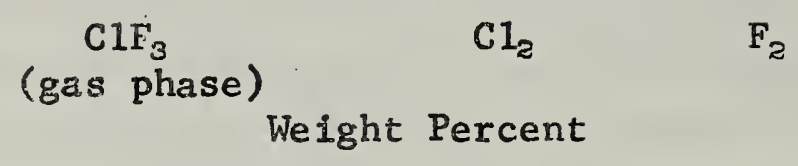

99.82

$-$

.15

.01

*

.01

*

$*$

$*$

$*$

-

- Not detected

* Detected
$\mathrm{F}_{2}$

Weight Percent

$\begin{array}{ccc}99.93 & - \\ 01 & - & 99.85 \\ 01 & .02 & .11 \\ & * 05 & .004 \\ & * & .012 \\ & - & .02 \\ & - & * \\ & - & * \\ & - & * \\ & - & *\end{array}$

.004

.012

.02

$*$

$*$

$*$ 
sampling bulb to achieve complete absorption of the chlorine. The Pyrex bulb was filled to one atm and then agitated and heated gradually with hot water. The analysis of the chlorine sample is given in Table 2.

Fluorine. The analysis of the fluorine sample given in Table 2 was obtained earlier by the mercury absorption and mass spectrometric methois [2]. The fluorine was transferred to the sample bulbs using a manifold described earlier [1].

It is noted that the major impurities in the oxidizer gases are oxygen and nitrogen. It is shown later that a correction is applied to the heat measurement data for the heat of reaction of the impurity oxygen with hydrogen.

\section{Calibration of the Calorimeter}

A preliminary calibration of the calorimeter is obtained from the known heat of the oxygen-hydrogen reaction. The selected value for the heat of this reaction is based on the work of Rossini [4]. The procedures and corrections for using this reaction for calibrations are outlined by Rossini.

Table 3 shows the heat measurement data and the corrections applied for a typical experiment on the oxygen-hydrogen reaction. $\mathrm{m}_{\mathrm{S}}$ is the mass of the oxygen sample. The mass of oxygen reacted is based on the analysis which shows the sample to be 99.987 weight percent oxygen. $\Delta t(\operatorname{cor} r), \Delta t_{c}$ and $t_{\text {ave }}$ are respectively, the corrected temperature rise, the correction to the temperature rise and the average temperature of the calorimeter. $t$ (ave) is the temperature of the reaction. The heat corrections applied are $q$ (ign), the ignition energy, $q$ (vap), the heat effect of the condensation of the water in the reacting hydrogen, and $q$ (temp), the heat of tempering the reacting gases from the room temperature to tave. These corrections were applied to $\mathrm{q}\left(\mathrm{O}_{2}\right)$, the heat of the reacting oxygen, to 
Table 3

\section{Calibration of the Calorimeter. \\ The $\mathrm{O}_{2}-\mathrm{H}_{2}$ Reaction.}

Experiment 6

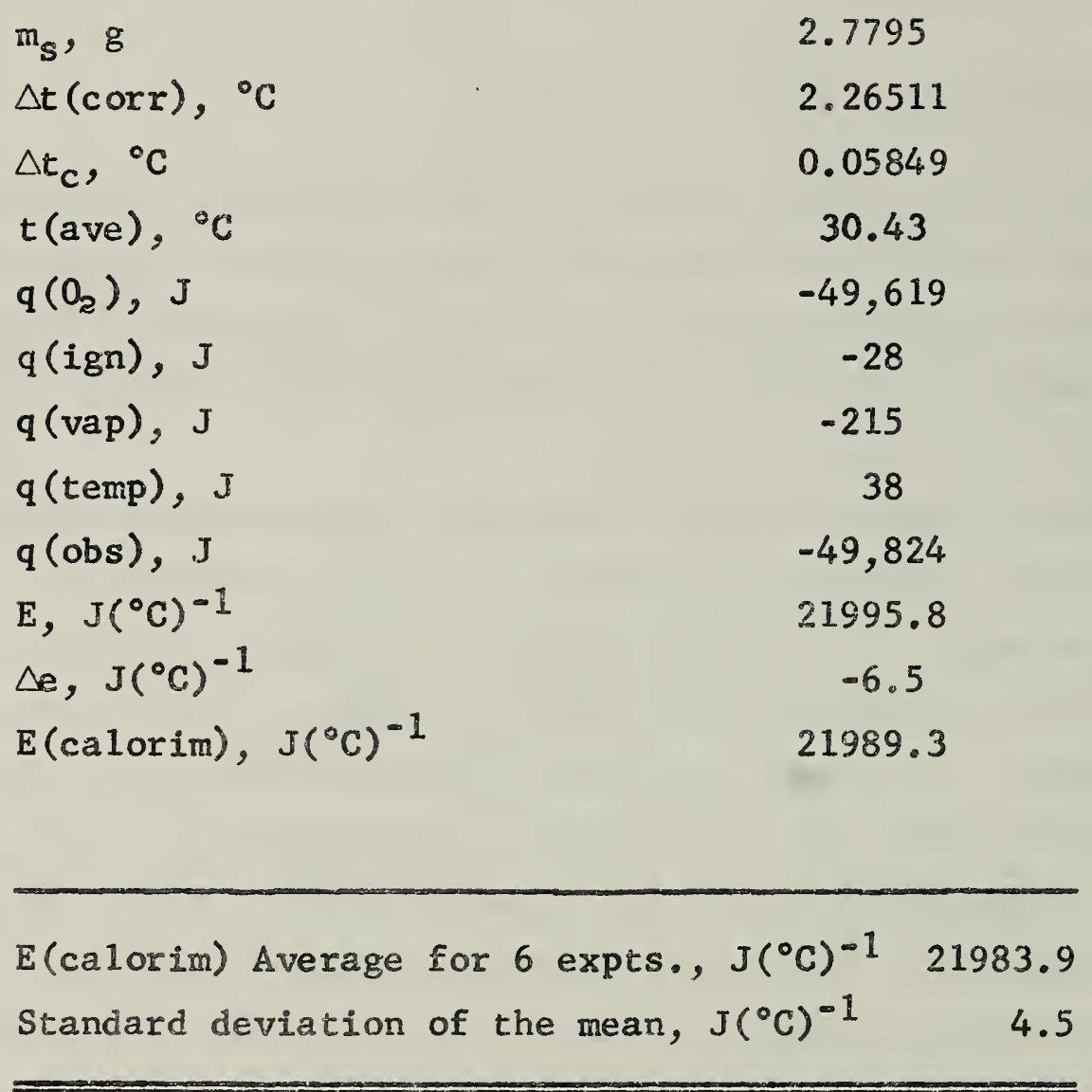


obtain the observed heat, $\mathrm{q}$ (obs). $\Delta e$ is a correction to the energy equivalent for one-half of the water formed in the reaction. The average value for six experiments is given. In an earlier study, the heat of the $a_{z}-H_{2}$ reaction based on electrical calibrations was determined in our apparatus. The close agreement between Rossini's value and our value suggests that our procedures are valid. The standard deviation of the mean shown in Table 3 is larger $(0.02 \%)$ than expected. Additional calculations of the data may reveal the reason for this standard deviation of the mean.

\section{The Completeness of the Reactions}

For the oxygen-hydrogen reaction, the amount of reaction is based on the weight of oxygen introduced into the reaction vessel. Earlier comparisons between the amount of oxygen reacted and the amount of water formed showed that the oxygen was completely reacted.

The completeness of the $\mathrm{ClF}_{3}-\mathrm{H}_{2}-\mathrm{H}_{2} \mathrm{O}$ reaction was determined by analyses of the product solutions. Each solution was analyzed for $\mathrm{H}^{+}$, and for two typical experiments analyses were performed for $\mathrm{Cl}^{-}$and $\mathrm{F}^{-}$. These results are given in Table $4 . \mathrm{n}_{\mathrm{H}^{+}}$(obs) $/ \mathrm{n}_{\mathrm{H}^{+}}$(calc) for these experiment resembles the results for the $\mathrm{F}_{2}-\mathrm{H}_{2}-\mathrm{H}_{2} 0$ reactions [1]. The generally low values can be explained by the extremely reactive nature of the product acid mixture [ $\mathrm{HCl} \cdot 3 \mathrm{HF}$ ] the lowest value for experiment 1 suggests that more conditioning of the combustion chamber took place in that experiment. No explanation is offered for the erratic but favorable value for experiment 6 .

A comparison between the $\mathrm{n}_{\mathrm{Cl}}{ }^{-}$and $\mathrm{n}_{\mathrm{F}}{ }^{-}$shows a value of 0.3337 , which agrees fairly closely with the theoretical ratio of 0.3333 . This suggests that very little, if any of the $\mathrm{ClF}_{3}$ sample is other C1-F compounds. The presence of these would change the value for $\mathrm{n}_{\mathrm{C}} \mathrm{I}^{-/ \mathrm{n}_{\mathrm{F}}}{ }^{-}$. 


\section{Table 4}

The Completeress of the $\mathrm{ClF}_{3}-\mathrm{H}_{2}-\mathrm{H}_{2} \mathrm{O}$ Reaction

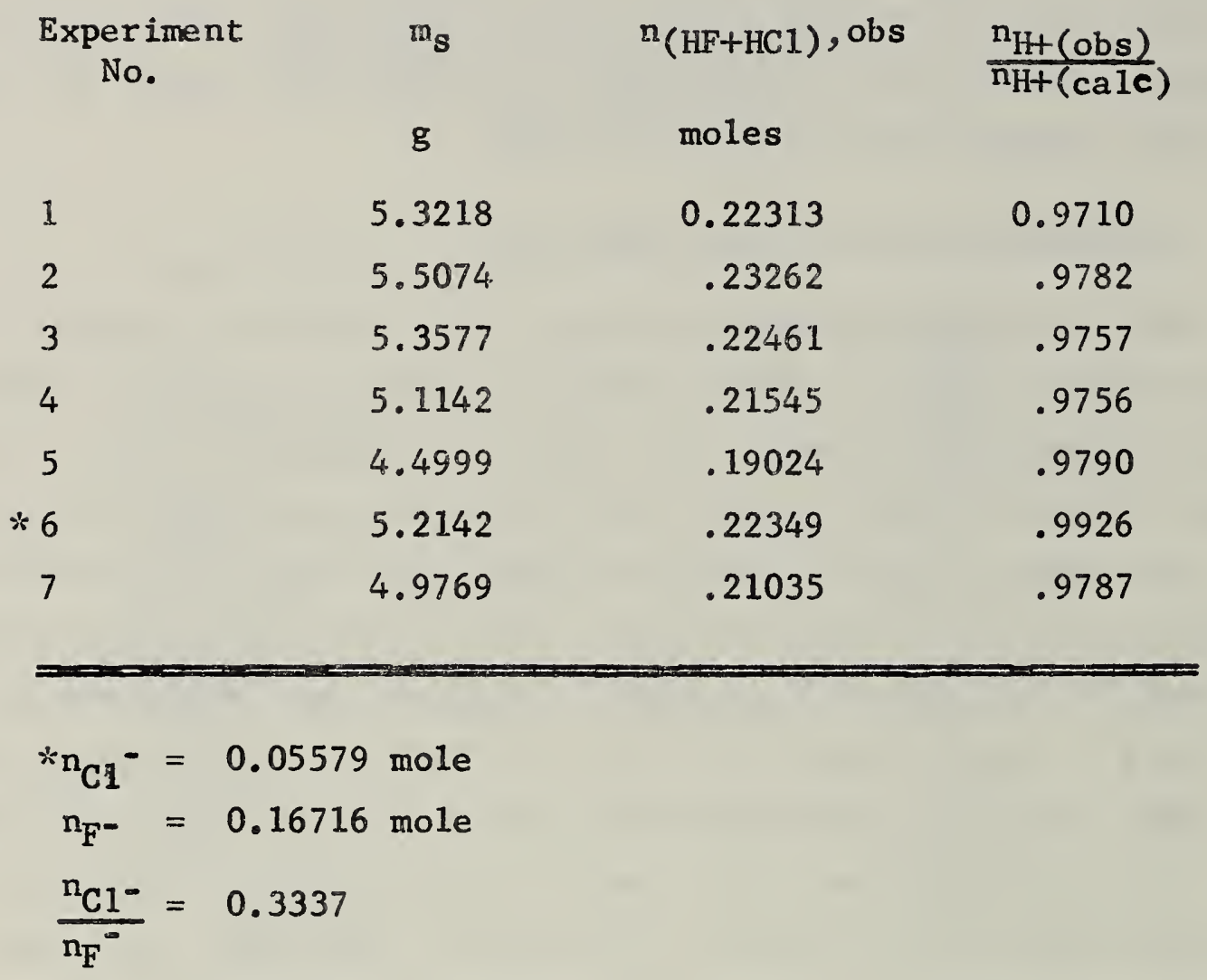


All of the analyses for the $\mathrm{ClF}_{3}$ experiments were performed in the Analytical Chemistry Division at the National Bureau of Standards. The $\mathrm{H}^{+}$and $\mathrm{Cl}^{\text {* }}$ were determined by the conductometric method and the $F^{\infty}$ was measured by potentiometric titration with $\mathrm{Ia}\left(\mathrm{NO}_{3}\right)_{3}$.

The data for the $\mathrm{Cl}_{2}-\mathrm{H}_{2}-\mathrm{H}_{2} \mathrm{O}$ and $\mathrm{Cl}_{2}-\mathrm{H}_{2}-\mathrm{HF}$ aq reactions are given in Table 5. The reactions are generally more complete than the $\mathrm{ClF}_{3}-\mathrm{H}_{2}-\mathrm{H}_{2} \mathrm{O}$ reactions. The $\mathrm{n}_{\mathrm{Cl}_{1}}-/ \mathrm{n}_{\mathrm{H}^{+}}$is larger than the stoichiometric, suggesting that the amount of acid not recovered is consumed by corrosion.

\section{Reaction Heat Measurements}

$\mathrm{C} \mathrm{F}_{3}-\mathrm{H}_{2}-\mathrm{H}_{2} \mathrm{O}$. Typical reaction quantities for this system are given in Table 6. ${ }^{\mathrm{C}_{\mathrm{C}}} \mathrm{F}_{3}$ (reacted) is based on $\mathrm{n}_{\mathrm{H}^{+}}$(obs), and ${ }^{\Delta \mathrm{n}_{\mathrm{ClF}}}$ (.corros) is based on $\mathrm{n}_{\mathrm{H}^{+}}$(calc-obs). The other notations have the same meaning given earlier [1].

The typical heat measurements and the corrections to the heat data are given in Table 7 . With the exception of $\Delta, q$ (corros) and $\mathrm{q}^{\prime} \mathrm{ClF}_{3}$, the symbols have the same meaning as for the oxygen-hydrogen experiments. $\Delta e$ is a correction to the energy equivalent for one-half the product formed. $q$ (corros) corrects for the corrosion by $\mathrm{ClF}_{3}$.

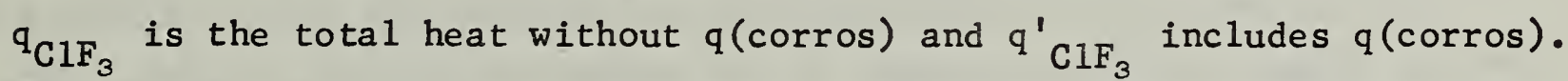
In calculating $q$ (corros), it is assumed that the $\mathrm{ClF}_{3}$ reacts with nickel to give $\mathrm{NiCl}_{2}$ and $\mathrm{NiF}_{2}$.

The heat of the $\mathrm{ClF}_{3}-\mathrm{H}_{2}-\mathrm{H}_{2} \mathrm{O}$ reaction is given in Table 8 . Similar to the earlier work the heat of reactions were calculated in three different ways [1]. Referring to Table $7, \Delta \mathrm{H}(1)$ is $\mathrm{q}_{\mathrm{ClF}_{3}} / \mathrm{n}_{\mathrm{H}^{+}}$(calc); $\Delta H(2)$ is $q_{C 1 F_{3}} / n_{H^{+}}$(obs), and $\Delta H(3)$ is $q^{\prime} \mathrm{ClF}_{3} / \mathrm{n}_{\mathrm{H}^{+}}$(obs). We assume that $\triangle H(3)$ is the most valid treatment of the data because it is based on the heat effect, corrected for corrosion, which the reaction showed evidence of, and also because $\mathrm{n}_{\mathrm{H}^{+}}$(obs) is the actual amount of acid present in the solution. The $\Delta H(2)$ and $\Delta H(1)$ values for experiment six suggest that the good recovery of the acid as shown in Table 4 
may be high. This is suggested also because the standard deviation of the mean for $\Delta H(1)$ where the amount of reaction is based on $n_{\mathrm{H}^{+}}$(calc) is lower than that for $\Delta H(3)$ based on $n_{H^{+}}$(obs). A check on the analyses for experiment six may explain the discrepancy. In the meantime, the average value for $\triangle H(3)$ is used in the calculation of the heat of formation of chlorine trifluoride.

Calculations similar to those given for the $\mathrm{ClF}_{3}-\mathrm{H}_{2}-\mathrm{H}_{3} \mathrm{O}$ reaction were made for the $\mathrm{Cl}_{2}-\mathrm{H}_{2}-\mathrm{H}_{2} \mathrm{O}$ and $\mathrm{Cl}_{2}-\mathrm{H}_{2}-\mathrm{HF}_{\mathrm{aq}}$ solutions and the results are given in Tables 9-11. The notations have been explained for the $\mathrm{ClF}_{3}-\mathrm{H}_{2}-\mathrm{H}_{2} \mathrm{O}$ experiment. Table 10 shows typical calculations for $\Delta H(1), \Delta H(2)$, and $\Delta H(3), q($ corros) is based on the heat of the reaction of chlorine with nickel.

Table 11 gives the values of $\triangle H(1), \triangle H(2)$ and $\triangle H(3)$. The uncertainty figures are the standard deviation of the mean and do not represent the overall uncertainty in the heats of reaction. We assume here also that $\triangle \mathrm{H}(3)$ is the most accurate treatment of the data. We observe that the average values for the heat of formation [ $\mathrm{HC} 1 \cdot \mathrm{H}_{2}$ ] ]

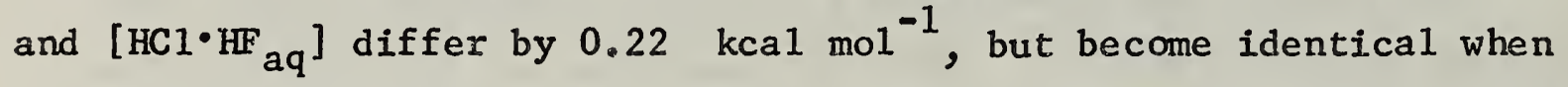
the standard deviation of the mean is applied to each. The preliminary value for $\triangle \mathrm{Hf}\left[\mathrm{HC1} \cdot 50 \mathrm{H}_{\mathrm{z}} \mathrm{O}\right]$ of $-39.71 \mathrm{kcal} \mathrm{mol}^{-1}$ can be compared with the "selected" value of $-39.521 \mathrm{kcal} \mathrm{\textrm {mol } ^ { - 1 }}$ [1].

Preliminary data for the $\mathrm{F}_{3}-\mathrm{H}_{2}-\mathrm{HCl}_{\mathrm{aq}}$ reaction are given in Tables 12 and 13. These results are based on the amount of fluorine reacted. The notations used are the same as described for the earlier reactions.

In Table 14, the preliminary value for the heat of formation of chlorine trifluoride is calculated. This value can be compared with the current selected values of -38 . [3] and $-38.869 \pm 1.0$ [5] kcal mol ${ }^{-1}$ : 
Table 5

The Completeness of the

$$
\mathrm{Cl}_{2}-\mathrm{H}_{2}-\mathrm{H}_{2} \mathrm{O} \text { and } \mathrm{Cl}_{2}-\mathrm{H}_{2}-\mathrm{HF}_{\text {aq }} \text { Reactions }
$$

\begin{tabular}{|c|c|c|c|}
\hline \multirow[t]{2}{*}{$\begin{array}{c}\text { Experiment } \\
\text { No. }\end{array}$} & $\mathrm{m}_{\mathrm{s}}$ & $\mathrm{n}_{\mathrm{HC} 1}$ (obs) & \multirow[t]{2}{*}{$\frac{\mathrm{n}_{\mathrm{HCl}}(\mathrm{obs})}{\mathrm{n}_{\mathrm{HCl}}(\mathrm{calc}}$} \\
\hline & $g$ & moles & \\
\hline \multicolumn{4}{|c|}{$\mathrm{Cl}_{2}-\mathrm{H}_{2}-\mathrm{H}_{2} \mathrm{O}$} \\
\hline 1 & 9.6607 & 0.26976 & 0.9907 \\
\hline 2 & 6.7661 & .19053 & .9990 \\
\hline$* 3$ & 6.6417 & .18702 & .9990 \\
\hline 4 & 7.6865 & .21625 & .9982 \\
\hline \multicolumn{4}{|c|}{$\mathrm{Cl}_{2}-\mathrm{H}_{2}-\mathrm{HF}_{\mathrm{aq}}$} \\
\hline 1 & 2.1408 & 0.06019 & 0.9975 \\
\hline 2 & 2.5748 & .07250 & .9989 \\
\hline 3 & 4.4517 & .12526 & .9982 \\
\hline 4 & 4.5999 & .12793 & - \\
\hline 5 & 2.2925 & .06416 & .9923 \\
\hline
\end{tabular}

${ }^{*} \mathrm{n}_{\mathrm{Cl}^{-}}$(obs) $=0.18715$ mole

$\frac{\mathrm{n}_{\mathrm{C} 1}-}{\mathrm{n}_{\mathrm{H}}}$ (obs) $=1.0007$ 
Table 6

The $\mathrm{ClF}_{3}-\mathrm{H}_{2}-\mathrm{H}_{2} \mathrm{O}$ Reaction

Typical Reaction Quantities

Expt. No.

$\mathrm{n}_{\mathrm{H}+}(\mathrm{calc})$, moles

$\mathrm{n}_{\mathrm{H}}$ (obs), moles

${ }^{\mathrm{C}_{1 F}}{ }_{3}$ (reacted), moles

$\Delta \mathrm{n}_{\mathrm{CHF}_{3}}$ (corros), moles

$\mathrm{n}_{\mathrm{H}_{2}} \mathrm{O}$, moles

$\mathrm{n}_{H_{2}} O /{ }^{\mathrm{n}} \mathrm{HF}$

$\mathrm{n}_{\mathrm{H}_{2}} \mathrm{O} /{ }^{\mathrm{n}} \mathrm{HCl}$
6

0.22516

.22349

.055873

.00042

5.55

84

33 


\section{Table 7}

The $\mathrm{ClF}_{3}-\mathrm{H}_{2}-\mathrm{H}_{2} \mathrm{O}$ Reaction

Typicai Heat Measurements

Expt. No.

$m_{s}, g$

$\Delta t$ (corr),${ }^{\circ} \mathrm{C}$

$\Delta t_{c}$,

$t$ (ave), ${ }^{\circ} \mathrm{C}$

se, $\mathrm{J}\left({ }^{\circ} \mathrm{C}\right)^{-1}$

$\mathrm{E}$ (calorim), $\mathrm{J}\left({ }^{\circ} \mathrm{C}\right)^{-1}$

$q$ (obs), J
6

5.2142

2.48202

.05437

30.69

6.5

21990.4

54581

Corrections to the heat measurements

$\begin{array}{lr}q(\text { ign }), J & -33 \\ q\left(0_{2}\right), J & -131 \\ q(\text { vap }), J & -144 \\ q(\text { temp), J } & 36 \\ q \text { (corros), J } & -421 \\ \mathrm{q}_{\mathrm{C}_{1} \mathrm{~F}_{3}, \mathrm{~J}} & -54303 \\ \mathrm{q}_{\mathrm{C} 1 \mathrm{~F}_{3}, J} & -53882\end{array}$


Table 8

The Heat of the $\mathrm{C1F}_{3}-\mathrm{H}_{2}-\mathrm{H}_{2} \mathrm{O}$ Reaction. $303^{\circ} \mathrm{K}$ $\mathrm{ClF}_{3}(\mathrm{~g})+2 \mathrm{H}_{\mathrm{g}}(\mathrm{g})+100 \mathrm{H}_{2} \mathrm{O}(1) \rightarrow\left[\mathrm{HCl} \cdot 3 \mathrm{HF} \cdot 100 \mathrm{H}_{2} \mathrm{O}\right](1)$

\begin{tabular}{|c|c|c|c|}
\hline Expt. No. & $-\Delta H(1)$ & $\begin{array}{l}-\Delta \mathrm{H}(2) \\
\mathrm{ol} \mathrm{ClF}_{3}\end{array}$ & $-\triangle H(3)$ \\
\hline 2 & 963.51 & 985.06 & 962.64 \\
\hline 3 & 962.74 & 987.09 & 961.74 \\
\hline 4 & 962.57 & 986.70 & 961.58 \\
\hline 5 & 964.61 & 985.30 & 963.81 \\
\hline 6 & 964.70 & 981.95 & 964.42 \\
\hline 7 & 963.65 & 984.54 & 962.80 \\
\hline s.d.m. & $\begin{array}{r}963.63 \\
.37\end{array}$ & $\begin{array}{r}985.11 \\
.75\end{array}$ & $\begin{array}{r}962.83 \\
.45\end{array}$ \\
\hline
\end{tabular}


Table 9

The $\mathrm{Cl}_{2}-\mathrm{H}_{2}-\mathrm{H}_{2} \mathrm{O}$ and $\mathrm{Cl}_{2}-\mathrm{H}_{2}-\mathrm{HFaq}$.

Typical Reaction Quantities

\begin{tabular}{|c|c|c|}
\hline & $\mathrm{Cl}_{2}-\mathrm{H}_{2}-\mathrm{H}_{2} \mathrm{O}$ & $\mathrm{Cl}_{2}-\mathrm{H}_{2}-\mathrm{HF}$ aq \\
\hline Experiment No. & 4 & 1 \\
\hline $\mathrm{n}_{\mathrm{HCl}}(\mathrm{calc})$, mole & 0.21625 & 0.06034 \\
\hline $\mathrm{n}_{\mathrm{HC} 1}$ (obs), mole & 0.21636 & 0.06019 \\
\hline $\mathrm{n}_{\mathrm{HF}}$, mole & - & .16665 \\
\hline $\mathrm{n}_{\mathrm{H}_{2} \mathrm{O}}$, mole & 5.55 & 5.45 \\
\hline$n_{\mathrm{HCl}}($ obs $)-n_{\mathrm{HCl}}(\mathrm{calc})$ & .00028 & .00015 \\
\hline$\Delta \mathrm{n}_{\mathrm{Cl}_{2}}$ (corros) & .00014 & .00008 \\
\hline $\mathrm{n}_{\mathrm{H}_{2} \mathrm{O}} / \mathrm{n}_{\mathrm{HCl}}$ & 25.7 & 90.3 \\
\hline $\mathrm{n}_{\mathrm{H}_{2} \mathrm{O}} / \mathrm{n}_{\mathrm{HF}}$ & - & 32.7 \\
\hline $\mathrm{n}_{\mathrm{HCl} 1} \cdot \mathrm{n}_{\mathrm{HF}}$ & - & 0.36 \\
\hline
\end{tabular}




\section{The $\mathrm{Cl}_{2}-\mathrm{H}_{2}-\mathrm{H}_{2} \mathrm{O}$ and $\mathrm{Cl}_{2}-\mathrm{H}_{2}-\mathrm{HFaq}$ Reactions}

Typical Heat Measurements

$\begin{array}{lcc} & \mathrm{Cl}_{2}-\mathrm{H}_{\mathrm{Z}}-\mathrm{H}_{\mathrm{Z}} \mathrm{O} & \mathrm{Cl}_{2}-\mathrm{H}_{2}-\mathrm{HFaq} \\ \text { Expt. No. } & 4 & 6 \\ \mathrm{~m}_{\mathrm{s}}, \mathrm{g} & 7.6865 & 1.5869 \\ \Delta t(\operatorname{corr}),{ }^{\circ} \mathrm{C} & 1.63739 & .33382 \\ \Delta t_{\mathrm{c}},{ }^{\circ} \mathrm{C} & .04724 & .02717 \\ \mathrm{t}(\text { ave }),{ }^{\circ} \mathrm{C} & 30.92 & 30.33 \\ \triangle \mathrm{e}, \mathrm{J}\left({ }^{\circ} \mathrm{C}\right){ }^{-1} & 6.3 & -7.1 \\ \mathrm{E}(\mathrm{calorim}), \mathrm{J}\left({ }^{\circ} \mathrm{C}\right)^{-1} & 21998.9 & 21985.5 \\ \mathrm{q}(\text { obs }), \mathrm{J} & 36020 & 7339\end{array}$

\begin{tabular}{|c|c|c|}
\hline Cor & ons to the heat & measurements \\
\hline$q(i g n), J$ & -28 & -15 \\
\hline$q\left(O_{2}\right), J$ & -23 & -6 \\
\hline$q($ vap $), J$ & -132 & -27 \\
\hline$q($ temp), J & 40 & 9 \\
\hline$q(\operatorname{corros}), \mathrm{J}$ & -3 & - \\
\hline${ }^{\mathrm{q}} \mathrm{Cl}_{2}, \mathrm{~J}$ & -35861 & -7297 \\
\hline${ }^{\mathrm{q}_{\mathrm{Cl}}}{ }_{2} / \mathrm{n}(\mathrm{calc}), \mathrm{kJ}(\mathrm{mol} \text { soln })^{-1}$ & -166.21 & -165.08 \\
\hline $\mathrm{q}^{\prime} \mathrm{Cl}_{2} / \mathrm{n}(\mathrm{obs}), \mathrm{kJ}(\mathrm{mol} \mathrm{soln})^{-1}$ & -166.51 & -164.60 \\
\hline $\mathrm{q}^{\prime} \mathrm{Cl}_{2} / \mathrm{n}(\mathrm{obs}), \mathrm{kJ}(\mathrm{mol} \mathrm{soln})^{-1}$ & -165.83 & -163.72 \\
\hline
\end{tabular}


凷

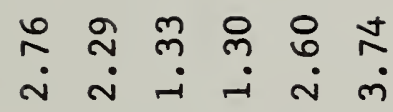

$\stackrel{\varpi 1}{\circ}$

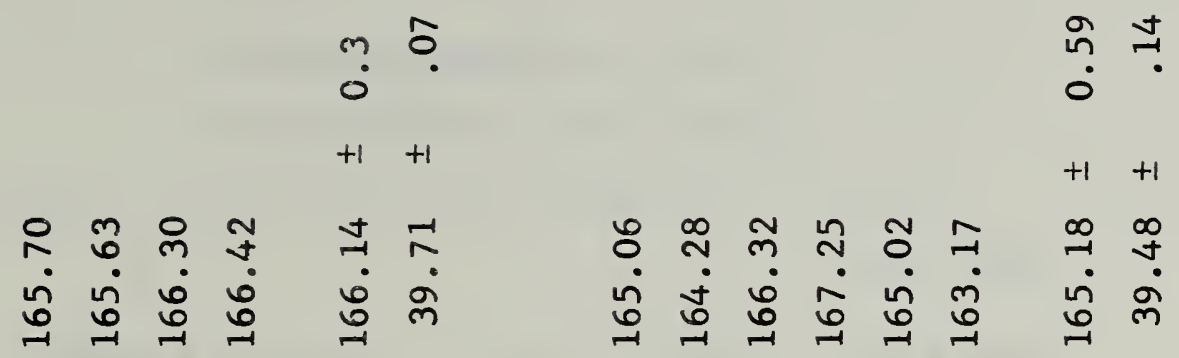

ํํㅇ.

กำ

$\rightarrow$ ฮ

$\int_{\substack{y \\ y}}$

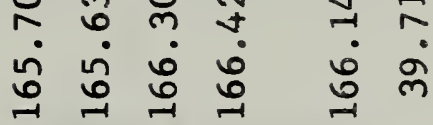

ஸे

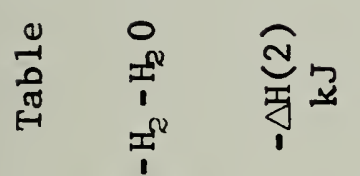

$+1+1$

$+1+1$

चु

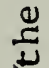

岁

声

$\stackrel{8}{\mathrm{E}-1}$

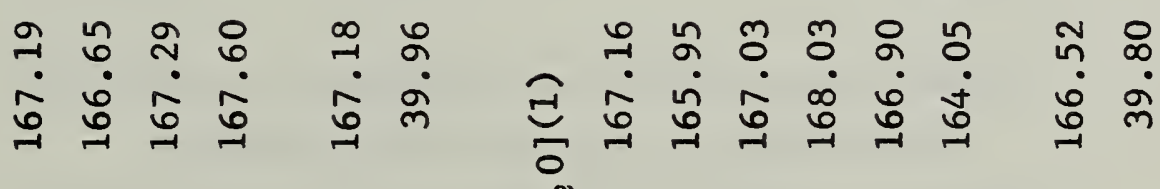<smiles>[CH-]</smiles>

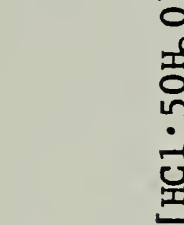

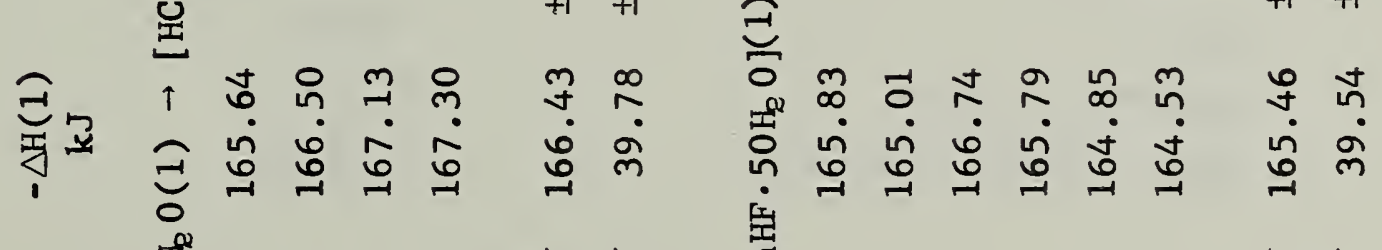

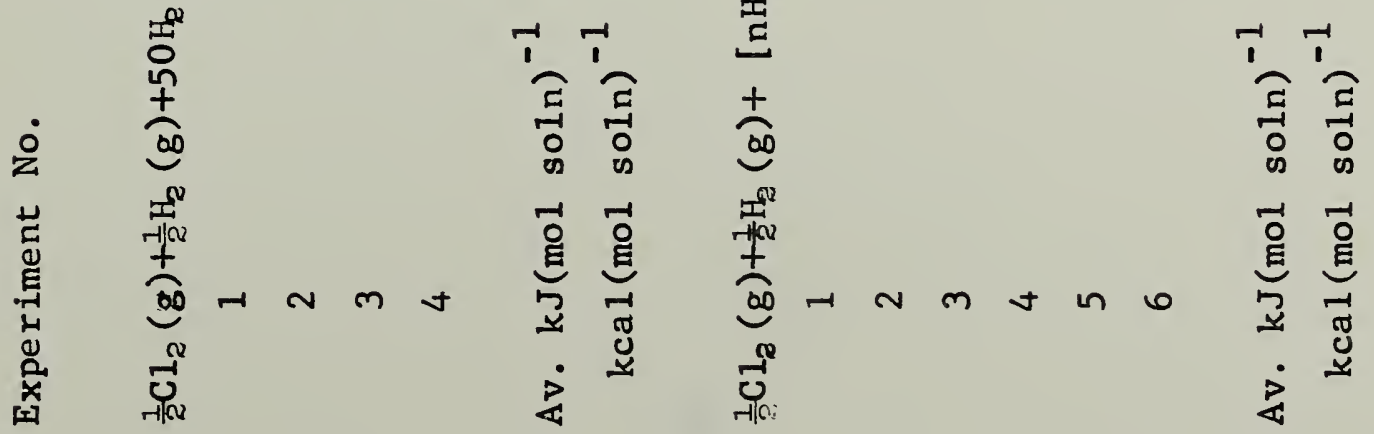




\section{Table 12}

The $\mathrm{F}_{2}-\mathrm{H}_{2}-\mathrm{HCl}$ aq Reaction

Typical Heat Measurements.

Expt. No.

$\mathrm{m}_{\mathrm{s}}, \mathrm{g}$

3.3330

$\Delta t(\operatorname{cor} r),{ }^{\circ} \mathrm{C}$

2.55912

$\Delta t_{\mathrm{c}},{ }^{\circ} \mathrm{C}$

0.05977

t (ave), ${ }^{\circ} \mathrm{C}$

30.51

$\Delta e, J\left({ }^{\circ} \mathrm{C}\right)-1$

$-3.4$

$\mathrm{E}$ (calorim), $\mathrm{J}\left({ }^{\circ} \mathrm{C}\right)^{-1}$

21980.5

$q$ (obs), J

56251

Corrections to the heat measurements

$\begin{array}{lc}\mathrm{q}(\mathrm{ign}), \mathrm{J} & -51 \\ \mathrm{q}\left(0_{2}\right), \mathrm{J} & -86 \\ \mathrm{q}(\operatorname{vap}), \mathrm{J} & -112 \\ \mathrm{q}(\text { temp), J } & 28 \\ \mathrm{qF}_{2}, \mathrm{~J} & 56030 \\ \mathrm{n}_{\mathrm{HF}}(\mathrm{calc}), \text { moles } & 0.17518 \\ \Delta \mathrm{H}_{\mathrm{F}_{2}}, \mathrm{~kJ}(\mathrm{~mol} \mathrm{HF} \mathrm{soln})^{-1} & -319.84\end{array}$




\section{Table 13}

The Heat of the $\mathrm{F}_{\mathrm{z}}-\mathrm{H}_{\mathrm{G}}-\mathrm{HCl}_{\mathrm{aq}}$ Reaction. $303.6^{\circ} \mathrm{K}$

$$
\frac{1}{2} \mathrm{~F}_{2}(\mathrm{~g})+\frac{1}{2} \mathrm{H}_{2}(\mathrm{~g})+50 \mathrm{H}_{2} \mathrm{O}(1) \rightarrow\left[\mathrm{HF}+0.31 \mathrm{HC} 1+50 \mathrm{H}_{2} 0\right](1)
$$

\begin{tabular}{|c|c|c|c|c|}
\hline Expt. No. & $\begin{array}{l}\mathrm{n}_{\mathrm{HF}} \\
\text { mole }\end{array}$ & $\begin{array}{l}{ }_{\mathrm{HCl}} \\
\text { mole }\end{array}$ & $\mathrm{n}_{\mathrm{H}_{2}} \mathrm{O}^{/ \mathrm{n}_{\mathrm{HF}}}$ & $\begin{array}{l}-\Delta H_{R} \\
k J(\operatorname{mol} H F \text { soln })^{-1}\end{array}$ \\
\hline 1 & 0.11626 & 0.0549 & 48 & 320.50 \\
\hline 2 & 0.17518 & 0.0549 & 32 & 319.84 \\
\hline 3 & 0.13190 & 0.0549 & 42 & 318.84 \\
\hline & & & Average & 319.72 \\
\hline
\end{tabular}


Table 14

Preliminary Calculation of the

Heat of Formation of Chlorine Irifluoride.

(1) $\mathrm{ClF}_{3}(\mathrm{~g})+2 \mathrm{H}_{2}(\mathrm{~g})+100 \mathrm{H}_{8} \mathrm{O}(1) \rightarrow\left[3 \mathrm{HF} \cdot \mathrm{HC1} \cdot 100 \mathrm{H}_{2} 0\right](1) \quad-962.83$

(2) $\frac{1}{2} \mathrm{Cl}_{2}(\mathrm{~g})+\frac{1}{2} \mathrm{H}_{2}(\mathrm{~g})+\left[3 \mathrm{HF} \cdot 100 \mathrm{H}_{2} \mathrm{O}\right](1) \rightarrow\left[3 \mathrm{HF} \cdot \mathrm{HCl} \cdot 100 \mathrm{H}_{2} 0\right](1)-165.18$

(3) $\frac{3}{2} \mathrm{~F}_{2}(\mathrm{~g})+\frac{3}{2} \mathrm{H}_{2}(\mathrm{~g})+\left[\mathrm{HC1} \cdot 100 \mathrm{H}_{2} 0\right](1)-\left[3 \mathrm{HF} \cdot \mathrm{HCl} \cdot 100 \mathrm{H}_{2} 0\right](1) \quad-959.19$

(4) $\quad \frac{1}{2} \mathrm{Cl}_{2}(\mathrm{~g})+\frac{3}{2} \mathrm{~F}_{2}(\mathrm{~g}) \rightarrow \mathrm{ClF}_{3}(\mathrm{~g})$

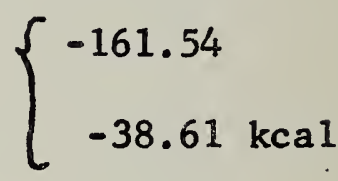




\section{References}

1. R. C. King and G. T. Amstrong, J. Res. NBS 72A, 113 (1968).

2. E. S. Domalski and G. T. Amstrong, J. Res. NBS 71A, 195-202 (1967).

3. D. D. Wagman, W. H. Evans, I. Ha low, V. B. Parker, S. M. Bailey, and R. H. Schumn, Selected Values of Chemical Thermodynamic Properties, Part 1. Tables for the First TwentyThree Elements in the Standard Order of Arrangement, NBS Technical Note 270-1 (U. S. Government Printing Office, Washington, D. C. 20402, 1965).

4. F. D. Rossini, J. Res. NBS 6, 1 (1931) R. P. 259; see also Chapter 4 Experimental Thermochemistry, ed. F. D. Rossini interscience Publishers, Inc., New York, N. Y., 1956).

5. JANAF Thermochemical Tables, PB 168370, Dow Chemical Co., Midland, Michigan (Clearinghouse for Federal Scientific and Technical information, Springfield, Va., August 1966). 
The heat capacity of very fine powders is expected to be higher than that of large crystals, the relative effect of particle size becoming larger with decrease in temperature. The values of heat capacity of $\mathrm{MgO}$ powder of average cube size of $2 \times 10^{-8} \mathrm{~m}(200 \AA)$ reported by Giauque and Archibald [7] are considerably higher than those of large fused Mgo crystals reported by Barron, Berg, and Morrison [2] $(130 \%$ at $20 \mathrm{~K}, 17 \%$ at $50 \mathrm{~K}, 7 \%$ at $100 \mathrm{~K}, 3.5 \%$ at $150 \mathrm{~K}$, $2.6 \%$ at $200 \mathrm{~K}$, and $1.3 \%$ at $250 \mathrm{~K}$ ). Kelley [15] reported heat-capacity measurements on $\mathrm{BeO}$ powder of unspecified crystallite size. The measurements reported by Aslanian and Weil [1] and by Gmelin [8] were on samples from the same source prepared by hot sintering under pressure (sintering temperature unspecified). Aslanian and Weil [1] reported that the three measurements (between 2 and $4 \mathrm{~K}$ ) made on the sample (as received, annealed at $800 \mathrm{C}$, and annealed at $1200 \mathrm{C}$ ) were the same within the experimental accuracy.

Commercially available beryllium oxide powder is usually prepared by thermal decomposition of the hydroxide, the hydroxide being obtained by precipitation from the halide, sulfate, or acetate solution by increasing the $\mathrm{pH}$. The crystallite size of the powder is dependent largely upon the decomposition temperature. Duval and Duval [3] interpreted their thermal gravimetric analysis work to indicate that the decomposition of $\mathrm{Be}(\mathrm{OH})_{2}$ to $\mathrm{BeO}$ and $\mathrm{H}_{2} \mathrm{O}$ starts around $150 \mathrm{C}$ and complete decomposition occurs only on heating to 951 C. Funston, Kirkpatrick, and Turner [4] reported a flat in the thermogram of the decomposition process at about $850 \mathrm{C}$. The crystallite size of the $\mathrm{BeO}$ powder obtained by decomposing $\mathrm{Be}(\mathrm{OH})_{2}$ (precipitated from beryliium basic acetate $\left(\mathrm{Be}_{4} \mathrm{O}\left(\mathrm{OCOCH}_{3}\right)_{6}\right)$ at $85^{\circ}$ to $1000 \mathrm{C}$ was reported by Funston et aI [4] to be around 2 to $5 \times 10^{-8} \mathrm{~m}$ (200 to $500 \AA$ ). Calcination at higher temperatures yield larger crystallites [4]. 
The sample investigated by Kelley [15] was assumed to be a very fine powder, considering the probable method of preparation and the expected particle size discussed above. For the heat-capacity measurements presented in this report the BeO sample was sintered at 1700 to $1800^{\circ} \mathrm{C}$ for about 24 hours in order to obtain large crystallites. The results of the measurements obtained on the sample of average crystallite size of $3 \times 10^{-5} \mathrm{~m}$ were found to be considerably lower than those reported by Kelley [15]. The values were so extremely different that repeat measurements on a sample of even larger crystallite were considered to be desirable. A BeO sample prepared by arc fusion and of fairly uniform crystallite size of about $6 \times 10^{-5} \mathrm{~m}$ was subsequently obtained. Since the measurements on the second sample are being delayed because of pressing work on other substances and since the measurements on the second sample will probably show relatively small differences, if any, the results of the measurements on the first sample are being given in this report. (The crystallite sizes of the two samples are not widely different.)

\section{Sample}

In order to obtain a $\mathrm{BeO}$ sample of large crystallite size, commercially available high-purity $\mathrm{BeO}$ powder was pelletized by F. P. Knudsen of the Inorganic Materials Division of the Bureau into short cylinders of about 3/8" diameter and $1 / 8 "$ long. The pellets were then fired in a gas furnace at about 1700 to $1800^{\circ} \mathrm{C}$ for 24 hours. Some erosion and, consequently, reduction in the size of the pellets occurred through vaporization of $\mathrm{BeO}$ in presence of water vapor at the furnace temperatures $[10,13,25]$.

Spectrochemical analysis of the sintered sample by B. F. Scribner of the Spectrochemical Analysis Section of the Bureau showed the impurities given in Table 1 . 
A petrographic (microscopic) examination of the BeO sample was made by A. Van Valkenburg of the Crystallography Section of the Bureau. The crystallites ware fourd to have an average length of about $3 \times 20^{-5} \mathrm{~m}$ with the sinallest ones about $1 \times 10^{-6} \mathrm{~m}$. The crystals were c.lear with some voids.

Since the BeO pellets were slightly too large, they were split into halves along their axes and introduced into the calorimeter sample vessel through its 1/4" opening [5]. The vessel containing the sample was alternately pumped to a high vacuum and purged several times with dry helium gas and finally sealed with $1.316 \times 10^{4} \mathrm{~N} / \mathrm{m}^{2}$ $(98.7 \mathrm{~mm} \mathrm{Hg})$ pressure of helium gas. The mass of sample investigated was $77.354 \mathrm{~g}$.

\section{Apparatus and Method}

The heat-capacity measurements on the BeO sample were carried out in an adiabatic calorimeter very similar in principle and design to that described previously [21]. The sample vessel was suspended within the adiabatic shield system by means of a nylon string instead of the filling tube shown in the above reference. Details of the calorimeter design and its operation will be described in a subsequent publication.

Briefly, the calorimeter sample vessel, constructed principally of copper, was a short cylinder with spherical sections for its ends. A re-entrant well, located at the axis with its opening at the bottom of the vessel, contained a heater-platinum resistance thermometer assembly. In order to attain rapid temperature equilibrium, copper vanes were arranged radially from the central well to the outer wall of the vessel. A thin coating of pure tin applied to the entire inner surfaces held the vanes in good thermal contact with the vessel and provided a chemically inert surface. The space between the vanes was no greater than $8 \mathrm{rm}$. A specially designed gold-gasket, screw-cap closure was attached at the top of the vessel. The outer surface of 
the vessel was gold plated and polished. A thin gold-plated copper shell enclosed the sample vessel to provide a more reproducible surface temperature for adiabatic control. The shell was in good thermal contact with the samole vessel around a ring located on the upper cylindrical portion of the vessel.

The adiabatic shield was constructed entirely of copper. It was a cylindrical shell with conical ends. Heater wires were wound on the outer surface. The inner surface was gold plated and polished to minimize the heat transfer by radiation.

Constantan versus Chromel-P differential thermocouples were attached to the adiabatic shield and to the outer thin shell of the sample vessel for temperature control. During the heat-capacity measurements the shield terperature was maintained as close as possible to that of the thin shell of the sample vessel by means of the thermocouples and the shield heaters.

The electrical power to the calorimeter heater was measured by means of a Wenner potentiometer in conjunction with a saturated standard cell, volt box, and standard resistors. The standard cell and the standard resistors were calibrated at the National Bureau of Standards in terms of the United States standards of emf and ohm. A constant-current power supply stable to about 2ppm was used to furnish electrical power to the calorimeter heater. The duration of each heating interval was determined by means of a high-precision interval timer operated on the 60- $\mathrm{Hz}$ frequency standard provided by the National Bureau of Standards. The $60-\mathrm{Hz}$ frequency standard is based on a $100-\mathrm{kHz}$ quartz oscillator which is stable to 1 part in $10^{10}$ over a 24-hour period. The $100-\mathrm{kHz}$ oscillator is maintained in terms of the $60-\mathrm{kHz}$ broadcast from WWVB. An electronic counter containing a I-MHz quartz oscillator was used simultaneously in the measurement of the heating interval. The estimated uncertainty, including the assymetry in the on-off switch operation to the calorimeter heater, in the determination of the heating interval is not greater than 
$\pm 0.01 \mathrm{sec}$ for any heating period, none of which was less than $2 \mathrm{~min}$ in these experiments.

Temoeratures were determined by means of a platinum-resistance thermometer installed in the re-entrant well of the calorimeter vessel. At the time of these measurements the resistance of the thermometer was measured with a high-precision manually operated Mueller bridge capable of measurements up to $422.17110 \mathrm{ohms}$ to the nearest 0.00001 . ohm. (At present an automatic Mueller bridge is being used.) The thermometer (Iaboratory designation: L-18) was calibrated above $90 \mathrm{~K}$ in accordance with the 1948 International Practical Temperature Scale [22]. The temperatures in kelvin were obtained by adding 273.15 to the temperatures in degrees Celsius $\left({ }^{\circ} \mathrm{C}\right)$. Below $90 \mathrm{~K}$, the thermometer was calibrated on the NBS-1955 provisional scale which is nurnerically $0.01 \mathrm{~K}$ lower than the former NBS-1939 provisional scale [12].

IV. Results

Two series of heat-capacity measurements were carried out, one on the calorimeter vessel with the sample (gross) and the other on the empty vessel (tare). The measured energy increments $(\Delta Q)$ and the corresponding thermometer resistances $(R)$ before and after heating [Chapter 2, NBS Report No. 9500, issued I January 1967] were analyzed on the high-speed digital computer to obtain $\mathrm{dQ} / \mathrm{dR}$ of the sample (net) as a function of the thermometer resistance [6]. After adjusting for the heat capacity of the helium exchange gas and for the small difference in the mass of the vessel for the tare and gross measurements, the values of heat capacity $(\mathrm{d} Q / \mathrm{dT})$ of the sample were then calculated at equally spaced integral temperatures from the $R$ versus $T$ calioration and $\mathrm{dR} / \mathrm{dT}$ for the thermometer using the relation:

$$
d Q / d T=(d Q / d R)(d R / d T) \text {. }
$$

Briefly, the procedure was to obtain the polynomial equation of the form

$$
d Q / d R=\sum_{n=0}^{N} a_{n}((\ln R) / R)^{n}
$$


to represent the experimental data on the empty calorimeter vessel (tare). The polynomial equation for the empty vessel was then evaluated to obtain values of $\Delta Q$ (tare) corresponding to the thermometer resistance intervals observed for the gross measurements in order to obtain the energy increinents for sample only, i.e.,

$$
\Delta Q(\text { sample })=\Delta Q(\text { gross })-\Delta Q(\text { tare }) \text {. }
$$

The best polynomial equation giving $d Q / d R$ for sample only was next obtained and $d Q / d T$ calculated according to eq. (I) above. For the sample an equation of the form

$$
\mathrm{dQ} / \mathrm{d} R=\sum \mathrm{a}_{\mathrm{n}} \mathrm{R}^{\mathrm{n}}
$$

was found to fit the data adequately.

Figure $I$ shows the percentage deviation of the experimental data on the empty vessel from the polynomial equation fitted to the data by the method of least squares. A fifteenth degree polynomial equation (eq. (2), $\mathrm{n}=0$ to $\mathrm{n}=15$ ) was found to fit the data from 15 to $370 \mathrm{~K}$ well within \pm 0.04 percent. The slight trend shown in the figure suggests that a better equation could be obtained, but the maximum deviations are small enough to be negligible for the present study. The first and second derivatives of the equation were found also to have the properties expected of a "heat-capacity curve". Figures 2 and 3 show the deviation of the sample data (net) from the final smooth values based upon the polynomial equation (eq. (4), $\mathrm{n}$ ranging from -1 to +8 ) fitted to the data in the range 15 to $370 \mathrm{~K}$ combined with the extrapolation of the data to $0 \mathrm{~K}$ as shown in Figure 4. The values of $\mathrm{dQ} / \mathrm{dT}$ obtained from the polynomial were adjusted slightly below $40 \mathrm{~K}$ to be consistent with the extrapolated values to $0 \mathrm{~K}$. Figure 4 shows the $\mathrm{C} / \mathrm{T}^{3}$ versus $\mathrm{T}$ plot of the final values of heat capacity extrapolated to $0 \mathrm{~K}$. The values of heat capacity on MgO reported by Barron, Berg, and Morrison [2] were used as a guide in the extrapolation. The observed values of heat capacity on BeO are shown for comparison with the extrapolation. The Debye characteristic temperature $\theta$ at $0 \mathrm{~K}$ corresponds to $1269 \mathrm{~K}$ $\left(0 \mathrm{~K}\right.$ intercept $\left.=\left(2 \times 12 \pi^{4} \mathrm{R} / 5\right)\left(1 / \theta^{3}\right)\right)$. 
Considering the precision of the measurements and the possible systematic errors, the estimated uncertainty in the smoothed values of heat capacities is 0.1 percent above $100 \mathrm{~K}$. Below $100 \mathrm{~K}$ the net heat caracity becomes a progressively smaller fraction of the gross heat capacity with decrease in temperature. At the lowest temperature of the measurements $(15.6 \mathrm{~K}$ ) the heat capacity of the sample constituted only 2.3 percent of the gross, hence the uncertainty in the values at $15 \mathrm{~K}$ may be as high as 5 to 10 percent.

The thermodynamic properties were calculated by tabular numerical integration using the values of heat capacity obtained from 0 to $370 \mathrm{~K}$ with the usual thermodynamic relations:

$$
\begin{gathered}
\mathrm{H}_{\mathrm{T}}-\mathrm{H}_{0}^{\mathrm{O} K}=\int_{0}^{\mathrm{T}} \mathrm{CdT}, \\
\mathrm{S}_{\mathrm{T}}=\int_{0}^{\mathrm{T}}(\mathrm{C} / \mathrm{T}) \mathrm{d} \mathrm{T},
\end{gathered}
$$

and

$$
G_{T}-H_{O K}^{O}=\left(H_{T}-H_{O K}^{O}\right)-T_{T}
$$

The values are given in Table 2 .

The values of heat capacity reported by previous investigators are compared with the present measurements in Figure 5. The values reported by Kelley [15] and those by Gmelin [8] are for most of the temperature range of the measurements unusually higher than the values found in the present study. The deviations of the values reported by Kelley [15] were found to increase with decrease in temperature. At $55 \mathrm{~K}$ the deviation is +45 percent and from about 200 to $290 \mathrm{~K}$ the deviations do not exceed 1 percent. The values reported by Gmelin [8] are on the average about 20 percent higher between 15 and $75 \mathrm{~K}$. The extrapolated values (below $15 \mathrm{~K}$ ) obtained for this report are higher than the experimental values reported by Gmelin [8]. The Debye characteristic temperature reported by Gmelin is $1400 \pm 10 \mathrm{~K}$ as 
compared to $1269 \mathrm{~K}$ taken for this study. The values reported by Gunther [II] are about 30 percent lower.

The entralpy difference between 273.15 and $373.15 \mathrm{~K}$ obtained from the heat-capacity measurements (Table 2) was compared with the experimental relative enthalpy values reported by Victor and Douglas [23]. Victor and Douglas reported measurements on two samples. Sample 1 consisting of crystallites of $2.5 \times 10^{-5} \mathrm{~m}$ on an edge was similar to the sample used in the present study. Sample 2 was needle-like, $1 \times 10^{-5} \mathrm{~m}$ in length and $1 \times 10^{-6} \mathrm{~m}$ in cross section. The comparison is summarized in Table 3. The results of the present study are between the values reported by Victor and Douglas for the two samples. The agreement is within a few tenths of a percent of either sample.

The unusually large deviation in the values of heat capacity at the lower temperatures with fairly close agreement at the higher temperatures can be ascribed to the particle size effects $[2,16,17]$. The increasing positive deviation with decrease in temperature of the values reported by Kelley [15] suggests that his sample was probably very finely divided. The heat treatment of the samples investigated by Gmelin [8] suggests that his samples and the sample used in the present study were similar. The wide deviations in the results shown in Figure 5 are probably due to experimental differences. Finely divided samples are subject to contamination by adsorbed impurities. Unless special precautions are taken to remove the adsorbed impurities, significant variations in the experimental heat capacities would be expected from the impurities present, any change in the surface properties, or compound formation at the surface.

The new values of heat capacity are now being combined with other high temperature relative enthalpy data up to $2500 \mathrm{~K}$. A combined table of thermodynamic properties will be presented in the forth-coming semi-annual report. The measurements on the second sample of $B e O$ are being considered for the near future. 


\section{Table 1}

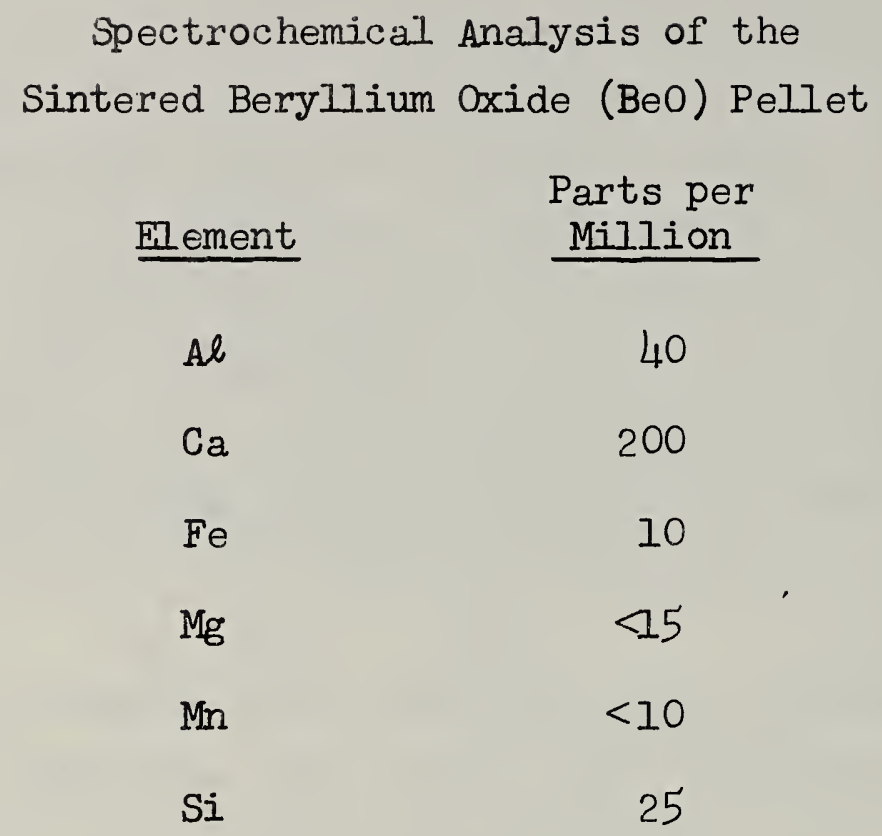

The limit of detection for Ti was $20 \mathrm{ppm}$ and for $P$ was $200 \mathrm{ppm}$ 
THERMODYNAMIC FUHETIONS FOR BERYLLIUM OXIDE IDE O )

SQLID PIHASE

$1 \mathrm{MOL}=0.0250116 \mathrm{KG}$

$C A L=4.1840 \mathrm{~J}$

$$
K=273 \cdot 15+{ }^{\circ} \mathrm{C}
$$

$T$

$$
-\left(G_{T}^{0}-H_{C}^{C}\right) / T
$$

$\bar{k} \cdot \frac{S A L}{K D L}$

5.00

10.00

15.00

20.00

25.00

30.00

35.00

40.00

45.00

50.00

60.00

65.00

70.00

75.00

80.00

85.00

90.00

95.00

100.00

105.00
110.00

115.00

120.00

123.00

130.00

135.00

140.00

145.00

150.00

155.00

160.00

165.00

170.00

175.00

180.00

185.00
190.00

195.00

200.00

205.00

210.00

215.00

220.00

230.00

235.00

240.00

245.00

250.00

255.00

260.00

265.00

270.00

273.15

275.00

280.00

285.00

290.00

295.00

298.15

300.00

305.00

310.00

315.00

320.00

325.00

330.00

335.00

340.00

345.00

350.00

355.00

360.00

365.00

370.00

373.15

.001

.001

.002

.004

.005

.007

.011

.014

.018

022

027

. 033

.046

.054
.063

.073

.083

.095

-10?

.120

.150

.166

183

.201

.240

. 261

.283

.306

329
.354

.379

.405

.432

.460
.488

.518

. 548

.578

.610

.642
.674

.708

.742

.776

.811

.833
.847

. 883

- 919

.957

.994
1.018

1.032

1.071

1. 149

1.189

1.229
1.269

1.310

1.351
1.392

1.434

1.476

1.518
1.560

1.603
$\mathrm{iH}_{\mathrm{T}}^{\mathrm{O}}-\mathrm{H}_{\mathrm{O}}^{\mathrm{C}}: / \mathrm{T}$

$18_{p}^{0}-s_{0}^{c}$;

k.

$\left(H_{T}^{O}-H_{O}^{C}\right)$

fat

.000

.000

.001

.00 i

.004

$$
\begin{aligned}
& .000 \\
& .000 \\
& .000 \\
& .000 \\
& .002 \\
& .002 \\
& .003 \\
& .005 \\
& .008 \\
& .011 \\
& .015 \\
& .021 \\
& .028 \\
& .036 \\
& .047 \\
& .058 \\
& .073 \\
& .089 \\
& .100
\end{aligned}
$$

.000

.002

.003

.005

.011

.015

.021
.028

.036

.047

.107

$-128$

.151

.176

.203
.233

.265

.299

- 335

373
-414

.4156

.500

- 546

- 594

.644

.695
.747

.801

- 856

- 912

-970

1.028

1.088
1.148

1.148
1.209

1. 270

1.332

1.395

1.458

1.522

1.586
1.650

1.714

1.779

1.844

1.908

1.949

2.038

2.103

2.167

2.232

2.272

2.296

2.360

.424

2.488

2.552
2.615

2.678

2.740

2.802

2.926

2.987
3.047

3.108

3.167
.007

.010

.015

.020
.028

- 037

.048

.061

.077

- 126

- 142

.167

197

- 266

305
-348

. 393

- 442

.494
.548

.606

.665

- 730

.795
.864

.035

1.008

1.084

1.162
1.242

1.324

1. 407

1. 580

1.668

1. 759

1.850

.943

2.036

2.227

2.324

2.422

.520

2.620

2.719
2.783

2.820

2.921

3.022

3.124

3.226

3.291
3.328

3.431

3.534

3.637

3.740

3.843
3.947

3.947
4.050

4.153

4.256

4.462
4.565

4.668

4.771

20

.000
.000
.001
.006
.018
.045
.094

$c_{p}^{0}$

$-\left(G_{T}^{0}-H_{0}^{C}\right)$

K. A A Not

等

$$
\begin{aligned}
& .000 \\
& .000 \\
& .000 \\
& .002 \\
& .004 \\
& .007 \\
& .013 \\
& .020 \\
& .031
\end{aligned}
$$

.000

.004

.013

.046

.065
.089

$-120$ 


\section{Table 3}

Comparison of Enthalpy Values of Table 2 with the Experimental Relative Enthalpy Data of Victor and Douglas

$I \mathrm{cal}=4.1840 \mathrm{~J}$

Victor and Douglas [23] This Work

Temperature

Intervals

$\mathrm{K}$

$273.15-323.15$

$273.15-373.15$
Sample 1

$\mathrm{J} / \mathrm{mol}$

1270.3

1271.5

1270.9

(average)

2765.2

2776.5

2770.9

(average)
Sample 2

$\mathrm{J} / \mathrm{mol}$

$\mathrm{J} / \mathrm{mol}$

1278.6

1278.2

1278.4

(average)

1276.1

2784.5

2785.7

2789.1

2786.4

(average)

2775.9 
[1] J. Aslanian and L。 Weil, Contribution of Specific Heat Measurements below $4^{\circ} \mathrm{K}$ to the Observation of Helium Diffusion after Annealing in Irradiated Beryllium Oxide, Cryogenics 3, 36-39 (1963).

[2] T. H. K. Barron, W. T. Berg, and J. A. Morrison, on the heat capacity of crystalline magnesium oxide, Proc. Roy. Soc. (Iondon) 250A, 70-83 (1959).

[3] T. Duval and C. Duval, Sur la Thermogravimétrie des Précipités Analytiques. VI. Dosage du Glucinium (Béryllium), Anal. Chim. Acta. $\underline{2}$, 53-56 (1948).

[4] E. S. Funston, W. J. Kirkpatrick, and P. P. Turner, Preparation of High Purity BeO Powder, J. Nuclear Mat. 11, 310-319 (1964).

[5] G. T. Furukawa, M. L. Reilly, and J. H. Piccirelli, Calorimetric Properties of Some Alkali Pentaborate Hydrates from 15 to $370^{\circ} \mathrm{K}$, J. Res. NBS 68A (Phys. and Chem.) No. 4, 381-389 (1964).

[6] G. T. Furukawa and M. L. Reilly, Application of Precise HeatCapacity Data to the Analysis of the Temperature Intervals of the NBS (1955) and the International Practical Temperature Scales in the Region of $90^{\circ} \mathrm{K}$, J. Res. NBS (Phys. and Chem.) 69A, 5-12 (1965).

[7] W. F. Giauque and R. C. Archibald, The Entropy of Water from the Third Law of Thermodynamics. The Dissociation Pressure and Calorimetric Heat of the Reaction $\mathrm{Mg}(\mathrm{OH})_{2}=\mathrm{MgO}+\mathrm{H}_{2} \mathrm{O}$. The Heat Capacities of $\mathrm{Mg}(\mathrm{OH})_{2}$ and $\mathrm{MgO}$ from 20 to $300^{\circ} \mathrm{K}$, J. Am. Chem. Soc. 59, 561-569 (1937).

18] E. Gmelin, Mesures de la chaleur spécifique de l'oxyde de beryllium et de I'oxyde de calcium a basses températures, Compt. rend. 262C, 1452-1455 (1966).

[9] M. A. Greenbaum, J. Weiher, and M. Farber, The Thermodynamic and Physical Properties of Beryllium Compounds. VIII. Heat of Fusion and Hign-Temperature Heat Capacity of Beryllium Oxide, J. Phys. Chem. 69, 4035-4037 (1965).

[10] L. I. Grossweiner and R. I. Seifert, The Reaction of Beryllium Oxide with Water Vapor, J. Am. Chem. Soc. 74, 2701-2704 (1952).

[II] P. Günther, Untersuchungen über die spezifische Wärme bei tiefen Temperaturen, Ann. Physik 51, 828-846 (1916). 
[12] H. J. Hoge and F. G. Brickwedde, Establishment of a Temperature Scale for the Calibration of Thermometers between $14^{\circ}$ and $83^{\circ} \mathrm{K}$, J. Res. NBS 22, 351-373 (1939) RP1188.

[13] C. Ao Hutchison, Jr. and J. G. Malm, The Volatilization of Beryllium Oxide in the Presence of Water, J. Am. Chem. Soc. II, 1330-1339 (1949).

[14] V. V. Kandyba, P. B. Kantor, R. M. Krasovitskaya, and E. N. Fomichev, Determination of Enthalpy and Heat Capacity of Beryllium Oxide in the Temperature Range $1200-2820^{\circ} \mathrm{K}$, Doklady. Akad. Nauk. S.S.S.R. 131, 566-567 (1960).

[15] K. K. Kelley, The Specific Heats at Low Temperatures of Beryllium Oxide and Beryllium Orthosilicate (Phenacite), J. Am. Chem. Soc. 61, 1217-1218 (1939).

[16] W. H. Lien, Heat-Capacity Studies at Iiquid Helium Temperatures and Below. Part I: The Alkali Metals, Part II: Small Particles of Magnesium Oxide, U. S. At. Energy Comm. UCRL-9880, 72pp. (1962).

[17」 W. H. Lien and N. E. Phillips, Heat Capacity of Small Particles of $\mathrm{MgO}$ between $1.5^{\circ}$ and $4^{\circ} \mathrm{K}$, J. Chem. Phys. 29, 1415-1416 (1958).

[18] A. Magnus and H. Danz, Die spezifische Wärme von Wolfram, Bor, Borstickstoff und Berylliumoxyd, Ann. Physik (4) 81, 407-424 (1926).

[19] L. F. Nilson and 0. Pettersson, Ueber Molekularwärme und Molekularvolumina der seltenen Erden und deren Sulfate, Ber. chem. Gese11. 13, 1459-1465 (1880).

[20] E. N. Rodigina and K. Z. Gomel'skii, Enthalpy of Beryllium and Iithium Oxides at High Temperatures, Zhur. Fiz. Khim. 35, 1828-1831 (1961).

[21] R. B. Scott, C. H. Meyers, R. D. Rands, Jr., F. G. Brickwedde, and N. Bekkedahl, Thermodynamic Properties of 1,3-Butadiene in the Solid, Liquid, and Vapor States, J. Res. Natl. Bur. Std. 35, $39-85(1945)$.

[22] H. F. Stimson, International Practical Temperature Scale of 1948. Text Revision of 1960. J. Res. NBS (Phys. and Chem.) 65A, No. 3, $139-145$ (1961).

[23] A. C. Victor and T. B. Douglas, Thermodynamic Properties of Magnesium Oxide and Beryllium Oxide from 298 to $1200^{\circ} \mathrm{K}$, J. Res. NBS (Phys. and Chem.) 67A, No. 4, 325-329 (1963). 
[24] B. E. Walker, Jr., C. T. Ewing, and R. R. Miller, Specific Heat of Some High Temperature Materials, J. Chem. Eng. Data ?, 595-597 (1962).

[25] W. A. Young, The Reactions of Water Vapor with Beryllia-Alumina Compounds, J. Phys. Chem. 64, 1003-1006 (1960). 


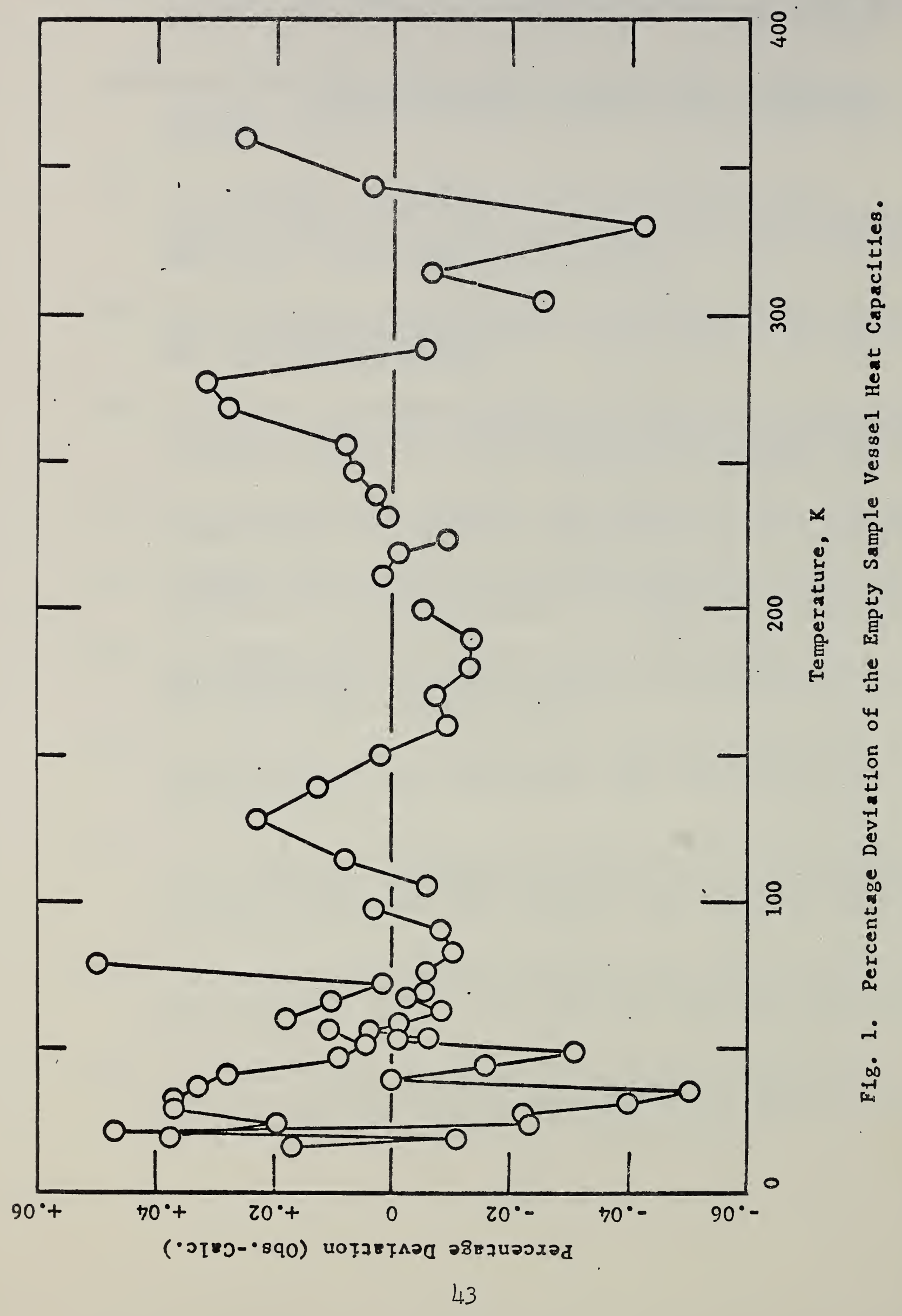




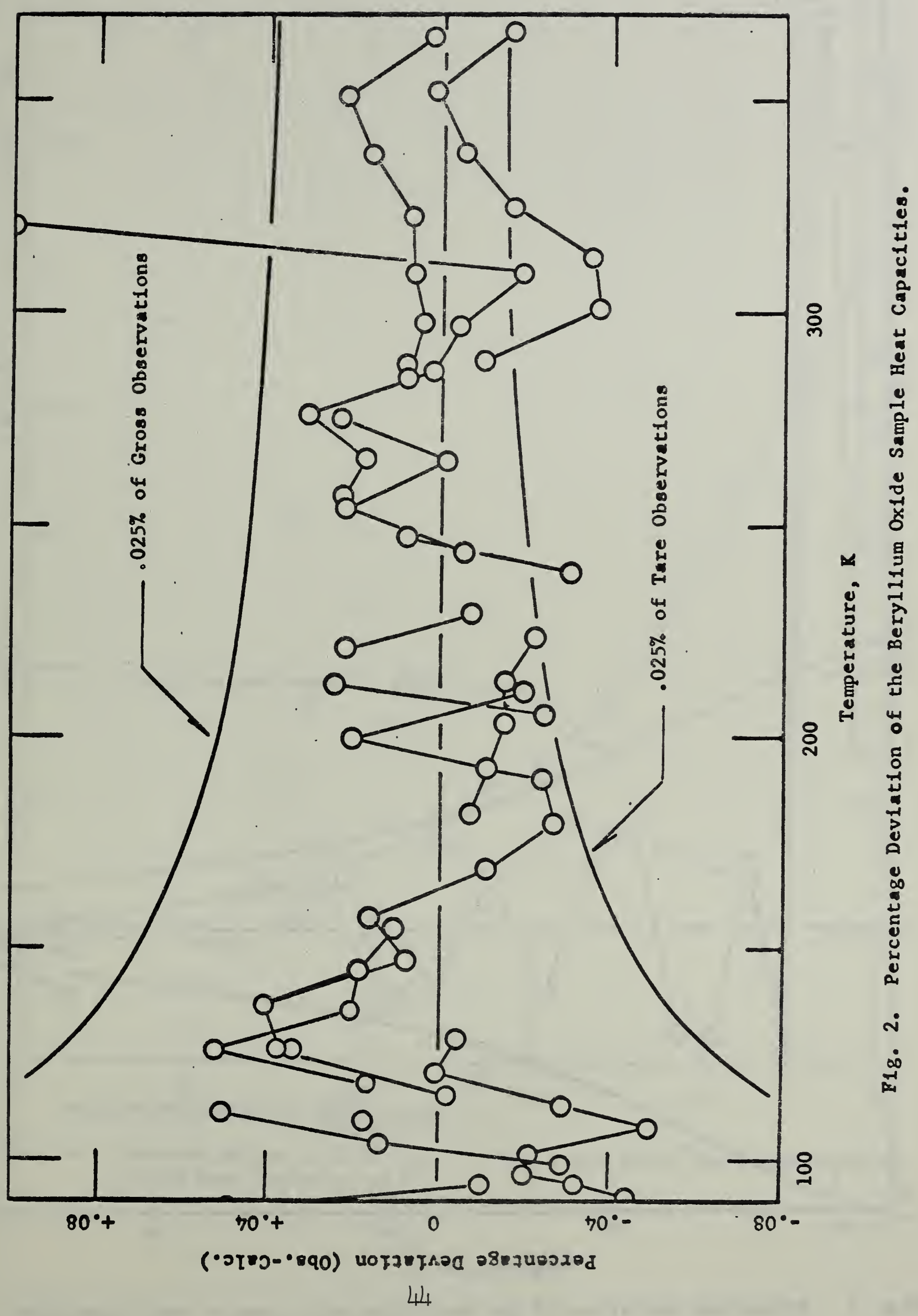




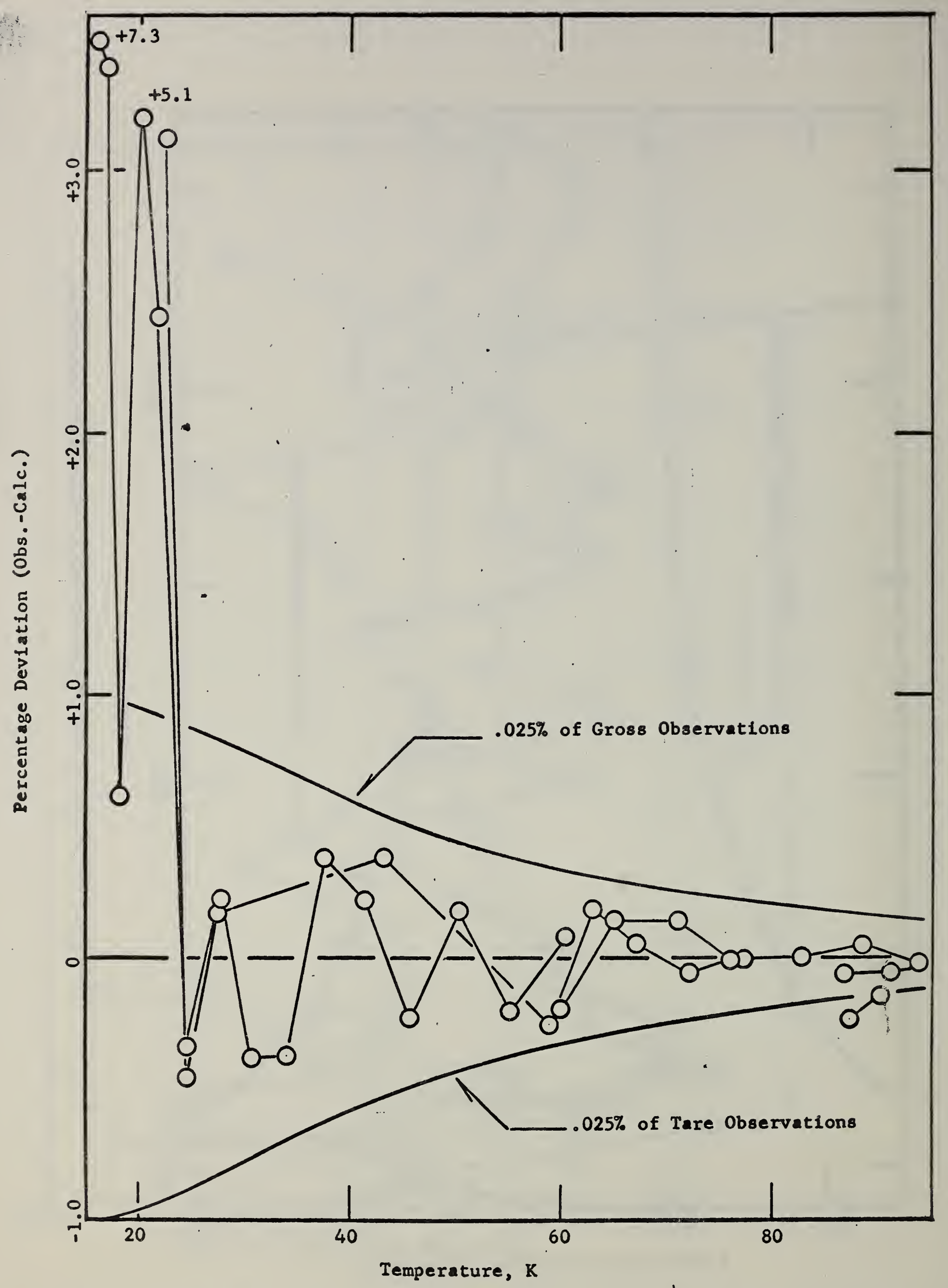

Pig. 3. Percentage Deviation of the Berylilum Oxide Sample Heat Capacities. 


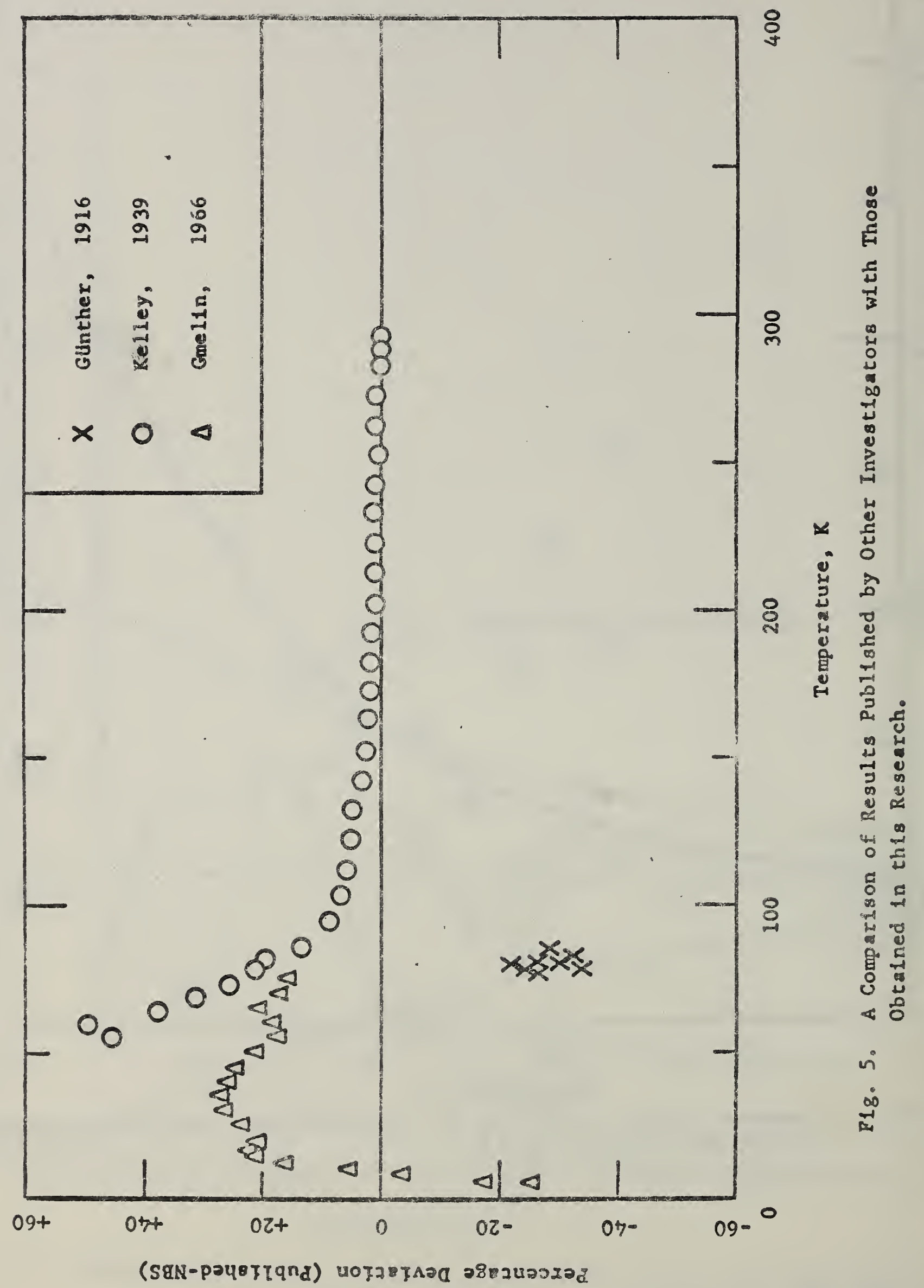


DYNAMIC MEASUREMENT OF HEAT CAPACITY, ELECTRICAL RESISTIVITY AND

HEMISPHERICAL TOTAL EMITTANCE OF MOLYBDENUM IN THE RANGE $1800-2800 \mathrm{~K}$
A. Cezairliyan, M.S. Morse, H.A. Berman,
G.M. Foley*, and C.W. Beckett

\begin{abstract}
A system for the simultaneous dynamic measurement of heat capacity, electrical resistivity, and hemispherical total emittance of electrical conductors at high temperatures (above $1800 \mathrm{~K}$ ) with millisecond resolution is described. The specimen is heated from room temperature to its melting point by a single heavy current pulse of subsecond duration. Temperature of the specimen is measured with a high-speed photoelectric pyrometer of $0.4 \mathrm{~ms}$ time resolution. Dynamic recording of variables: current, voltage, and temperature, required for the determination of the above properties, is achieved by a high-speed digital data acquisition system. Preliminary results on molybdenum in the temperature range $1800-2800 \mathrm{~K}$ are presented.
\end{abstract}

* Leeds and Northrup Company, North Wales, Pennsylvania, also Guest Worker at NBS. 


\section{Introduction}

In view of the growing interest and urgency in understanding the behavior of matter at temperatures above the limit of accurate steady-state experiments, it has become necessary to develop dynamic methods for the measurement of properties of substances. They show great promise at high temperatures since the duration of a dynamic experiment may be so short that the role of various phenomena, such as heat transfer, chemical reactions, evaporation, diffusion, etc. which set the upper limit in steady-state experiments, becomes negligible. In recent years, considerable progress has been made in high-speed thermodynamic measurement methods and related instrumentation techniques. A general review of these methods is in preparation [5].

Over the past fifty years several investigators $[3,4,6,9$, 11-16, 19-22] have developed dynamic techniques for the measurement of specific heat of electrical conductors. They differ considerably from each other depending on the pulse power source and the method of measurement of specific variables. In general, either heavy batteries or capacitors were used as the pulse power source. In all cases, power imparted to the specimen was obtained from pulse current and voltage measurements. The temperature of the heating specimen was measured either by thermocouples or was determined from dynamic electrical resistivity measurements. The first method has severa1 limitations and cannot be used for very high speed work. The second 
one requires a separate steady-state determination of the electrical resistivity of the specimen as a function of temperature. In almost all of the recent investigations oscilloscopic techniques were employed for the dynamic recording of variables.

As a step toward establishing accurate high-speed thermodynamic measurement methods, investigations have been and continue to be undertaken in the High-Speed Thermodynamics Laboratory at the National Bureau of Standards. The first phase of this program is concentrated on the development of a dynamic technique for the accurate measurement of heat capacity of solid electrical conductors at high temperatures. The preliminary version of a high-speed (millisecond resolution) method for the measurement of heat capacity has been described [6]. The present study is an extension of this earlier work with several major changes in the physical system, measurement techniques, and calculation methods. They are summarized in the following paragraph.

Instead of the continuous detection of the radiation from the specimen by means of a photomultiplier tube, a millisecond resolution photoelectric pyrometry technique was employed for the dynamic temperature measurements. This eliminates most of the uncertainties that result from the instability of the radiation detector. A highspeed, multichannel, digital data acquisition system has replaced the oscilloscopes, improving the recording accuracy by approximately two orders of magnitude. Also, several changes were made in the test cell, 
specimen, and voltage probes. Another major improvement in the results is due to a change in the formulation of the calculations. Instead of assuming a constant value for the emittance, obtained from the literature, in the present work the hemispherical total emittance of the specimen was measured under dynamic conditions and this value was used in the calculations for the thermal radiation correction.

In order to check the operation of the system, dynamic experiments of millisecond resolution were conducted and heat capacity, electrical resistivity, and hemispherical total emittance of molybdenum were measured in the temperature range $1800-2800 \mathrm{~K}$. Results reported in this chapter are of preliminary nature in the sense that they are based on only a small portion of the data taken, and that simplified relations are used in computing the pertinent properties.

II. Description of the Method

The dynamic method employed in this study for the measurement of specified properties is based upon rapid joulean heating of the specimen by a single pulse of direct current and measuring the pertinent variables with millisecond resolution. Heat capacity and electrical resistivity are calculated from data obtained during the heating period. In order to apply a correction for the radiation loss, hemispherical total emittance is calculated from the data of the initial cooling period. In the following paragraphs the formulation 
of the relationships between various variables is presented.

\section{a. Heating Period}

The energy balance for the specimen during the heating period can be expressed as

\section{Energy Imparted = Energy Stored + Energy Losses}

In high temperature dynamic experiments of millisecond resolution the major source of power loss is that due to thermal radiation. Using the proper quantities, the above relation for unit time becomes

$$
e 1=c_{p} n(d T / d t)_{h}+\varepsilon \sigma A_{s}\left(T^{4}-T_{e}^{4}\right)
$$

Where

$$
\begin{aligned}
& e=\text { potential difference across the effective specimen (V) } \\
& i=\text { current through the specimen (A) } \\
& c_{p}=\text { heat capacity }\left(\mathrm{J} g m-a t^{-1} \mathrm{~K}^{-1}\right) \\
& \mathrm{n}=\text { weight of the effective specimen (gm-at) } \\
& \varepsilon=\text { hemispherical total emittance } \\
& \sigma=\text { Stephan-Boltzmann constant }\left(5.6697 \times 10^{-8} \mathrm{~W} \mathrm{~m}^{-2} \mathrm{~K}^{-4}\right) \\
& \mathrm{A}_{\mathrm{s}}=\text { effective surface area }\left(\mathrm{m}^{2}\right) \\
& \mathrm{T}=\text { temperature (K) } \\
& \mathrm{T}_{\mathrm{e}}=\text { room temperature }(\mathrm{K}) \\
& (\mathrm{dT} / \mathrm{dt})_{\mathrm{h}}=\text { heating rate }\left(\mathrm{K} \mathrm{s}^{-1}\right)
\end{aligned}
$$

Solving Eq. (1) for $\mathrm{c}_{\mathrm{p}}$ one obtains

$$
c_{p}=\frac{e i-\varepsilon \sigma A_{s}\left(T^{4}-T_{e}^{4}\right)}{n(d T / d t)_{h}}
$$




\section{b. Cooling Period}

The energy balance for the specimen during the initial cooling period can be written as

$$
\text { Energy Loss = Energy Radiated }
$$

which for unit time can be expressed as

$$
-c_{p} n(d T / d t)_{c}=\varepsilon \sigma A_{s}\left(T^{4}-T_{e}^{4}\right)
$$

where

$$
(\mathrm{dT} / \mathrm{dt})_{\mathrm{c}}=\text { cooling rate }\left(\mathrm{K} \mathrm{s}^{-1}\right)
$$

Solving Eq. (3) for $c_{p}$ one obtains

$$
c_{p}=\frac{\varepsilon \sigma A_{s}\left(T^{4}-T_{e}^{4}\right)}{-n(d T / d t)_{c}}
$$

\section{c. Relations for Properties}

Combination of Eqs. (2) and (4) yields

$$
e i=\varepsilon \sigma A_{S}\left(T^{4}-T_{e}^{4}\right)-\varepsilon \sigma A_{S}\left(T^{4}-T_{e}^{4}\right)\left[\frac{(d T / d t)_{h}}{(d T / d t)_{c}}\right]
$$

Defining,

$$
M=-\frac{(d T / d t)_{h}}{(d T / d t)_{c}}
$$

and substituting $\mathrm{Eq} .(6)$ in $\mathrm{Eq}$. (5) and solving for $\varepsilon$ one obtains

$$
\varepsilon=\frac{e i}{\sigma A_{s}\left(T^{4}-T_{e}^{4}\right)(1+M)}
$$

In this study Eq. (7) is used to calculate hemispherical total emittance of the specimen which, in turn, is substituted in Eq. (2) to obtain heat capacity. 
Electrical resistivity is calculated with the aid of the equation

$$
\rho=\frac{R A}{L}
$$

where,

$$
\begin{aligned}
& \rho=\text { electrical resistivity }(\Omega \mathrm{m}) \\
& \mathrm{R}=\text { resistance of effective specimen }(\Omega) \\
& \mathrm{A}_{\mathrm{c}}=\text { cross-sectional area }\left(\mathrm{m}^{2}\right) \\
& \mathrm{L}=\text { effective length }(\mathrm{m})
\end{aligned}
$$

\section{Description of the System}

The system used in this study consists of a principal electrical circuit and auxiliary measuring circuits. The principal circuit includes the specimen in series with a battery bank, a variable resistance, a shunt, and a switch. The measuring circuits include detectors and other related equipment and circuitry necessary for the dynamic measurement and recording of the pertinent quantities. A functional diagram of the complete system is presented in Fig. (1).

\section{a. Specimen and Test Cell}

The molybdenum specimen used in the experiments is a tube of the following nominal dimensions: length $=4$ in. $(101.6 \mathrm{~mm})$, outside diameter $=0.25$ in. $(6.35 \mathrm{~mm})$, thickness $=0.02$ in. $(0.51 \mathrm{~mm}) . A$ small rectangular hole ( $1.09 \mathrm{~mm}$ long, $0.56 \mathrm{~mm}$ wide) was fabricated in the wall at the middle of the specimen to approximate blackbody conditions. Calculations indicate that the quality of blackbody, based 


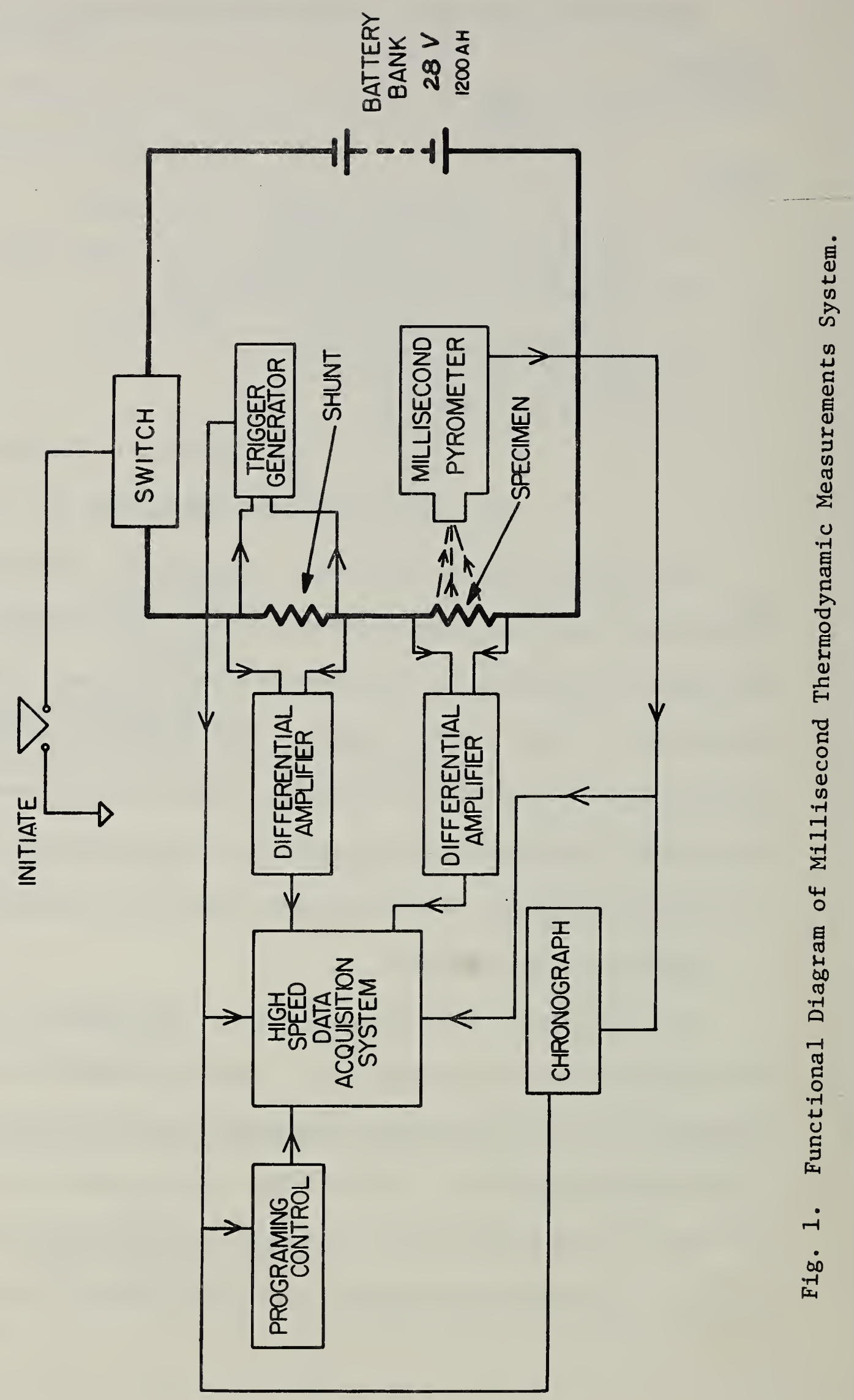


on geometrical considerations, thus achieved is 99.5 percent. Potential measurements were made using molybdenum knife edges each at a distance of $12.5 \mathrm{~mm}$ from the end clamps. This allows the "effective" portion of the specimen to be free from sharp temperature gradients. It is calculated that for the longest pulse (highest temperature) used in the experiments temperature non-uniformity between the midpoint of the specimen and the plane of the voltage probe due to transient axial thermal conduction is less than 0.1 percent. The specimen is free to expand in the downward direction. The specimen clamps and the walls of the test cell are water cooled. Experiments can be conducted either with the specimen in vacuum or in inert gas.

b. Rest of Main Circuit

The power supply for the pulse heating of the specimen is a $28 \mathrm{~V}$ heavy-duty battery bank. A series connected, water-cooled, variable resistance enables one to adjust the main current and thus to control the heating rate. The fast-acting switch is operated by a series of time-delay units which control the pulse length in addition to providing timing pulses to other electronic measuring and recording instruments. A standard resistor $(0.001 \Omega)$ placed in the main circuit enables one to measure the heavy pulse current flowing through the specimen.

c. High-Speed Pyrometer

The temperature of the rapidly heating specimen is measured by means of a high-speed photoelectric pyrometer, which permits 1200 
evaluations of the specimen temperature per second. The pyrometer passes a precisely timed sample of radiation from the specimen through an interference filter (wavelength $650 \mathrm{~nm}$, bandwidth $10 \mathrm{~nm}$ ) to an electron multiplier photocell. The anode current of the photocell during the exposure of $208 \mu \mathrm{s}$ is integrated and the resulting integrator voltage is recorded. Then, the integrator is reset to permit it to integrate the anode current due to a similar sample of radiation from a calibrated, gas-filled tungsten filament lamp, suitably attenuated by an optical attenuator. Thus, the pyrometer collects the results of an interlaced sequence of exposures to specimen and reference source. Successive exposures to the reference lamp are taken through a sequence of three different optical attenuators mounted on a rotating disc, resulting in a staircase of reference exposures with approximately 50 percent attenuation for each step. This scheme is used for temperature measurements up to $2500 \mathrm{~K}$, the limit of reliable operation of gas-filled lamps. For the measurement of higher temperatures, calibrated optical attenuators are placed in the path of the radiation from the specimen. d. High-Speed Digital Data Acquisition System

The signals at the output of detectors corresponding to the voltage, current, and temperature are in analog form. Normally, in dynamic experiments such signals are measured by oscilloscopic techniques. However, the expected recording accuracy of such methods cannot be better than one percent. In order to improve the overall accuracy, a high-speed digital data acquisition system has been 
designed and constructed to meet the special requirements of the experiments. The system consists of a multiplexer, analog-todigital converter, a core memory together with control and interfacing equipment. Oscilloscopes are used to monitor the general pattern of the experimental results, and to detect any anomalies. All signals are brought to the multiplexer through isolation amplifiers in order to avoid the inaccuracies arising from common ground points. The multiplexed signals (aperture time 50 ns) go to the analog-to-digital converter which has a full-scale reading of $\pm 10 \mathrm{~V}$, and a full-scale resolution of one part in 8192 . Digital output from the converter consists of 13 binary bits plus a sign bit. This output is stored in a core memory having a capacity of 2048 words of sixteen bits each.

Al1 the above takes place during a dynamic experiment of subsecond duration. After the experiment is over, information stored in the core memory, which is in parallel binary coded form, is converted to serial binary coded decimal form and retrieved in the form of numeric printing and punched paper tape. Since the laboratory has access to a remote-control, time-sharing computer, it is possible to unload the memory directly to the computer. This allows one to process the data immediately after an experiment, bypassing the intermediate stage of punching paper tape. A functional diagram of the high-speed data acquisition system is presented in Fig. (2). 


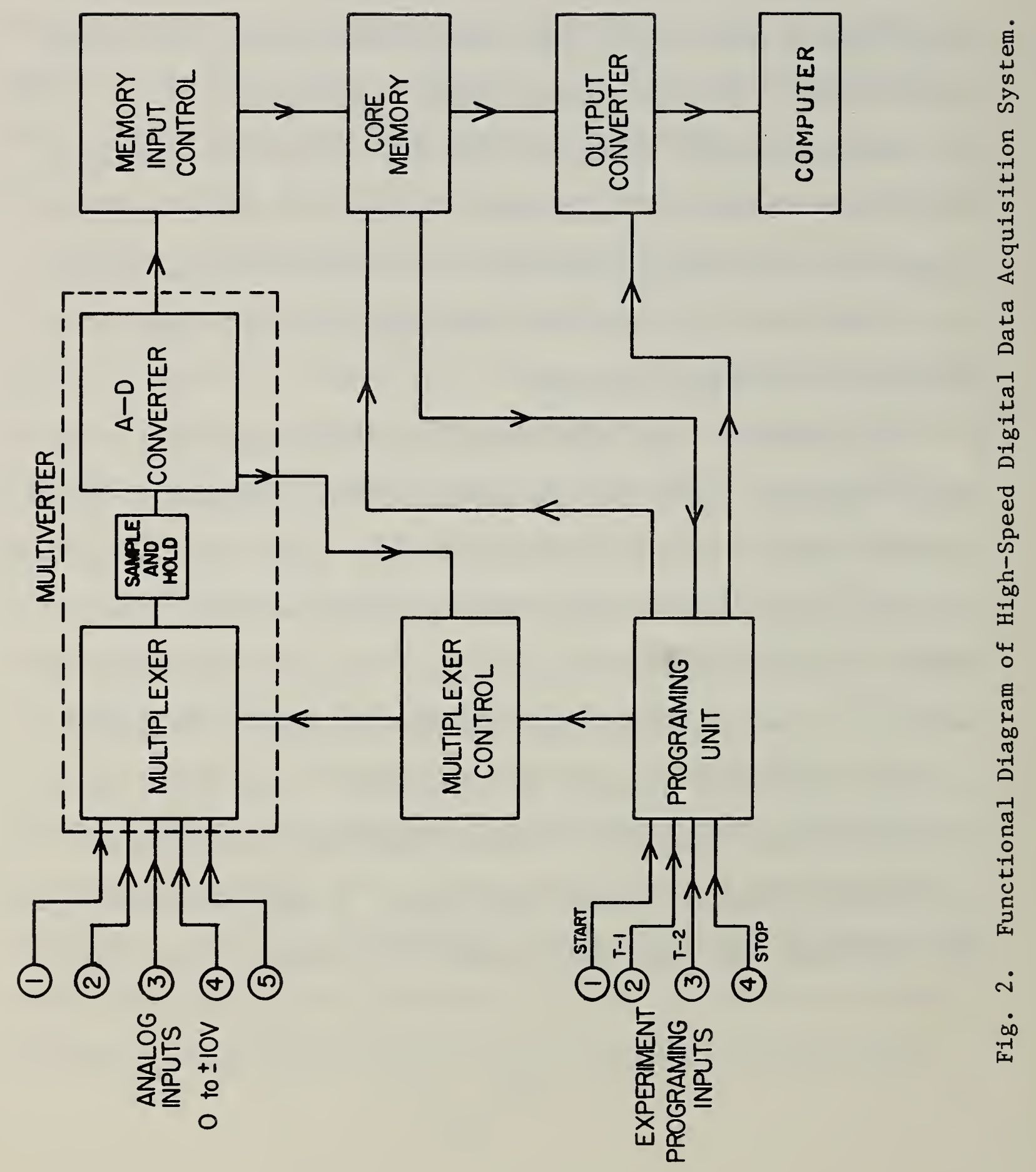




\section{Experimental Results}

The molybdenum specimen $\left(99.9^{+}\right.$percent pure, outer surface polished) was pulse heated in vacuum and data were taken during heating, as well as cooling periods. Pulse length varied from $285 \mathrm{~ms}$ to $380 \mathrm{~ms}$ depending on the temperature level. The entire temperature range (1800 - $2800 \mathrm{~K})$ was covered in three steps. Hemispherical total emittance was calculated from $\mathrm{Eq},(7)$, and a linear function for the entire range was obtained by least mean square approximation of the individual results which yields a standard deviation of 2 percent. Heat capacity was calculated from Eq. (2) after substituting the function for emittance. A quadratic fit over the entire temperature range gave a standard deviation of 0.3 percent. Electrical resistivity was calculated from Eq. (8). A linear fit over the entire range gave a standard deviation of 0.2 percent. Dimensions, in electrical resistivity and hemispherical total emittance calculations, were based on their room temperature values. Preliminary results on heat capacity, electrical resistivity and hemispherical total emittance are presented in graphical form in Figs. (3), (4), and (5), respectively. Pertinent preliminary equations for the above properties in the range 1800 to $2800 \mathrm{~K}$ are given below.

$$
\begin{aligned}
& c_{p}=34.58-1.096 \times 10^{-2} \mathrm{~T}+5.696 \times 10^{-6} \mathrm{~T}^{2} \\
& \rho=-9.798+3.146 \times 10^{-2} \mathrm{~T} \\
& \varepsilon=5.209 \times 10^{-2}+1.139 \times 10^{-4} \mathrm{~T}
\end{aligned}
$$




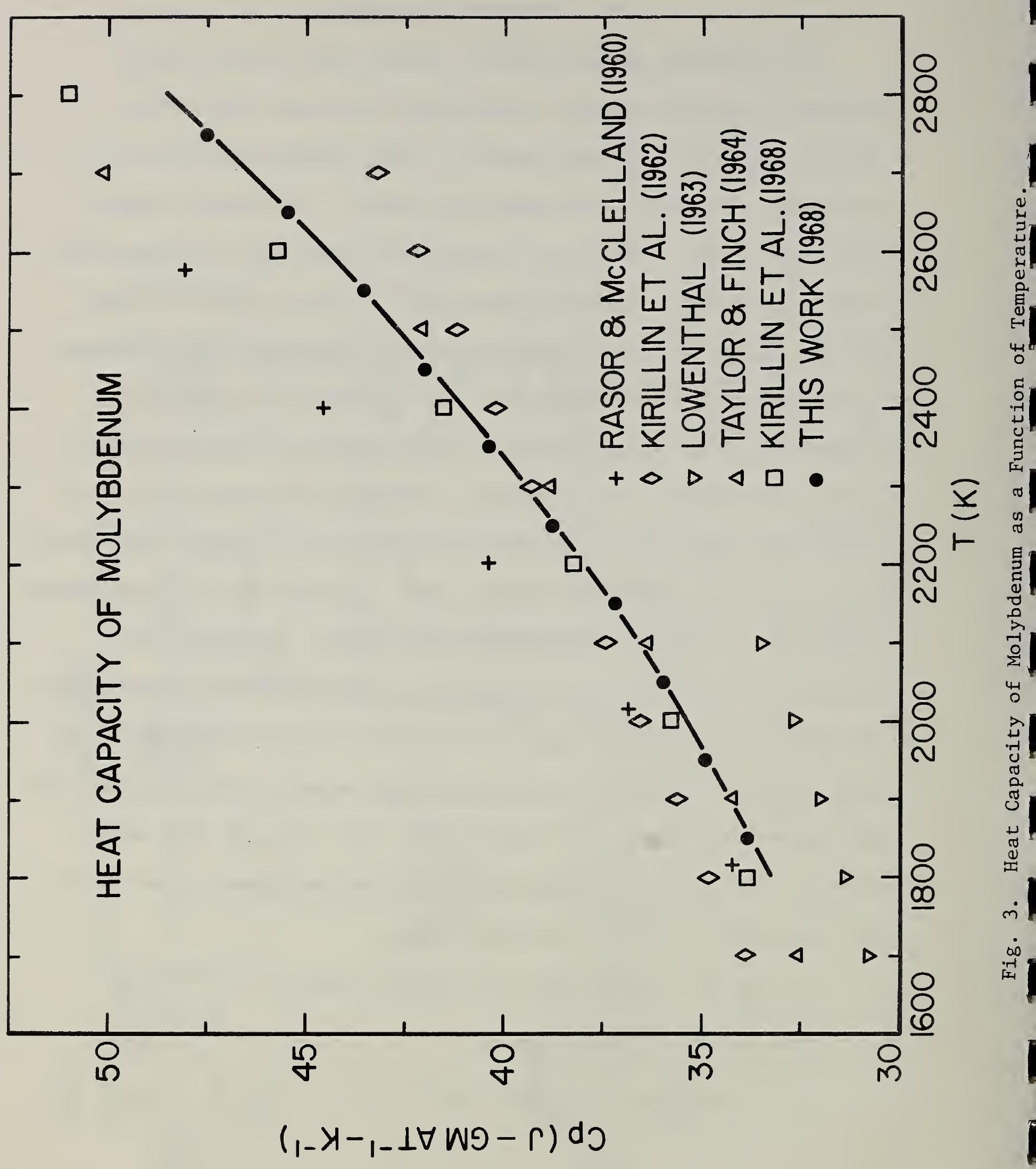




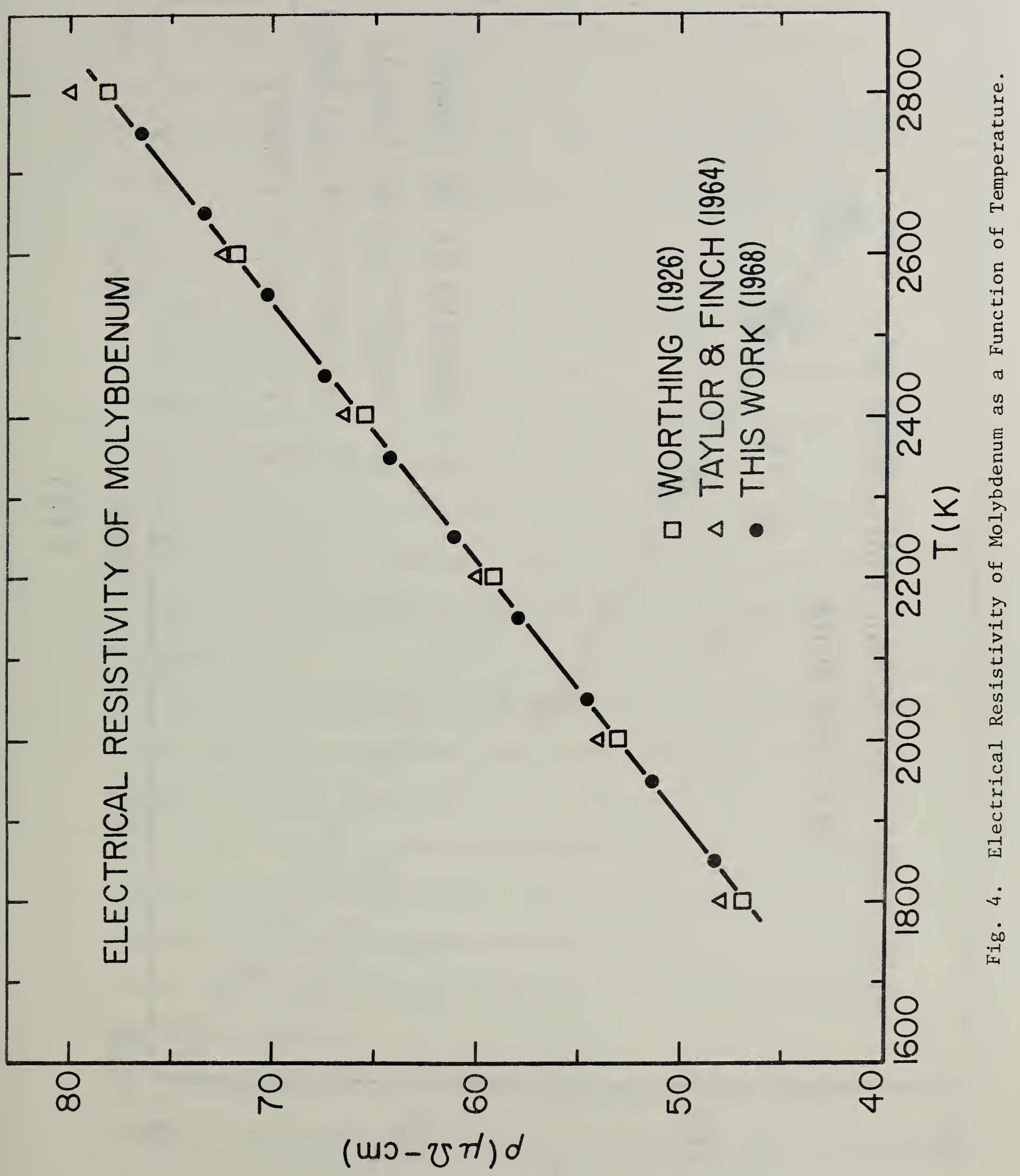




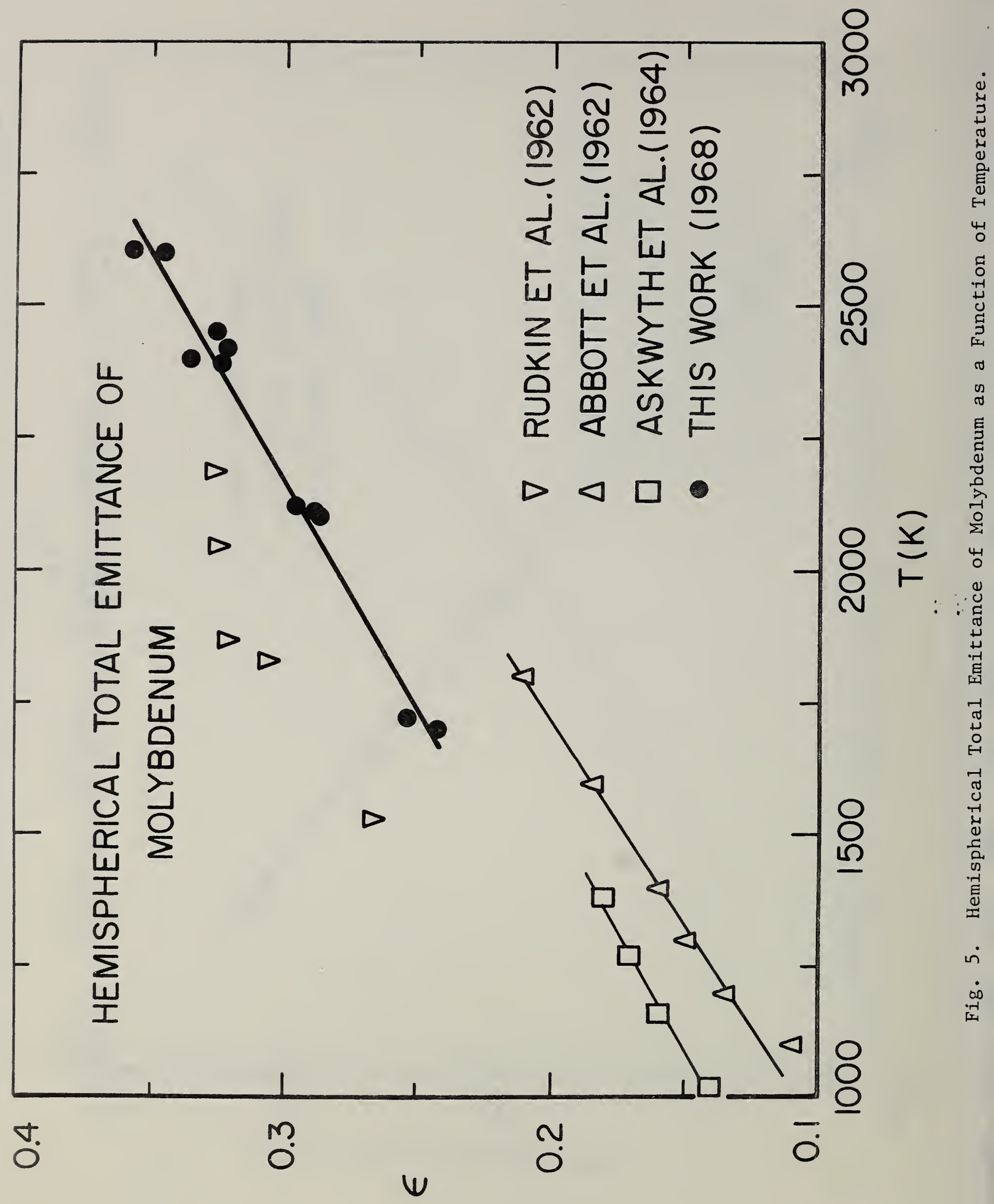


In temperature calculations, the scattered light effect in the high-speed pyrometer, as well as the departure from blackbody conditions were taken into account. The scattered light correction factor was 0.953 and the computed blackbody quality was 0.995 .

\section{Discussion}

The results based on a limited number of experiments do not indicate any sharp increase of heat capacity at high temperatures ( $\mathrm{T}<0.96 \mathrm{~T}_{\mathrm{m}}$, where $\mathrm{T}_{\mathrm{m}}$ is the melting point). Comparison of the results of this work with those in the literature shows that present values are, in genera1, higher than those obtained by most "drop" methods, with the exception of Kirfllin et al. [8], and lower than those of the two "pulse" methods of Taylor and Finch [19] and Rasor and McClelland [17].

Electrical resistivity agrees very closely with Worthing's [23] results and it is approximately two percent lower than the values given by Taylor and Finch [19].

In the literature, there is considerable scatter in the values of hemispherical total emittance. This can be expected since emittance is strongly dependent on surface conditions. The results of this work fall, in general, within the limits of the available data in the literature.

A preliminary list of estimated errors is given in Table 1. Studies so far' Indicate that temperature measurements have an estimated 
Table 1

Estimated Errors*

1. In Temperature Measurements

Pyrometer reproducibility

Scattered ligh correction

Light source alignment

Radiation standard lamp

Blackbody quality (geometrical)

Specimen temperature non-uniformity

Magnetic fields

Estimated total error in temperature

2. In Electrical Measurements

(for single determination with ms resolution)

Skin effect

Inductive effects

Thermoelectric effects

Voltage measurement

Current measurement

Power measurement

Resistance measurement

3. In Interpretation of Results

Effect of specimen evaporation

Effect of thermionic

Time synchronization

Length measurement

Weight measurement

Effective specimen weight

Heating rate

4. Estimated Total Error in Properties

Heat capacity

Electrical resistivity

Hemispherical total emittance
Estimated error in $\mathrm{K}$

\begin{tabular}{|c|c|}
\hline at $1800 \mathrm{~K}$ & at 2500 \\
\hline 1 & 2 \\
\hline 1 & 2 \\
\hline 1 & 2 \\
\hline 1 & 2.5 \\
\hline 1 & 2 \\
\hline 2 & 3 \\
\hline$<1$ & $<1$ \\
\hline 3 & 6 \\
\hline
\end{tabular}

Estimated error in percent

$<0.01$

$<0.01$

$<0.01$

$<0.05$

$<0.05$

$<0.07$

$<0.07$

Estimated error in percent

$<0.01$ (at $2800 \mathrm{~K}$ )

$<0.02$ (at $2800 \mathrm{~K}$ )

$<0.01$

0.02

0.01

0.1

0.3 (at $1800 \mathrm{~K}$ )

0.6 (at $2500 \mathrm{~K}$ )

at $1800 \mathrm{~K}$ at $2500 \mathrm{~K}$

percent

1

0.6

1.5

2

0.6

3

* Estimates of both random and systematic errors are given as being equivalent to "one standard deviation". 
error of $3 \mathrm{~K}$ at $1800 \mathrm{~K}$, and $6 \mathrm{~K}$ at $2500 \mathrm{~K}$. Errors in the measurement of electrical quantities give an estimated error of 0.07 percent in power and resistarce. Combination of various errors gives an approximate value of the total error in each of the properties measured: heat capacity 1 percent at $1800 \mathrm{~K}, 1.5$ percent at $2500 \mathrm{~K}$, electrical resistivity 0.6 percent at both levels, hemispherical total emittance 2 percent at $1800 \mathrm{~K}$ and 3 percent at $2500 \mathrm{~K}$. It should be emphasized that the results reported in the chapter are preliminary. The final results will be presented when the processing of the entire data on molybdenum is completed.

\section{Acknowledgment}

The authors would like to extend their appreciation to Messrs, J. Queiser, A.N. Graef, and M.E. Wilke for their expert assistance in constructing the test cell, auxiliary mechanical components, and machining of the specimen. 


\section{References}

1. Abbott, G.L., N.J. Alvares, and W.J. Parker, WADD-TR-61-94, II (1962).

2. Askwyth, W.H., R.J. Yahes, R.D. House, and G. Mikk, NASA-CR-56496 (1964).

3. Avramescu, A., Z. Tech. Physik, 20, p. 213, (1939).

4. Baxter, H.W., Nature, 153, p. 316, (1944).

5. Beckett, C.W., and A. Cezairliyan, "High-Speed Thermodynamic Measurements and Related Techniques," in J.P. McCullough, Ed., EXPERIMENTAL THERMODYNAMICS, Vo1. I, CALORIMETRY OF NON-REACTING SYSTEMS, Butterworths, Washington, to be published.

6. Cezairliyan, A., "A High-Speed (Millisecond) Method for the Simultaneous Measurement of Enthalpy, Specific Heat, and Resistivity of Electrical Conductors at High Temperatures, in ADVANCES IN THERMOPHYSICAL PROPERTIES AT EXTREME TEMPERATURES AND PRESSURES, ASME, New York, 1965.

7. Kirillin, V.A., A.E. Sheindlin, and V.Y. Chekhovskoi, Int. J. Heat Mass Transfer, 5, p. 1, (1962).

8. Kirillin, V.A., A.E. Sheindlin, V.Y. Chekhovskoi, and V.A. Petrov. "Enthalpy and Heat Capacity of Molybdenum at Extremely High Temperatures", in J.R. Moszynski, ed., PROC. OF FOURTH SYMPOSIUM ON THERMOPHYSICAL PROPERTIES, ASME, New York, 1968, p. 54.

9. Kurrelmeyer, B., W.H. Mais, and E.H. Green, Rev. Sci. Instr., 14, p. 349. (1943).

10. Lowentha1, G.C., Aust. J. Phys., 16, p. 47, (1963).

11. Nathan, A.M., J. App1. Phys., 22, p. 234, (1951).

12. Pallister, P.R., J. Iron Steel Inst., 161, p. 87, (1949).

13. Pasternak, R.A., E.C. Fraser, B.B. Hansen, and H.U.D. Wiesendanger, Rev. Sci. Instr., 33, p. 1320, (1962).

14. Pasternak, R.A., H.U.D. Wiesendanger, and B.B. Hansen, J. App1. Phys., 34, p. 3416, (1963).

15. Pochapsky, T.E., Acta Met., 1, p. 747, (1953).

16. Pochapsky, T.E., Rev. Sci. Instr., 25, p. 238, (1954).

17. Rasor, N.S., and J.D. McClelland, J. Phys. Chem. Solids, 15, p. 17, (1960). 
18. Rudkin, R.L., W.J. Parker, and R.J. Jenkins, "Measurement of Thermal Properties of Metals at Elevated Temperatures", in C.M. Herzfeld, ed., TEMPERATURE, ITS MEASUREMENT AND CONTROL IN SCIENCE AND INDUSTRY, Vol. III, Re1nhold. New York, 1962, Part 2, p. 523.

19. Taylor, R.E., and R.A. Finch, J. Less-Comon Metals, 6, p. 283, (1964). 20. Wallace, D.C., Phys. Rev., 120, p. 84, (1960).

21. Wallace, D.C., P.H. Sidles, and G.C. Danielson, J.App1. Phys., 31, p. 168, (1960).

22. Worthing, A.G., Phys. Rev., 12, p. 199, (1918).

23. Worthing, A.G., Phys. Rev., 28, p. 190, (1926). 
Chapter 4

MASS SPECTROMETRIC STUDY OF THE BERYLLIUM-ALUMINA REACTION

J. Efimenko

\section{Introduction}

The reduction reaction of alumina with beryllium was performed as an adjunct to the beryllia-alumina system which has been investigated in a metallic environment. Beryllium was selected as the reducer since it has a lower vapor pressure than aluminum. It was of interest to observe the predominant vapor species under such reducing conditions and to obtain data on the vapor reactions occurring in this system.

\section{Experimenta 1}

For this study, beryllium powder, less than 200 mesh, was tried and metal chips were used. Beryllium powder was mixed with carbon-free alumina and placed into a tungsten cup inside a tungsten effusion cell. In the second case, a chip of beryllium metal was placed on the bottom of the cup and covered with alumina. The mass spectrometer and geometry were those used for the alumina-beryllia studies. An effusion cell with one millimeter orifice was employed with the beryllium powderalumina mixture and a $0.5 \mathrm{~mm}$ orifice-effusion cell with beryllium chip-alumina mixture. A silver calibration was carried out with the $0.5 \mathrm{~mm}$ orifice effusion cell.

\section{Results}

It was possible to observe ion intensities of the reactant, beryllium, as well as the products, aluminum, its reduced oxides and oxygen, employing the second cell. Table 1 presents ion intensitytemperature data for the range 1511-1743K.

From the various equations that could describe this reducing system, the following were selected for computation:
(1) $\mathrm{Be}(\mathrm{g})+\mathrm{Al}_{2} \mathrm{O}_{3}(\mathrm{~s}) \rightleftarrows \mathrm{BeO}(\mathrm{s})+2 \mathrm{AI}(\mathrm{g})+20(\mathrm{~g})$
(2) $2 \mathrm{Al}(\mathrm{g})+\mathrm{O}(\mathrm{g}) \geq \mathrm{Al}_{2} \mathrm{O}(\mathrm{g})$
(3) $\mathrm{Be}(\mathrm{g})+\mathrm{Al}_{2} \mathrm{O}(\mathrm{g}) \rightleftharpoons \mathrm{BeO}(\mathrm{s})+2 \mathrm{Al}(\mathrm{g})$
(4) $\mathrm{Be}(\mathrm{g})+\mathrm{Al}_{2} \mathrm{O}_{3}(\mathrm{~s}) \rightleftharpoons \mathrm{BeO}(\mathrm{s})+2 \mathrm{AlO}(\mathrm{g})$ 
From the data, Table 1, and auxiliary data in Table 2, apparent equilibrium constants were computed. Second law plots for these reactions are shown in Figures 1, 2, 3, and 4. Enthalpies of these reactions were computed and are 1 isted in Table 3.

\section{Discussion}

The reduction reaction with beryllium powder produced copious amounts of $A 1$ and $A 1_{2} O$ species at a rapid rate. It was difficult to detect gaseous $\mathrm{Be}$ and $\mathrm{A} 10$ under these conditions. Also, a decrease in intensities of $\mathrm{Al}^{+}$and $\mathrm{Al}_{2} \mathrm{O}^{+}$occurred and on examining the effusion cell at the end of the experiment, the orifice was found to be filled with a solid.

Only the data from the second experiment, using a chip of beryllium underneath a layer of alumina, were employed. The data with index nos. 1 and 13 appear anomalous and were not considered in the second law treatment. The last points taken at the maximum temperature, $1420^{\circ} \mathrm{C}$ (uncorr.), show a loss of ion intensity and this effect is assumed to be coincident with the filling of this orifice. The ion intensities, identified by index no. 1, are larger than others at equivalent temperatures and this is probably due to contamination from the previous energetic experiment.

The causes for the scatter in the ion intensities are unknown and should require further investigation. During the experiments, ion intensities could be duplicated at a fixed temperature, which indicated that the electronic circuits were dependable. Since the ion intensities at $1200^{\circ} \mathrm{C}$, Table 1 , index nosi 2 and 10 , could not be duplicated, unknown changes may have occurred inside the effusion cell. The data shown in Table 1 were obtained over a period of five days with discontinuous operation. The effusion cell was maintained at a selected temperature on the average for thirty minutes and many times for one hour while the data were recorded.

Reaction enthalpies, Table 3, were obtained by the second law and third law calculations. For the second law least squares fit, data corresponding to index nos. 2, 3, and 7 were given weights of 0.5 , the remaining points, weights of 1.0 . The tabulated enthalpies are mean values. The second law values in this table are least squares fit with the standard deviations in the slopes.

The reaction enthalpies show a reasonable inter-consistency. The enthalpy difference between reaction 4 and 1 give the formation enthalpy of two Alo molecules. Reaction 2 gives the enthalpy of forming two $\mathrm{Al}-\mathrm{O}$ bonds in the $\mathrm{Al}_{2} \mathrm{O}$ molecule. Although the $\mathrm{Al}-0$ bonds in 
these two molecules are not the same, they differ by approximately $5 \mathrm{kcal}$. The difference in enthalpies from reactions 4 and 1 is 147 kcal, and reaction 2 gives $161 \mathrm{kcal}$. However, this type of calculation does not indicate the reliability of the enthalpy values themselves.

The partial pressures in Table 4 were obtained with the aid of a silver calibration using the $0.5 \mathrm{~mm}$ orifice effusion cell. These pressures involve the usual error associated with ionization crosssections of molecules but are of interest for relative comparison of partial pressure magnitude among the species observed. 


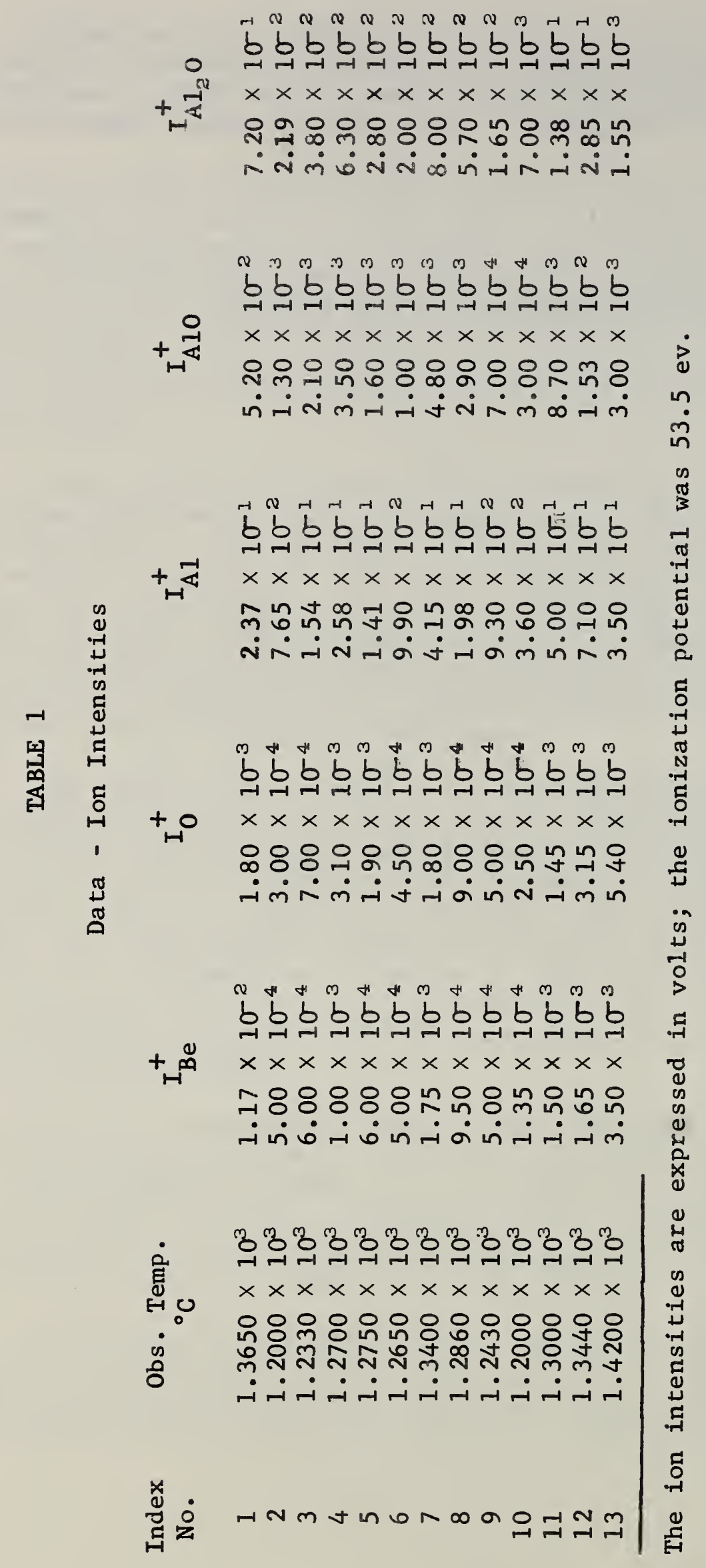


TABLE 2

\section{Auxiliary Data}

$\begin{array}{lll}\text { Specie } & \text { Multiplier } & \text { Ionization } \\ & \text { Efficiency } & \text { Cross-section }\end{array}$

\begin{tabular}{lcr}
\multicolumn{1}{c}{$\mathrm{M}^{+}$} & $\gamma,(1)$ & $\sigma,(2)$ \\
$\mathrm{Be}^{+}$ & 280 & 2.5 \\
$\mathrm{O}_{16}^{+}{ }_{+}^{+}$ & 180 & 1.6 \\
$\mathrm{Al}^{+}$ & 294 & 5.0 \\
$\mathrm{AlO}^{+}$ & 250 & 6.6 \\
$\mathrm{Al}_{2_{+} 0^{+}}$ & 260 & 11.6 \\
$\mathrm{Ag}_{107}^{+}$ & 153 & 10.1
\end{tabular}

(1) Author's values.

(2) R. F. Pottie, J. Chem. Phys. 44, 916 (1966).

Window-prism transmissivity, $\mathrm{A}=1.71 \times 10^{5}{ }^{\circ} \mathrm{K}^{-1}$

Ag sample $\quad 5.950 \times 10^{-3} \mathrm{gm}$ ( $99.9 \%$ pure)

Silver sensitivity $\quad 1.1683 \times 10^{-6} \mathrm{amp} / \mathrm{atm}$ at $1361^{\circ} \mathrm{K}$

Enthalpy Functions - Free Energy Functions

(Be, 0, Al, Al0, Be0) NBS Report 6928, July 1960

$\left(\mathrm{Al}_{2} \mathrm{O}_{3}\right) \quad$ NBS Report 6484, July 1959 
TABLE 3

\begin{tabular}{cccc}
\multicolumn{4}{c}{ Reaction Enthalpies } \\
2nd Law & 3rd Law \\
Reaction & $\Delta H_{1582}^{\circ} \mathrm{kcal} / \mathrm{mol}$ & $\Delta \mathrm{H}_{0}^{\circ} \mathrm{kcal} / \mathrm{mol}$ & $\Delta \mathrm{H}_{0}^{\circ} \mathrm{kcal} / \mathrm{mol}$ \\
1 & $265 \pm 0.5$ & 264 & 286.7 \\
2 & $-155 \pm 3$ & -150 & -161.2 \\
3 & $3 \pm 8$ & -0.7 & -39 \\
4 & $134 \pm 3.0$ & 126 & 140.0
\end{tabular}

NOTE : Cal. $\times 4.1840=$ joule 


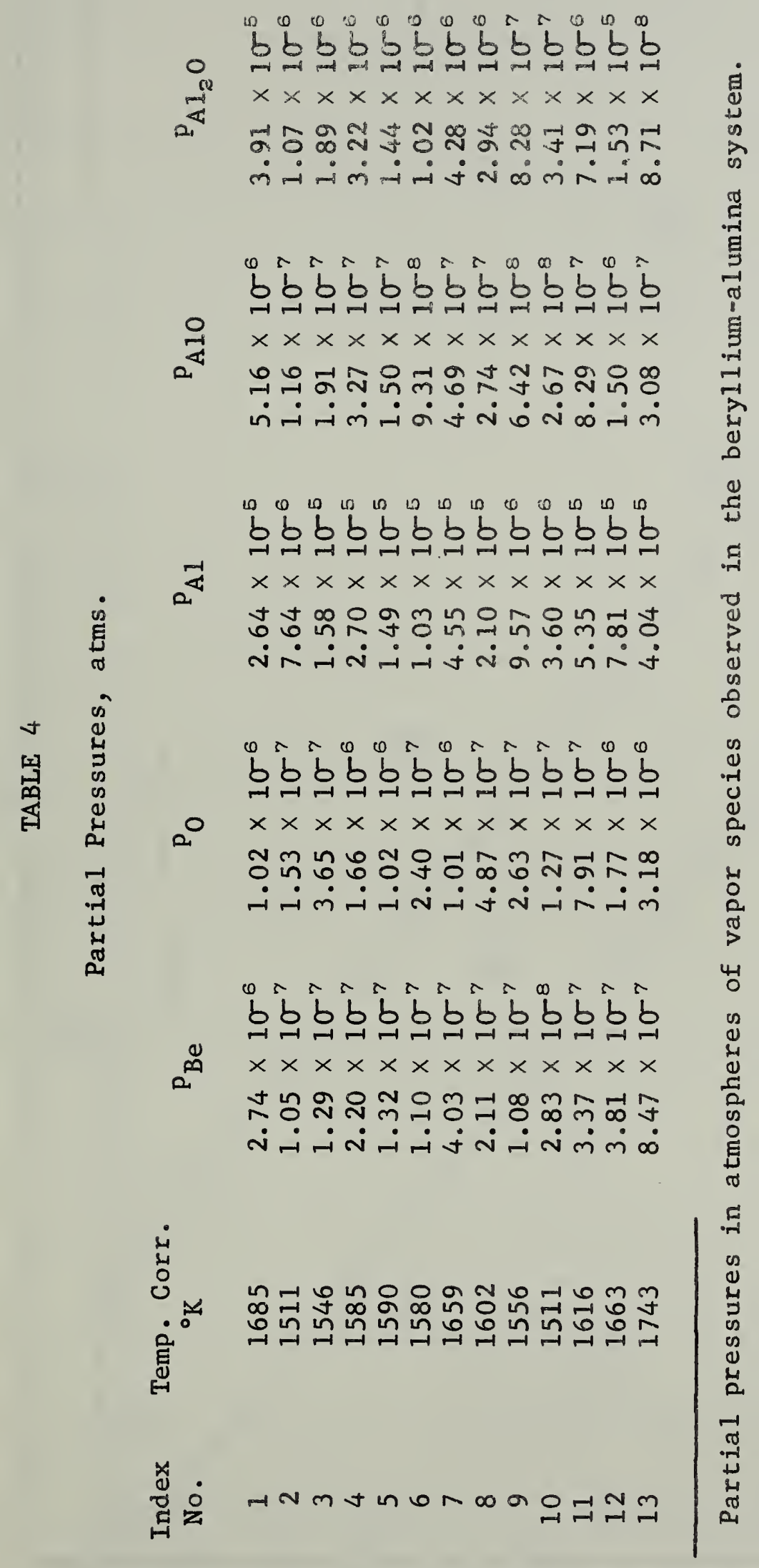




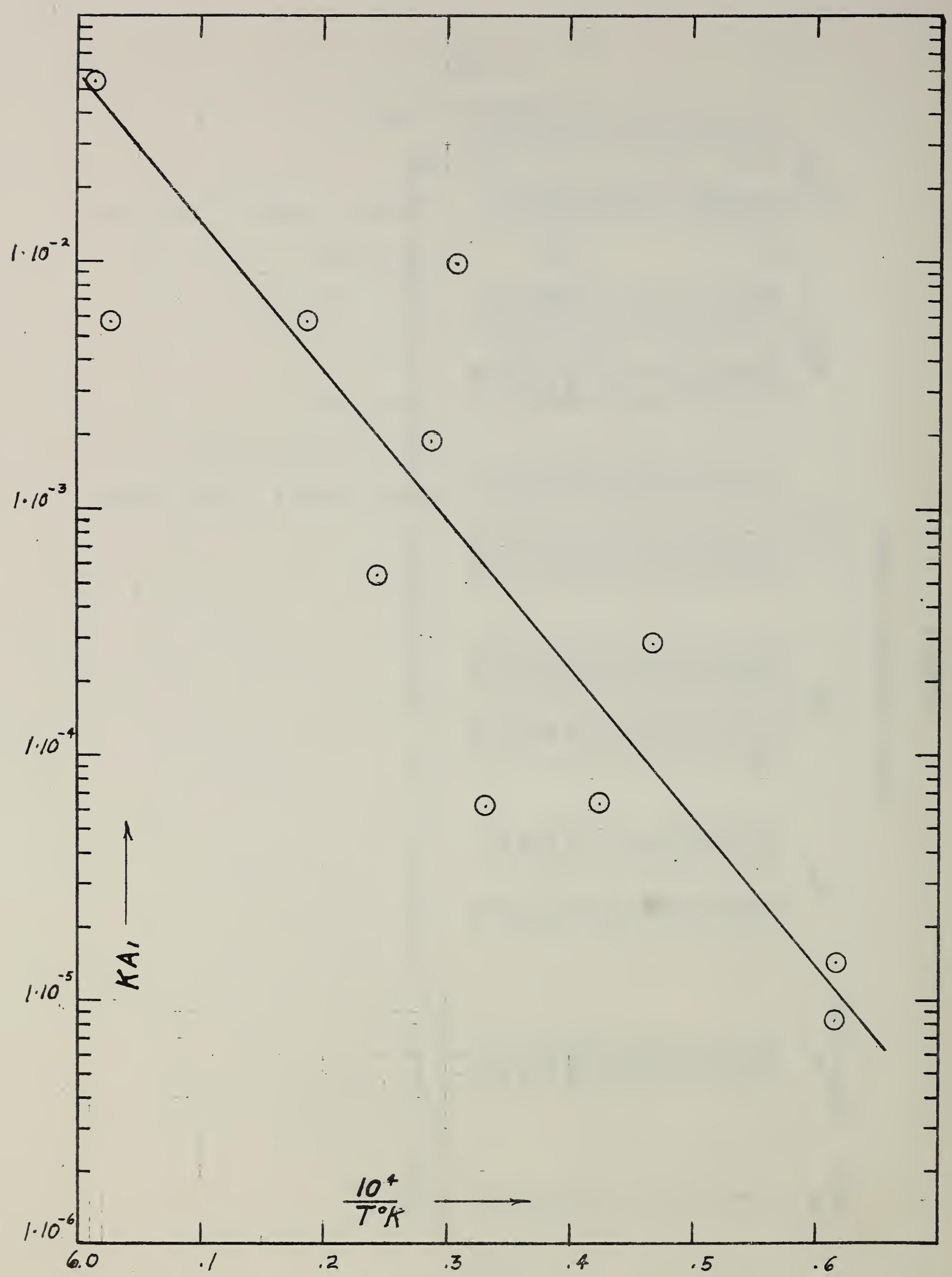

Figure 1. A van't Hoff plot for the reaction:

$\mathrm{Be}(\mathrm{g})+\mathrm{Al}_{2} \mathrm{O}_{3}(\mathrm{~s}) \rightleftharpoons \mathrm{BeO}(\mathrm{s})+2 \mathrm{Al}(\mathrm{g})+2 \mathrm{O}(\mathrm{g}), \Delta \mathrm{H}_{1582}^{0}=+265 \mathrm{kcal} / \mathrm{mol}$ at the mean reciprocal temperature, $6.3210 \times 10^{-4}{ }^{\circ} \mathrm{K}^{-1}$. 


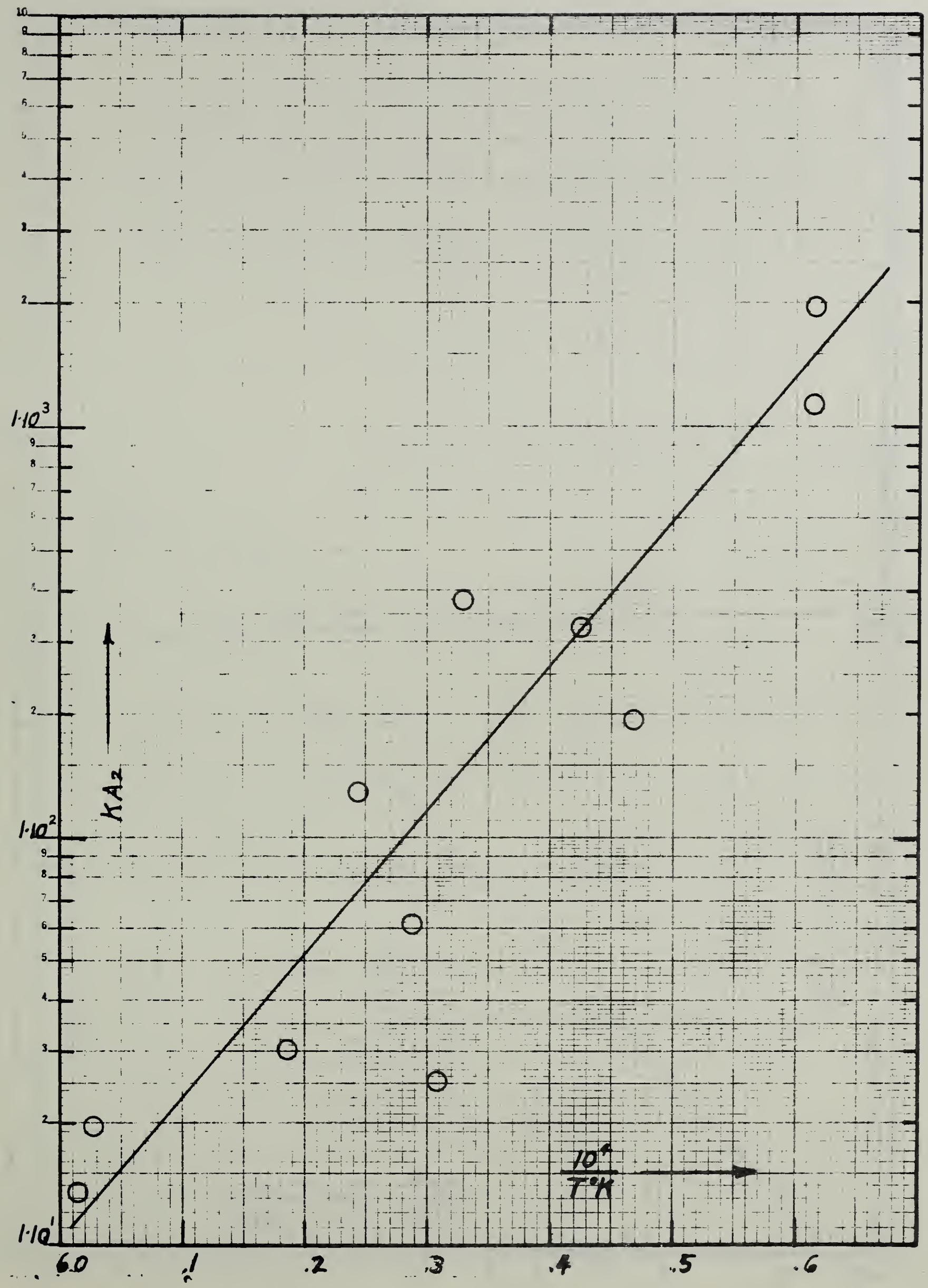

Figure 2. A van't Hoff plot for the reaction:

$2 \mathrm{Al}(\mathrm{g})+\mathrm{O}(\mathrm{g}) \rightleftharpoons \mathrm{Al}_{2} \mathrm{O}(\mathrm{g}), \Delta \mathrm{H}_{18 \mathrm{~B} 2}^{\circ}=-155 \mathrm{kcal} / \mathrm{mol}$. 


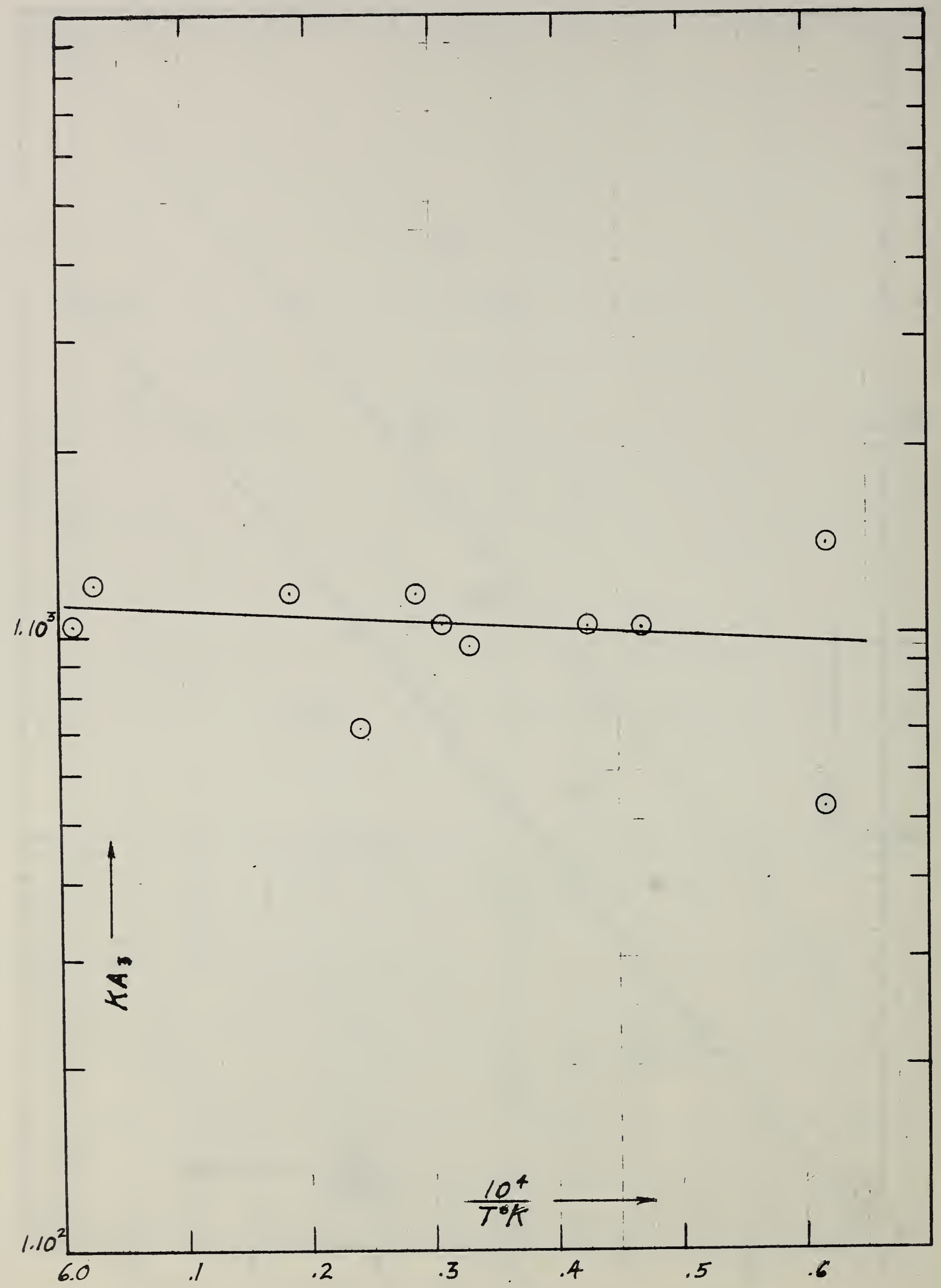

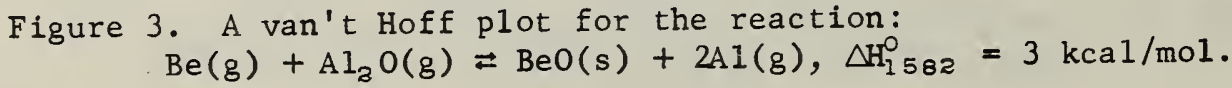




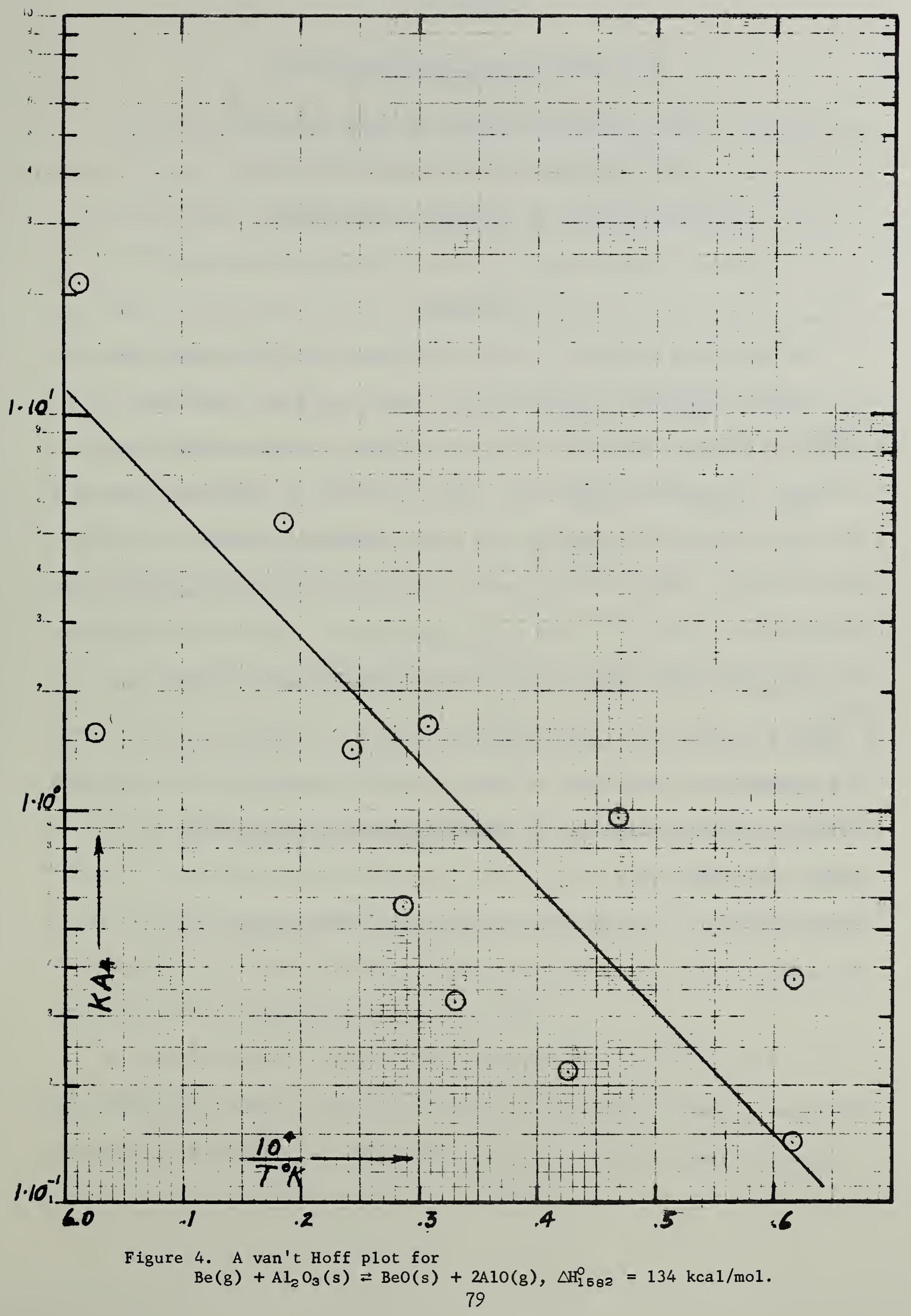




\section{STRUCTURE OF THE ALKALI HYDROXIDES.}

III. MICPOWAVE SPECTRA OF RBOH and RbOD ${ }^{\dagger}$

Chi riatsumura* and David R. Lide, Jr. National Bureau of Standards, Washington, D. C.

\section{ABSTRACT}

The microwave spectra of gaseous $\mathrm{RbOH}$ and $\mathrm{RbOD}$ have been measured with a high-temperature spectrometer. The spectra are generally similar to those observed in $\mathrm{CsOH}$ and indicate an essentially linear structure for rubidium hydroxide. The variation of rotational constant with excitation of the bending mode shows anomalies similar to those found in $\mathrm{CsOH}$. The $\mathrm{Rb}-\mathrm{O}$ bond length is found to be $2.30_{5} \AA$, while the $0-\mathrm{H}$ distance is $0.96_{5} \AA$. Analysis of the nuclear quadrupole hyperfine structure gives eqQ values of $-67.9 \mathrm{Mc} / \mathrm{s}$ in $\mathrm{Rb}^{85} \mathrm{OH}$ and $-35 \mathrm{Mc} / \mathrm{s}$ in $\mathrm{Rb}^{87} \mathrm{OH}$.

$\dagger_{\text {This }}$ research was supported by the U.S. Air Force Office of Scientific Research. Contribution of the National Bureau of Standards, not subject to copyright.

* Present address: Government Chemical Research Institute, Tokyo, Japan. 


\section{INIRODUCTION}

As reportad in paper I of this series, ${ }^{1}$ the microwave spectrum of gaseous cesium hydroxide indicates a linear or near-linear structure for the molecule. However, the dependence of the rotational constant $\mathrm{B}_{\mathrm{v}}$ on the vibrational quantum number $\mathrm{v}_{2}$ showed several anomalies. $\mathrm{B}_{\mathrm{V}}$ was found to decrease with increasing excitation of the bending mode $v_{2}$, which is opposite from the normal behavior in linear molecules. Furthermore, the dependence on $v_{2}$ was strongly non-linear, and the deuterium isotope effect was very large. A study has now been carried out on the spectrum of rubidium hydroxide. Similar anomalies have been found, which suggests that they are a general feature of the alkali hydroxide molecules.

\section{EXPERIMENTAL}

The microwave spectrometer used in this study was the same as described in I, except for a small modification. The pumping system was improved and a larger diameter tube was used for the vacuum jacket in order to allow more efficient removal of the water vapor which was formed by the rapid decomposition of $\mathrm{RbOH}$ at the operating temperature. In spite of this improvement, the water vapor still caused appreciable broadening of the lines. The $\mathrm{RbOH}$ spectrum was weaker and somewhat more difficult to obtain than that of $\mathrm{CsOH}$.

As the $\mathrm{Rb}$ atom has two isotopic species $72 \%$ of $\mathrm{Rb}^{85}$ and $28 \%$ of $\mathrm{Rb}^{87}$, and both species have large nuclear quadrupole moments, many weak lines had to be measured. Therefore, most measurements were done by 
slow sweep recording in order to obtain high sensitivity. However, the thermionic emission which was discussed in the previous paper ${ }^{1}$ made the application of a high Stark modulation voltage extremely difficult. The thermionic emission caused not only a wandering base line but also large amplitude random noise, so that the observation of $\Sigma$ states, which required high modulation, was possible oniy under optimum conditions. The conditions were not easily controlled in these experiments, but the lining of the waveguide with very pure silver $(99.99 \%)$ was effective for preventing the thermionic emission, and careful cleaning of the waveguide and quartz tube also rediced the difficulties.

The measurement of temperature was done with a thermocouple which was placed at the side of the waveguide. Since both the waveguide and the thermocouple were heated mainly by radiation from the furnace, and the temperature was not homogeneous, the thermocouple gave only a rough indication of the gas temperature. However, $550-600^{\circ} \mathrm{C}$ was believed to be the typical operating temperature. Because of the inhomogeneity of the temperature, the effective cell length was probably shorter than the oven length $(45 \mathrm{~cm})$. It seemed that the sample at the center portion of the cell was vaporized first and the working region expanded gradually. Although this effect reduced the sensitivity of the spectrometer, the gaseous molecules were produced for an extended period (1-2 hours). 


\section{ANALYSIS OF SPECTRUM}

Most observations were made on the $y=2 \rightarrow 3$ transition; since the sensitivity of the microwave spectrometer was optimized in this frequency region. Another merit of this transition was the convenient magnitude of the nuclear quadrupole splitting. The $J=1 \rightarrow 2$ and the $J=3 \rightarrow 4$ transitions of some states were observed for confirmation of assignments and calculation of nuclear quadrupole coupling constants. In some cases, the double-resonance procedure was helpful for finding or confirming $\sum$ states. The observed frequencies of the $\mathrm{J}=2 \rightarrow 3$ transitions are listed in Tables I and II.

As was the case with cesium hydroxide, the spectrum of rubidium hydroxide indicates an essentially. linear molecule with a large number of low-lying vibrational states. The assignment of vibrational satellites was done by Stark identification and from considerations of the reasonable - relative positions of lines in the series. The separation between lines of molecules containing $\mathrm{Rb}^{85}$ and $\mathrm{Rb}^{87}$ is the same order of magnitude as vibrational satellite shifts, so that the spectra overlapped each other. The hyperfine patterns were helpful in discriminating them. The $B_{V}$ values were calculated from $J=2 \rightarrow 3$ transitions by using the equation

$$
v=\left[2 B_{v} \pm \frac{q}{2}\left(v_{2}+1\right)\right](J+1)-4 D(J+1)\left[(J+1)^{2}-l^{2}\right]
$$

A value of $D=0.0067 \mathrm{Mc} / \mathrm{s}$ was used for this calculation. It was obtained from the equation $D=4 B_{e}^{3} \Sigma\left(\zeta_{2 s}^{(x)}\right)^{2} / \omega_{s}^{2}{ }^{2}$. It was not possible 
to obtain a good experimental v value from the transitions $J=2 \rightarrow 3$ and $J=1 \rightarrow 2$ because of hypertine complications, so that the calculated value seems to be more reliable. Whe $\mathrm{B}_{\mathrm{v}}$ values are listed in Table III, and the values of $q_{\ell}$ are given in Table IV.

The frequencies of the $\left(02^{\circ} 0\right)$ and $\left(12^{\circ} 0\right)$ states of RbOD could not be measured because of the exact overlapping with the $\left(01^{1} 0\right) l$ - and $\left(11^{1} 0\right) l$ - lines, respectively. On the other hand, the latter two lines were measured by using small Stark modulation. The overlapping was confirmed by comparison with the shape of the same lines in the normal is otopic species.

\section{NUCLEAR QUADRUPOLE COUPLING}

Since the line width in this molecule is fairly large while the hyperfine splitting in the transition $J=2 \rightarrow 3$ is small, it was difficult to determine the eqQ values with high accuracy. The splitting in the transition $\mathrm{J}=1 \rightarrow 2$ is larger, but the line strength of the weak components is not sufficient for accurate measurement. Assumed values of eqQ were used for analysis of weaker satellite lines from the higher vibrational states and for the RbOD species.

The values of eqQ are included in Table III. They are small in spite of the very large $Q$ values of $R b^{85}$ and $R b^{87}$. This shows that the $\mathrm{Rb}-\mathrm{O}$ bonding is almost completely ionic. The values of eqQ are the same order as those in $\mathrm{Rb}^{85} \mathrm{Cl}$ (eqQ $=-52.675 \mathrm{Mc} / \mathrm{s}$ ) and $\mathrm{Rb}^{87} \mathrm{Cl}$ $(e q Q=-25.485 \mathrm{Mc} / \mathrm{s})$. Though the exror in the measurement of eqQ is fairly large, it may be concluded that eqQ decreases markedly with increase of $v_{1}$. The patterns of hyperfine structure for $l=0$, 1 , and 
2 states fit exactly to the model of a linear molecule within the experimental error. This is further support for the linearity of the alkali hydroxide molecules.

\section{VIBRATION-ROTATION INTERACTIONS}

The gross features of the rubidium hydroxide spectrum are very similar to those found in cesium hydroxide. The variation of $B_{v}$ with $v_{1}$ (see Table $V$ ) is quite regular, yielding $\alpha_{1}$ values of $43.7 \mathrm{Mc} / \mathrm{s}$ in $\mathrm{RbOH}$ and $38.2 \mathrm{Mc} / \mathrm{s}$ in $\mathrm{RbOD}$. The dependence of $\alpha_{1}$ on the $\mathrm{Rb}$ isotope is too small to be measured accurately. On the other hand, the variation of $B_{v}$ with $v_{2}$ is 'strongly non-linear, is in the opposite direction from that in normal linear molecules, and shows a large deuterium isotope effect. These anomalies are not so pronounced as in the cesium compound but are still quite noticeable.

It was found in cesium hydroxide that the $B_{v}$ values could be fit to a power series containing terms in $\left(v_{2}+1\right),\left(v_{2}+1\right)^{2}$ and $l^{2}$. The same is true for rubidium hydroxide. A least squares fit resulted in the following coefficients :

$\mathrm{Rb}^{85} \mathrm{OH}: \quad \mathrm{B}_{\mathrm{v}}=6321.57-33.38\left(\mathrm{v}_{2}+1\right)+1.905\left(\mathrm{v}_{2}+1\right)^{2}-2.05 l^{2}$ $\mathrm{Rb}^{85} \mathrm{OD}: \mathrm{B}_{\mathrm{v}}=5730.85-11.16\left(\mathrm{v}_{2}+1\right)+1.08\left(\mathrm{v}_{2}+1\right)^{2}-1.152^{2}$ $\mathrm{Rb}^{87} \mathrm{OH}: \mathrm{B}_{\mathrm{v}}=6297.05-32.31\left(\mathrm{v}_{2}+1\right)+1.613\left(\mathrm{v}_{2}+1\right)^{2}-2.04 l^{2}$ $\mathrm{Rb}^{87} \mathrm{OD}: \mathrm{B}_{\mathrm{v}}=5707.57-10.32\left(\mathrm{v}_{2}+1\right)+0.88\left(\mathrm{v}_{2}+1\right)^{2}-1.132^{2}$. In $\mathrm{Rb}^{85} \mathrm{OH}$ and $\mathrm{Rb}^{85} \mathrm{OD}$, where the fit was over-determined, the inclusion of a $\left(v_{2}+1\right)^{3}$ term leads to no significant improvement. In the other two species the number of $B_{v}$ values was just sufficient to determine the coefficients given above. The precision of the fit for $\mathrm{Rb}^{85} \mathrm{OH}$ and 
and $\mathrm{Rb}^{85} \mathrm{OD}$ is illustrated in Table $\mathrm{VI}$.

The genctai similarkty of the vibration-rotation interactions in CsOH and RbOH suggests that the anomalous behavior is characteristic of the alkali hydroxide molecules, and is not the result of some accidental resonance. Furthermore, the cbility to fit the variation of $\mathrm{B}_{\mathrm{v}}$ with $\mathrm{v}_{2}$ in both molecules to a truncated power series lends some confidence to the identification of the coefficients of the series with the usual spectroscopic constants $\alpha_{2}, \gamma_{22}$, and $\gamma_{\ell, 2}$. Some progress has been made in the explanation of the anomalous values of these constants; the details will be reported in a subsequent paper.

\section{STRUCTURE}

The interatomic distances have been calculated from the rotational constants of $\mathrm{RbOH}$ and $\mathrm{RbOD}$ on the assumption of a linear model. Following the procedure used for $\mathrm{CsOH}$, the calculation was done both with the ground state constants and with the extrapolated constants obtained from the power-series fit discussed in the last section. The results are given in Table VII. Essentially the same distances were obtained from the constants of the $\mathrm{Rb}^{85}$ and $\mathrm{Rb}^{87}$ species.

As was found for $\mathrm{CsOH}$, the $\mathrm{O}-\mathrm{H}$ distance derived from the extrapolated $B$ values has a more reasonable magnitude. The' $\mathrm{Rb}-0$ distance of $2.30_{5} \&$ is not far from the $r_{e}$ value of $2.265 \&$ in $R b F$.

\section{ACKNOWLEDGMENTS}

We wish to acknowledge the preliminary search for the $\mathrm{RbOH}$ spectrum carried out by R. L. Kuczkowski. We also appreciate helpful discussions with J. T. Hougen. 


\section{REFERENCES}

1. D. R. Lide and R. L. Kuczkowski, J. Chem. Phys. 46, 4768 (1967).

2. H. H. Nielsen, Rev, Mod. Fhys. 23, 90 (1951). 
Table I. Observed frequencies in $\mathrm{Rb}{ }^{85} \mathrm{OH}$ and $\mathrm{Rb}{ }^{85} \mathrm{OD}$ in $\mathrm{Mc} / \mathrm{s}$ $(J=2 \rightarrow 3$ cransition $)$.

\begin{tabular}{|c|c|c|c|c|}
\hline State & $F$ & $=$ & $\mathrm{Rb}^{85} \mathrm{OH}$ & $\mathrm{Rb}^{85} \mathrm{OD}$ \\
\hline \multirow{7}{*}{$\left(00^{\circ} 0\right)$} & $5 / 2$ & $5 / 2$ & 37744.8 & \\
\hline & $7 / 2$ & $(7 / 2,9 / 2)$ & \multirow[b]{2}{*}{37741.2} & \multirow[b]{2}{*}{34324.6} \\
\hline & $9 / 2$ & $11 / 2$ & & \\
\hline & $5 / 2$ & $7 / 2$ & 37738.3 & 34321.6 \\
\hline & $3 / 2$ & $5 / 2$ & \multirow{2}{*}{37734.9} & \multirow{2}{*}{34317.9} \\
\hline & $1 / 2$ & $3 / 2$ & & \\
\hline & $9 / 2$ & $(7 / 2,9 / 2)$ & 37728.6 & 34311.9 \\
\hline \multirow{8}{*}{$\left(01^{1} 0\right) \mathrm{lt}$} & $5 / 2$ & $3 / 2$ & \multirow{2}{*}{37600.7} & \multirow{4}{*}{34301.9} \\
\hline & $3 / 2$ & $1 / 2$ & & \\
\hline & $5 / 2$ & $5 / 2$ & \multirow{2}{*}{37594.3} & \\
\hline & $9 / 2$ & $11 / 2$ & & \\
\hline & $7 / 2$ & $(7 / 2,9 / 2)$ & 37591.3 & 34299.0 \\
\hline & $5 / 2$ & $7 / 2$ & \multirow{2}{*}{37589.4} & \multirow{2}{*}{34297.3} \\
\hline & $3 / 2$ & $5 / 2$ & & \\
\hline & $9 / 2$ & $(7 / 2,9 / 2)$ & 37584.7 & 34292.3 \\
\hline \multirow{8}{*}{$\left(01^{1} 0\right) \ell-$} & $5 / 2$ & $3 / 2$ & \multirow{2}{*}{37541.0} & \multirow{4}{*}{34242.9} \\
\hline & $3 / 2$ & $1 / 2$ & & \\
\hline & $5 / 2$ & $5 / 2$ & \multirow{2}{*}{37534.9} & \\
\hline & $9 / 2$ & $11 / 2$ & & \\
\hline & $7 / 2$ & $(7 / 2,9 / 2)$ & 37532.0 & 34240.1 \\
\hline & $5 / 2$ & $7 / 2$ & \multirow{2}{*}{37530.6} & \multirow{2}{*}{34238.5} \\
\hline & $3 / 2$ & $5 / 2$ & & \\
\hline & $9 / 2$ & $(7 / 2,9 / 2)$ & 37525.5 & 34233.5 \\
\hline
\end{tabular}


Table I. Continued

\begin{tabular}{|c|c|c|c|c|}
\hline & $7 / 2$ & $(7 / 2,9 / 2)\}$ & 37430.5 & 34242.8 \\
\hline & $9 / 2$ & $i 1 / 2$ & & \\
\hline$\left(02^{0} 0\right)$ & $5 / 2$ & $7 / 2$ & 37417.1 & 34240.0 \\
\hline & $3 / 2$ & $5 / 2$ & & \\
\hline & $1 / 2$ & & & 34236.0 \\
\hline & $1 / 2$ & $(1 / 2,3 / 2)$ & 37394.0 & 34228.8 \\
\hline & $3 / 2$ & $(1 / 2,3 / 2,5 / 2)$ & & \\
\hline$\left(02^{2} 0\right)$ & $9 / 2$ & $(7 / 2,9 / 2,11 / 2)$ & 37385.2 & 34220.1 \\
\hline & $5 / 2$ & $(3 / 2,5 / 2,7 / 2)$ & 37375.6 & 34210.4 \\
\hline & $7 / 2$ & $(5 / 2,7 / 2,9 / 2)$ & 37372.2 & 34207.1 \\
\hline & $5 / 2$ & & 37362.2 & 34278.3 \\
\hline & $9 / 2$ & $11 / 2$ & & \\
\hline$\left(03^{1} 0\right)$ & $7 / 2$ & $(7 / 2,9 / 2)$ & 37358.9 & 34275.4 \\
\hline & $5 / 2$ & $7 / 2$ & 0 & 0 \\
\hline & $3 / 2$ & $5 / 2$ & 2. ונבעת & 年 \\
\hline & $9 / 2$ & $(7 / 2,9 / 2)$ & 37352.5 & \\
\hline & $5 / 2$ & $5 / 2$ & & \\
\hline & $9 / 2$ & $11 / 2$ & 37238.1 & 34152.2 \\
\hline$\left(03^{1} 0\right) \ell-$ & $7 / 2$ & $(7 / 2,-9 / 2)$ & 37235.0 & 34149.3 \\
\hline & $5 / 2$ & $7 / 2$ & 372330 & 341478 \\
\hline & $3 / 2$ & $5 / 2$ & & \\
\hline
\end{tabular}


Table I. Continued

\begin{tabular}{|c|c|c|c|c|}
\hline \multirow{4}{*}{$\left(04^{2} 0\right)$} & $1 / 2$ & $(1 / 2,3 / 2)$ & 37179.4 & \\
\hline & $\begin{array}{l}3 / 2 \\
9 ! 2\end{array}$ & $\begin{array}{l}(1 / 2,3 / 2,5 / 2) \\
(7 / 2,9 / 2,11 / 2)\end{array}$ & 37170.7 & 34189.2 \\
\hline & $5 / 2$ & $(3 / 2,5 / 2,7 / 2)$ & 37160.9 & 34179.2 \\
\hline & $7 / 2$ & $(5 / 2,7 / 2,9 / 2)$ & 37157.8 & 34174.8 \\
\hline \multirow{3}{*}{$\left(10^{0} 0\right)$} & $\begin{array}{l}7 / 2 \\
9 / 2\end{array}$ & $\left.\begin{array}{l}(7 / 2,9 / 2) \\
11 / 2\end{array}\right\}$ & 37479.1 & 34095.4 \\
\hline & $\begin{array}{l}3 / 2 \\
1 / 2\end{array}$ & $\left.\begin{array}{l}5 / 2 \\
3 / 2\end{array}\right\}$ & 37472.7 & 34089.0 \\
\hline & $\begin{array}{l}9 / 2 \\
9 / 2\end{array}$ & $\begin{array}{l}7 / 2 \\
9 / 2\end{array}$ & 37466.7 & 34082.9 \\
\hline \multirow{4}{*}{$\left(11^{1} 0\right) \mathrm{lt}$} & $\begin{array}{l}5 / 2 \\
9 / 2\end{array}$ & $\left.\begin{array}{c}5 / 2 \\
11 / 2\end{array}\right\}$ & 37333.6 & 34071.0 \\
\hline & $7 / 2$ & $(7 / 2,9 / 2)$ & 37330.8 & 34068.2 \\
\hline & $\begin{array}{l}5 / 2 \\
3 / 2\end{array}$ & $\left.\begin{array}{l}7 / 2 \\
5 / 2\end{array}\right\}$ & 37329.0 & 34066.4 \\
\hline & $9 / 2$ & $(7 / 2,9 / 2)$ & 37324.1 & \\
\hline \multirow{4}{*}{$\left(11^{1} 0\right) \ell^{-}$} & $\begin{array}{l}5 / 2 \\
9 / 2\end{array}$ & $\begin{array}{r}5 / 2 \\
11 / 2\end{array}$ & 37269.2 & 34010.2 \\
\hline & $7 / 2$ & $(7 / 2,9 / 2)$ & 37266.4 & 34007.5 \\
\hline & $\begin{array}{l}5 / 2 \\
3 / 2\end{array}$ & $\left.\begin{array}{l}7 / 2 \\
5 / 2\end{array}\right\}$ & 37264.9 & 34006.1 \\
\hline & $9 / 2$ & $(7 / 2,9 / 2)$ & 37260.0 & \\
\hline
\end{tabular}


Table I. Continued

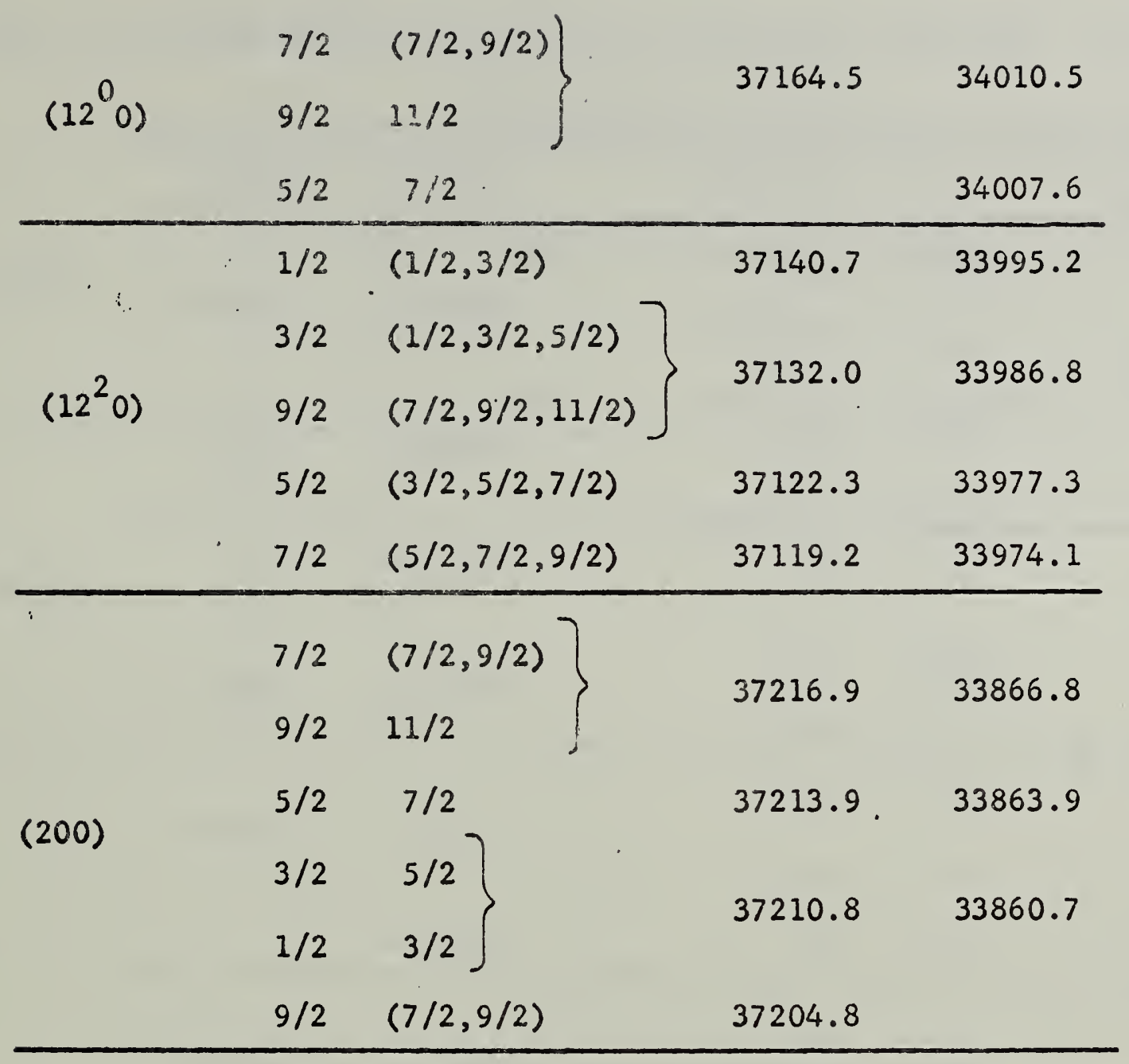


Table II. Observed frequencies in $\mathrm{Rb}^{87} \mathrm{OH}$ and $\mathrm{Rb}^{87} \mathrm{OD}$ in $\mathrm{Mc} / \mathrm{s}$ $(J=2-3$ transition).

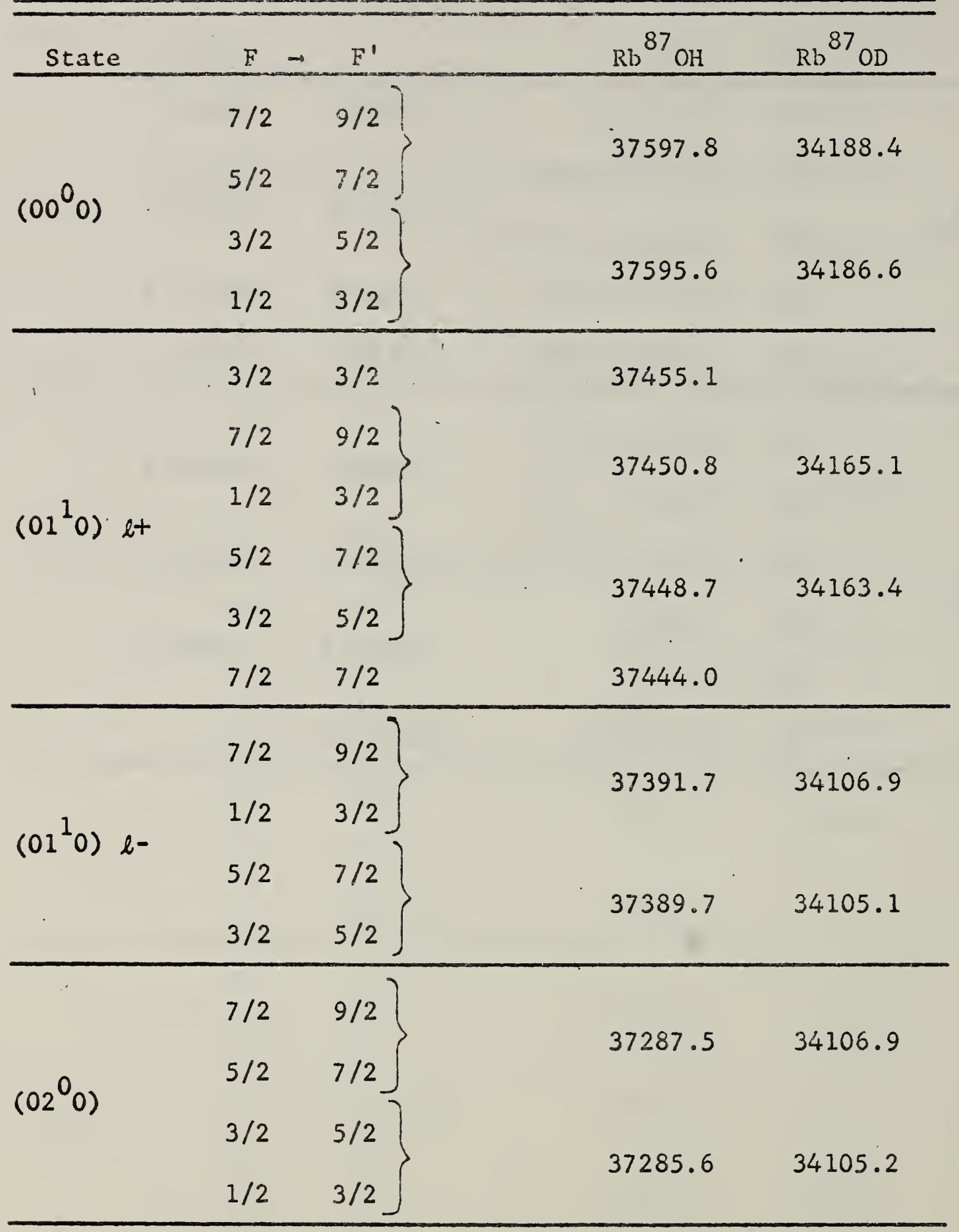


Table II. Continued

\begin{tabular}{|c|c|c|c|c|}
\hline \multirow{4}{*}{$\left(02^{2} 0\right)$} & $1 / 2$ & $3 / 2$ & 37246.8 & \multirow{3}{*}{34082.5} \\
\hline & $7 / 2$ & $(5 / 2,7 / 2,9 / 2)$ & 37241.1 & \\
\hline & $3 / 2$ & $(3 / 2,5 / 2)$ & 37238.3 & \\
\hline & $5 / 2$ & $(3 / 2,5 / 2,7 / 2)$ & 37232.8 & 34074.2 \\
\hline \multirow{4}{*}{$\left(10^{0} 0\right)$} & $7 / 2$ & $9 / 2$ & \multirow{4}{*}{37337.1} & \\
\hline & $5 / 2$ & $7 / 2$ & & 33960.8 \\
\hline & $5 / 2$ & $7 / 2$ & & \multirow{2}{*}{33959.0} \\
\hline & $3 / 2$ & $5 / 2$ & & \\
\hline
\end{tabular}


Table III. Effective rotational constants and nuclcar coupling constants (in $\mathrm{Mc} / \mathrm{s}$ ) for various vibrational states of $\mathrm{RbOH}$ and $\mathrm{RbOD}$.

\begin{tabular}{|c|c|c|c|c|}
\hline Stato & & $\mathrm{B}_{\mathrm{v}}\left(\mathrm{Rb}^{\mathrm{Sj} \mathrm{OH}}\right)$ & $\mathrm{B}_{\mathrm{V}}\left(\mathrm{Rb}^{85} \mathrm{OD}\right)$ & $\mathrm{eqQ}^{\mathrm{a}}$ \\
\hline $00^{\circ} 0$ & $\Sigma$ & 6290.15 & 5720.77 & -67.9 \\
\hline $01^{1} 0$ & $\pi$ & 6260.55 & 5711.69 & -67.6 \\
\hline $02^{0} 0$ & $\Sigma$ & 6238.37 & 5707.08 & $(-67,9)$ \\
\hline $02^{2} 0$ & $\Delta$ & 6230.13 & 5702.57 & -67.4 \\
\hline $03^{1} 0$ & $\pi$ & 6216.43 & 5702.34 & $(-67.6)$ \\
\hline $04^{2} 0$ & $\Delta$ & 6194.38 & 5697.42 & -67 \\
\hline $10^{0} 0$ & $\Sigma \Sigma$ & 6246.45 & 5682.50 & -65.9 \\
\hline $11^{1} 0$ & $\pi$ & 6216.70 & 5673.24 & -67 \\
\hline $12^{0} 0$ & $\sum$ & $\begin{array}{l}6194.03 \\
6187.95\end{array}$ & $\begin{array}{l}5668.37 \\
5663.35\end{array}$ & $\begin{array}{l}(-66) \\
-66.3\end{array}$ \\
\hline $20^{0} 0$ & $\Sigma$ & 6202.75 & 5644.40 & -64.2 \\
\hline State & & $\mathrm{B}_{\mathrm{v}}\left(\mathrm{Rb}^{87} \mathrm{OH}\right)$ & $\mathrm{B}_{\mathrm{V}}\left(\mathrm{Rb}^{87} \mathrm{OD}\right)$ & eqq \\
\hline $00^{0} 0$ & $\Sigma$ & 6266.35 & 5698.13 & -35 \\
\hline $01^{1} 0$ & $\pi$ & 6236.84 & 5689.32 & -33 \\
\hline $02{ }^{0} 0$ & $\Sigma$ & 6214.63 & 5684.53 & -31 \\
\hline $02^{2} 0$ & $\Delta$ & 6206.48 & 5680.02 & -32 \\
\hline $10^{0} 0$ & $\Sigma$ & 6222.90 & 5660.18 & $(-33)$ \\
\hline
\end{tabular}

$a$ The numbers in parentheses are assumed values. 
Table IV. $\quad$-doubling constants (Mc/s).

\begin{tabular}{lcccc} 
State & $\mathrm{q}\left(\mathrm{Rb}^{85} \mathrm{OH}\right)$ & $\mathrm{q}\left(\mathrm{Rb}^{85} \mathrm{OD}\right)$ & $\mathrm{q}\left(\mathrm{Rb}^{87} \mathrm{OH}\right)$ & $\mathrm{q}\left(\mathrm{Rb}^{87} \mathrm{OD}\right)$ \\
\hline$\left(01^{1} 0\right)$ & 9.87 & 9.82 & 9.85 & 9.70 \\
$\left(03^{1} 0\right)$ & 10.33 & 10.51 & & \\
$\left(11^{1} 0\right)$ & 10.73 & 10.12 & & \\
\hline
\end{tabular}


Table V. Variation of rotational constants with $\mathrm{v}_{1}$ in $\mathrm{Mc} / \mathrm{s}$.

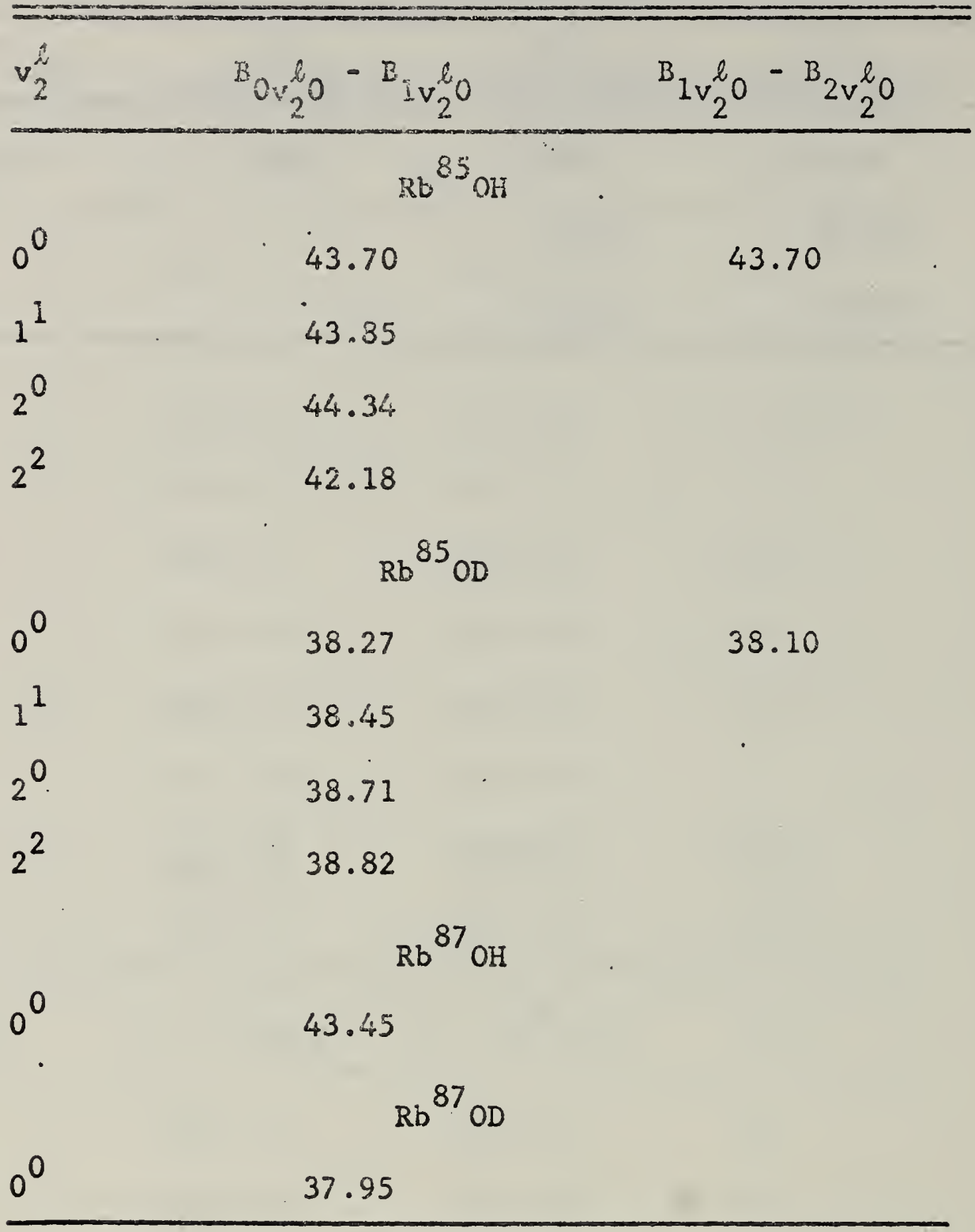


Table VI. Fit of $\mathrm{B}_{\mathrm{OV}}^{2} \mathrm{O}$ to power series in $\mathrm{Mc} / \mathrm{s}$.

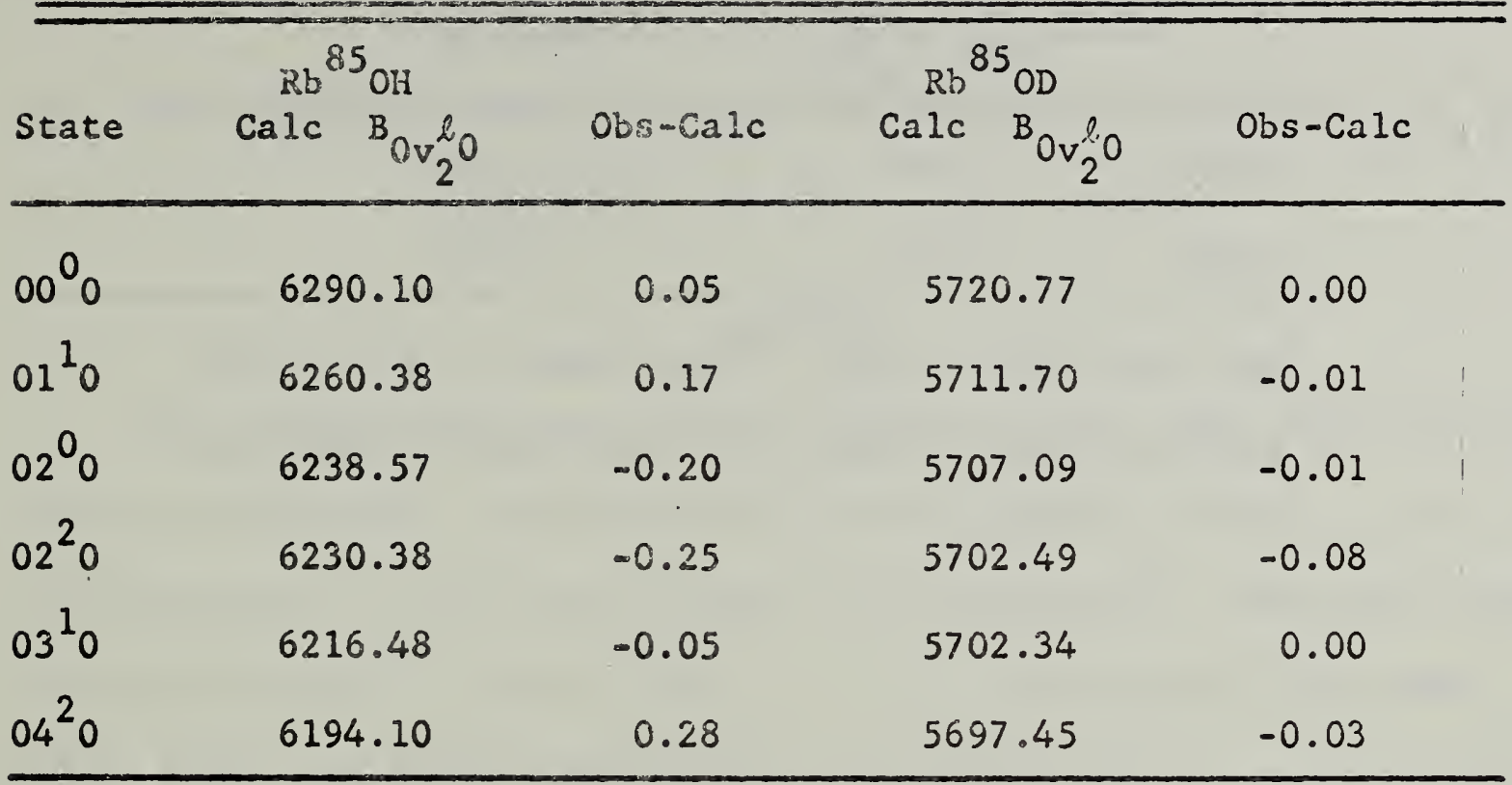


Table VII. Structural parameters of rubidium hydroxide in $A$.

\begin{tabular}{ccc} 
From $\mathrm{B}_{\mathrm{CO}} \mathrm{O}_{0}$ & From "B $\mathrm{e}^{\text {"la }}$ \\
$r(\mathrm{RbO})$ & 2.316 & 2.305 \\
$\mathrm{r}(\mathrm{OH})$ & 0.913 & 0.965 \\
\hline
\end{tabular}

a The first term in Eq. (1) was used as " $\mathrm{B}_{\mathrm{e}}$ " This set of values is felt to be the more reliable one. 


\section{STRUCTURE OH THE ALRALI HYDROXIDES}

IV. THE INERARED SPECTRA OF MATRIX ISOLATED RbOH, RbOD and NaOH, NaOD N. Acquista and Stanley Abramowitz

\section{ABSTRACT}

The infrared spectra of matrix isolated $\mathrm{RbOH}, \mathrm{RbOD}, \mathrm{NaOH}$ and $\mathrm{NaOD}$ have been observed. Both the alkali metal oxygen stretch, $v_{1}$, and the bending mode, $v_{2}$, has been assigned for each species. The metal oxygen stretching mode is found at $354.4,345,431$, and $422 \mathrm{~cm}^{-1}$ for $\mathrm{RbOH}$, $\mathrm{RbOD}, \mathrm{NaOH}$, and $\mathrm{NaOD}$, respectively; the bending mode, $v_{2}$, is observed at $309.0,229,337$, and $250 \mathrm{~cm}^{-1}$, respectively. Combination of the results of this study with the microwave measurements for $\mathrm{RbOH}$ and $\mathrm{RbOD}$ indicates an essentially linear structure for this species. The isotope shift for $v_{2}$ observed in $\mathrm{NaOH}$ coupled with reasonable bond lengths indicates an equilibrium configuration of $\mathrm{NaOH}$ which probably does not deviate significantly from linearity. The assumption of a linear model with a harmonic bending potential yields a force constant of .046 and $.053 \mathrm{md}-\AA$ for $\mathrm{RbOH}$ and $\mathrm{NaOH}$, respectively. These results are consistent with our previously reported results for $\mathrm{CsOH}$. 


\section{INTRODUCTION}

The second paper of this series described the infrared spectra of matrix isolated CsOH and CsOD. ${ }^{1}$ With the exception of the work by Spinar and Margrave, ${ }^{2}$ this is the only report on the infrared spectrum of $2 n$ isolated alkali metal hydroxide. other work on these systems ${ }^{3}$ was confined to solutions or single crystals which give 1ittle information on the structure of the monomeric species. Encouraged by the success encountered with $\mathrm{CsOH}$ a similar experiment was attempted for $\mathrm{RbOH}$ and $\mathrm{NaOH}$. The present paper presents the infrared spectra of matrix isolated $\mathrm{RbOH}, \mathrm{RbOD}, \mathrm{NaOH}$, and $\mathrm{NaOD}$.

\section{EXPERIMENTAL}

The experimental techniques used have been described previously by Mann et al. 4 The infrared spectra were obtained with a Perkin-Elmer 301 grating spectrophotometer with a wavenumber range of $4000-50 \mathrm{~cm}^{-1}$. $^{5}$ Refrigeration was provided by an Air Products Cryotip operated in the range of $20-33^{\circ} \mathrm{K}^{5}$ An electron bombardment furnace mounted in a vertical housing was utilized to vaporize the samples from double boiler silver Knudsen cells. In the course of this work it was found that the species studied react with tungsten, molybdenum, stainless stee1, nickel, nickel oxide, iron, copper, gold, and platinum at the high temperatures needed to obtain the spectra.

The $\mathrm{RbOH}$ and $\mathrm{NaOH}$ which were obtained from commercial sources were heated gradua11y to temperatures of about $600^{\circ} \mathrm{C}$ in order to remove water and other volatile impurities. Extended periods of outgassing were required in order to remove impurities which masked the spectrum of the 
various monomeric species. The deuteroxides were prepared from their respective hydroxides as prevlously described. ${ }^{6}$ However, it was difficult to prepare pure deuteroxides in this manner. Impurities thought to be oxides, peroxides, and/or superoxides tended to broaden the spectrum in the alkali retal oxygen stretching regions making it difficult to locate the vibrational frequencies of these modes with the usual accuracy. The difficulties in estimating temperatures of the effusing gas and the ratio of the matrix diluent to the sample (M/S) were similar to those in the case of $\mathrm{CsOH} .{ }^{1} \mathrm{M} / \mathrm{s}$ ratios of $300: 1$ to 1000:1 and temperatures of $700^{\circ} \mathrm{C}$ and $900^{\circ} \mathrm{C}$ for $\mathrm{RbOH}$ and $\mathrm{NaOH}$, respectively are probably representative of the conditions utilized in these experiments.

Diffusion studies in which the deposited sample was allowed to warm up to $33^{\circ} \mathrm{K}$ were performed in an effort to differentiate between monomeric and polymeric species. This method was partially successful for $\mathrm{NaOH}$, however as was the case for $\mathrm{CsOH}$, $\mathrm{RbOH}$ does not diffuse readily, even at $33^{\circ} \mathrm{K}$, probably because of its high molecular weight. The use of double boiler techniques in order to differentiate between monomeric and polymeric absorptions was more useful. It would be desirable, particularly for $\mathrm{NaOH}$ to go above $950^{\circ} \mathrm{C}$ for this purpose, however only silver crucibles were found to be relatively inert to $\mathrm{NaOH}$ at these high temperatures. One run was obtained with a platinum crucible at about $1100^{\circ} \mathrm{C}$, in which the corrosion of the crucible took place near the pinhole of the cell (as opposed to the bottom or side) allowing some $\mathrm{NaOH}$ effusing at this temperature to be trapped in an argon matrix. 
The frequencies were determined by using atmospheric water lines as calibration starcarcs. Spectral slit widths of about $1 \mathrm{~cm}^{-1}$ were used for frequency measurements which therefore are accurate to about $0.5 \mathrm{~cm}^{-1}$ except where noted.

\section{EXPERIMENTAL RESULTS}

These molecules have three normal modes; two of these $v_{1}$ and $v_{3}$ are the M-O and $0-\mathrm{H}$ stretching mode, while $\nu_{2}$ is the bending mode. Several strong bands appear in the region of $600-200 \mathrm{~cm}^{-1}$ in both $\mathrm{RbOH}$ and $\mathrm{NaOH}$. Figure 1 shows the pertinent portion of the spectra of $\mathrm{RbOH}$ in this region observed from two samples labeled $\mathrm{a}$ and $\mathrm{b}$. Spectrum $b$ was obtained from a sample effusing at a higher temperature than $a$. The band observed at $354.4 \mathrm{~cm}^{-1}$ is assigned to the $\mathrm{Rb}-0$ stretching mode, $v_{1}$, while the band at $309 \mathrm{~cm}^{-1}$ is assigned to the bending mode, $v_{2}$. A frequency of 371.3 has been observed for the $v_{0}$ vibration of RbF in the gas phase. ${ }^{7}$ All other bands in the spectrum decrease in intensity relative to these two as the temperature of the double boiler Knudsen cell (from which $\mathrm{RbOH}$ is effusing) is raised. These features also maintain their intensity relative to each other over a wide temperature range also indicating they belong to the same species. The bands whose relative intensity decrease are due to polymeric species of $\mathrm{RbOH}$, however it has not been possible to make definite assignments. Upon deuteration the $\mathrm{Rb}-0$ frequency shifts to $345 \pm 3 \mathrm{~cm}^{-1}$. The rather broad band observed for $v_{1}$ in $\mathrm{RbOD}$ is thought to be due to oxide, peroxide, and/or superoxide impurities introduced during 
deuteration. All these species could be expected to have bands in this region. A band also appears at $229 \pm 3 \mathrm{~cm}^{-1}$ which is assigned to $v_{2}$, the RbOD bending mode. This isotope shift observed for $v_{2}$ is in excellent agreement with that calculated for a linear model to the harmonic osc1llator approximation using the bond distances derived by Matsumura and Lide ${ }^{8}$ from an analysis of the microwave spectrum of RbOH and RbOD.

Infrared spectra of matrix isolated $\mathrm{NaOH}$ in the region of the $v_{1}$ and $v_{2}$ fundamentals are shown in Figure 2. Spectrum b was obtained from a higher temperature than a and spectrum $c$ results from allowing diffusion to take place in sample b. It can be seen that the $431 \mathrm{~cm}^{-1}$ is more intense relative to the others in spectrum $b$ than in $a$, while diffusion results in a diminution of the relative intensity of this feature as can be seen in c. This indicates that the $431 \mathrm{~cm}^{-1}$ band is due to a low molecular weight species, and it is assigned to $\nu_{1}$, the $\mathrm{Na}-0$ stretching mode of monomeric $\mathrm{NaOH}$. Confirmation of this hypothes is as well as an assignment for $v_{2}$ can be found in Figure 3 . This spectrum was obtained at a higher temperature in excess of $1000^{\circ} \mathrm{C}$ using a platinum Knudsen cell in which the corrosion took place at the top of the ce11. Three features appear in this spectrum at 431,400 , and $337 \mathrm{~cm}^{-1}$. The relative intensity of the $431 \mathrm{~cm}^{-1}$ to the $400 \mathrm{~cm}^{-1}$ feature confirms its assignment as the $v_{1}$ vibration. The $337 \mathrm{~cm}^{-1}$ is then assigned to $v_{2}$, the $\mathrm{NaOH}$ bending mode. This assignment is in agreement with Spinar and Margrave's observation of $437 \pm 10 \mathrm{~cm}^{-1}$ in the gas phase for the $\mathrm{Na}-\mathrm{O}$ stretching mode. Unlike $\mathrm{CsOH}$ and $\mathrm{RbOH}$, however the $\mathrm{NaOH}$ 
$v_{1}$ fundamental is rather far from the $522 \mathrm{~cm}^{-1}$ observed for the $v_{0}$ vibration of $\mathrm{Na}$ in the gas phase. ${ }^{7}$ The assignment of the other features observed in the spectrum between 450 and $250 \mathrm{~cm}^{-1}$ to particular polymers of NaOH is not possible.

The spectrum of NaOD observed in this region is shown in Figure 4. A comparable spectrum of $\mathrm{NaOH}$ is also given for comparison. By analogy with $\mathrm{NaOH}$ the $v_{1}$ fundamental is found at $422 \pm 3 \mathrm{~cm}^{-1}$. The breadth of this feature is probably due to oxide, peroxide, and/or superoxide impurities introduced during the synthesis of NaOD from NaOH. Confirmation of this assignment is found by observing $v_{2}$ shifted to $250 \mathrm{~cm}^{-1}$ as shown in Figure 5. This shift is consistent with a linear model for $\mathrm{NaOH}$ having bond lengths of 1.93 and $0.97 \AA$ for the $\mathrm{Na}-\mathrm{O}$ and $0-\mathrm{H}$ bonds, respectively. It is consistent with the explanation of the breadth of $v_{1}$ to note that two to three times longer deposition times are required to develop $v_{2}$ in NaOD than is required for $\mathrm{NaOH}$. A compilation of the data obtained together with previous results for $\mathrm{CsOH}$ can be found in Table. 1 .

The 0 -H stretching modes, $v_{3}$, should appear in the neighborhood of $3600 \mathrm{~cm}^{-1}$ for $\mathrm{RbOH}$ and $\mathrm{NaOH}$ and $2560 \mathrm{~cm}^{-1}$ for RbOD and NaOD. The spectra were studied in these regions, but no meaningful assignments could be made because of water absorption. 
TABLE 1

OBSERVM BANDS FOR MONOMERIC ALKAII METAL HYDROXIDES

\begin{tabular}{lccccc} 
Mo1ecule & $v_{1}$ & $v_{2}$ & $v_{3}$ & \multicolumn{2}{c}{ Microwave } \\
& & & & $r_{\mathrm{MO}}$ & $\mathrm{r}_{\mathrm{OH}}$ \\
$\mathrm{CsOH}$ & 335.6 & 309.8 & & & \\
$\mathrm{CsOD}$ & 330.5 & 226 & & 2.40 & 0.96 \\
$\mathrm{RbOH}$ & 354.4 & 309.0 & & & \\
$\mathrm{RbOD}$ & $345 \pm 3$ & $229 \pm 3$ & & & \\
$\mathrm{NaOH}$ & 431 & 337 & & & \\
$\mathrm{NaOD}$ & $422 \pm 3$ & 250 & & &
\end{tabular}


1. N. Acquista, S. Abramowitz, D. R. Lide, J. Chem. Phys. 49 , (July 15) 1968.

2. L。H. Spinar, J. L. Margrave, Spectrochim. Acta 12, 244 (1958).

3. K. Nakamoto, Infrared Spectra of Inorganic and Coordination Compounds (John Wiley \& Sons, Inc。, New York, 1963) p. 73.

4. D. E. Mann, G. V. Calder, D. White, K. S. Seshadri, M. J. Linevsky, J. Chem. Phys. 46, 1138 (1967).

5. Certain commercial instruments are identified in order to specify the complete experimental procedure. In no case does such identification imply a recommendation or endorsement by the National Bureau of Standards。

6. D. R. Lide, R. L. Kuczkowski, J. Chem。 Phys. 46 , 4768 (1967).

7. S. E. Veazey, W. Gordy, Phys。Rev。138, A1303 (1965).

8. C. Matsumura, D。R。 Lide, to be published. 


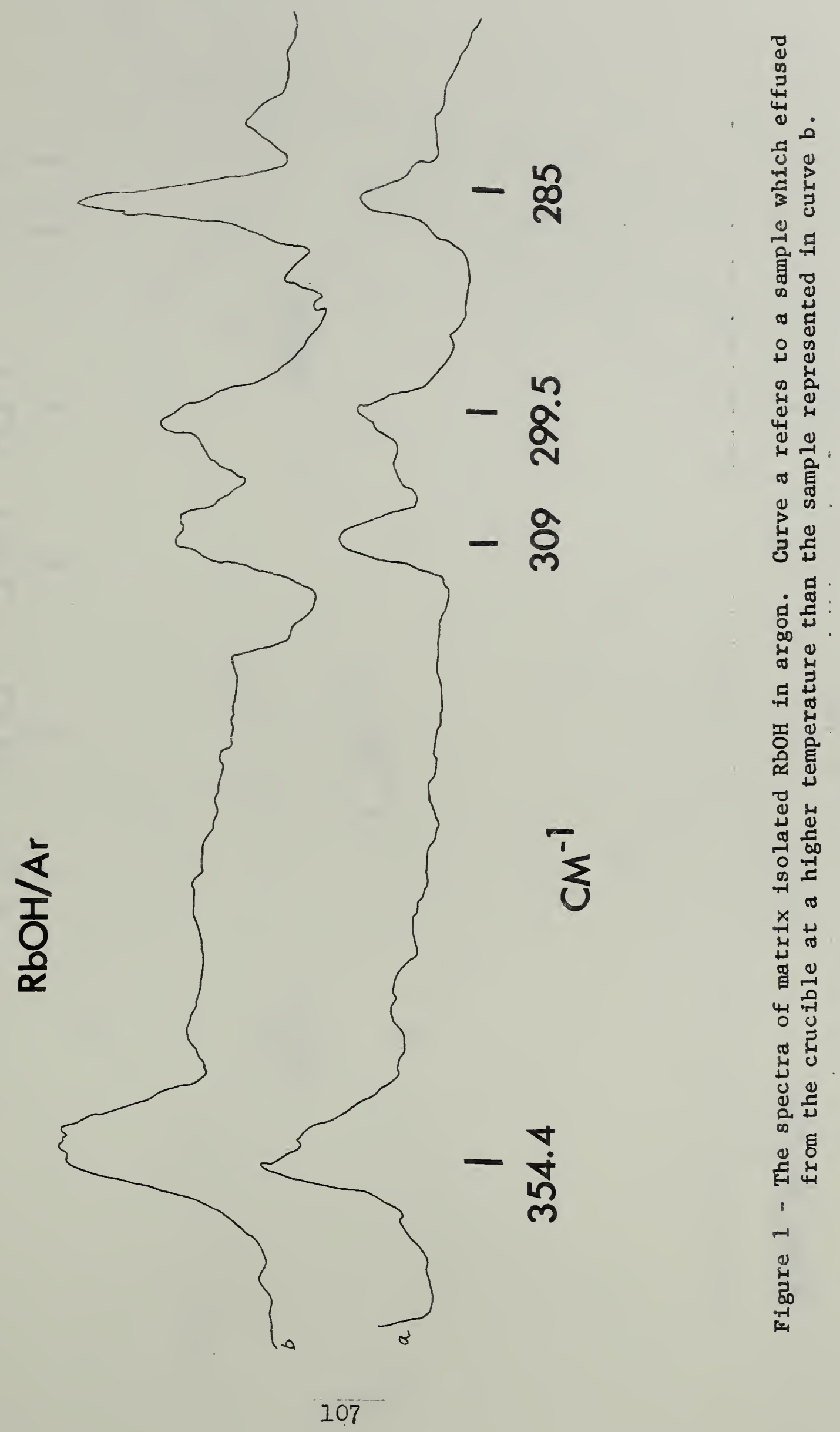




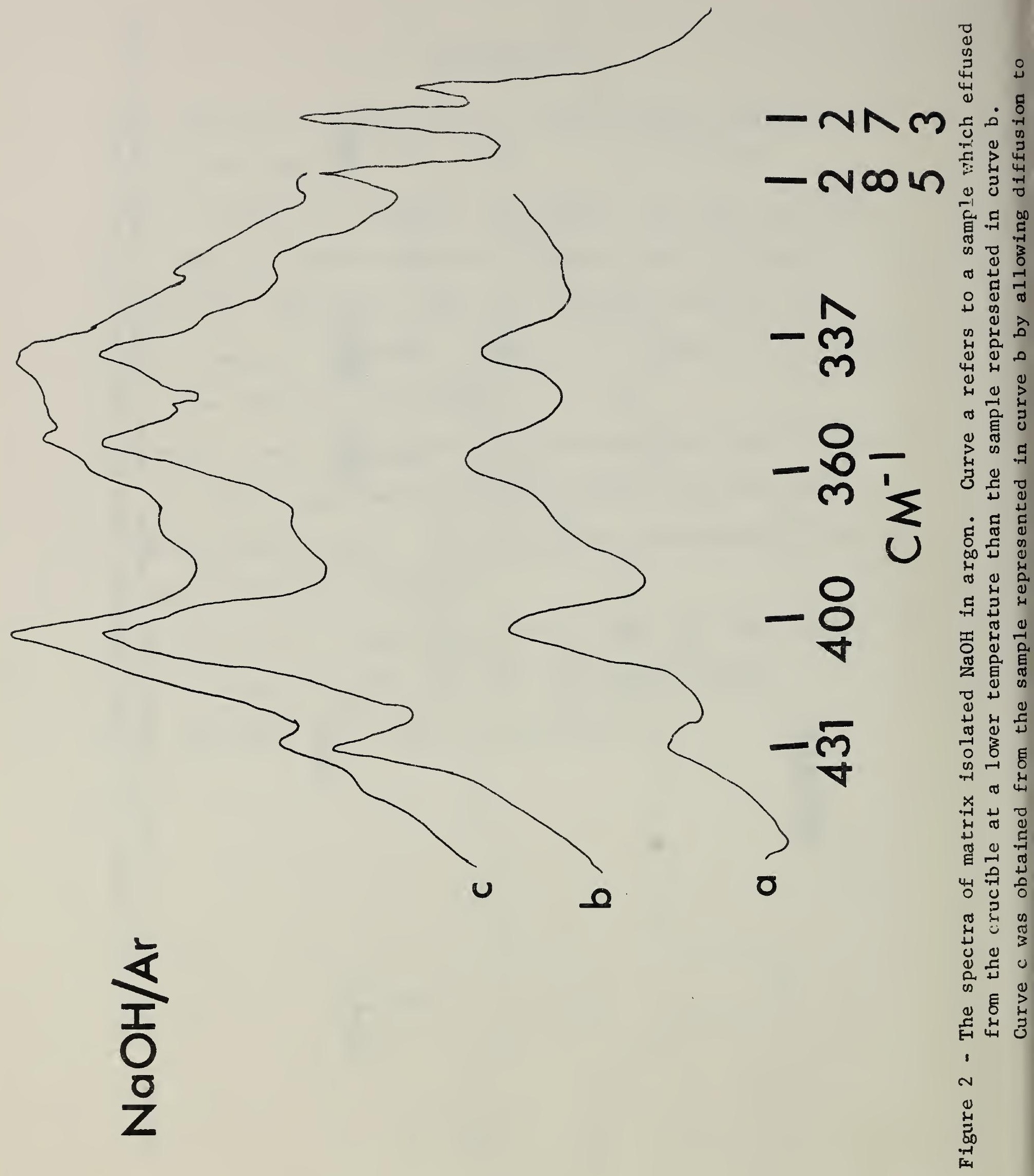



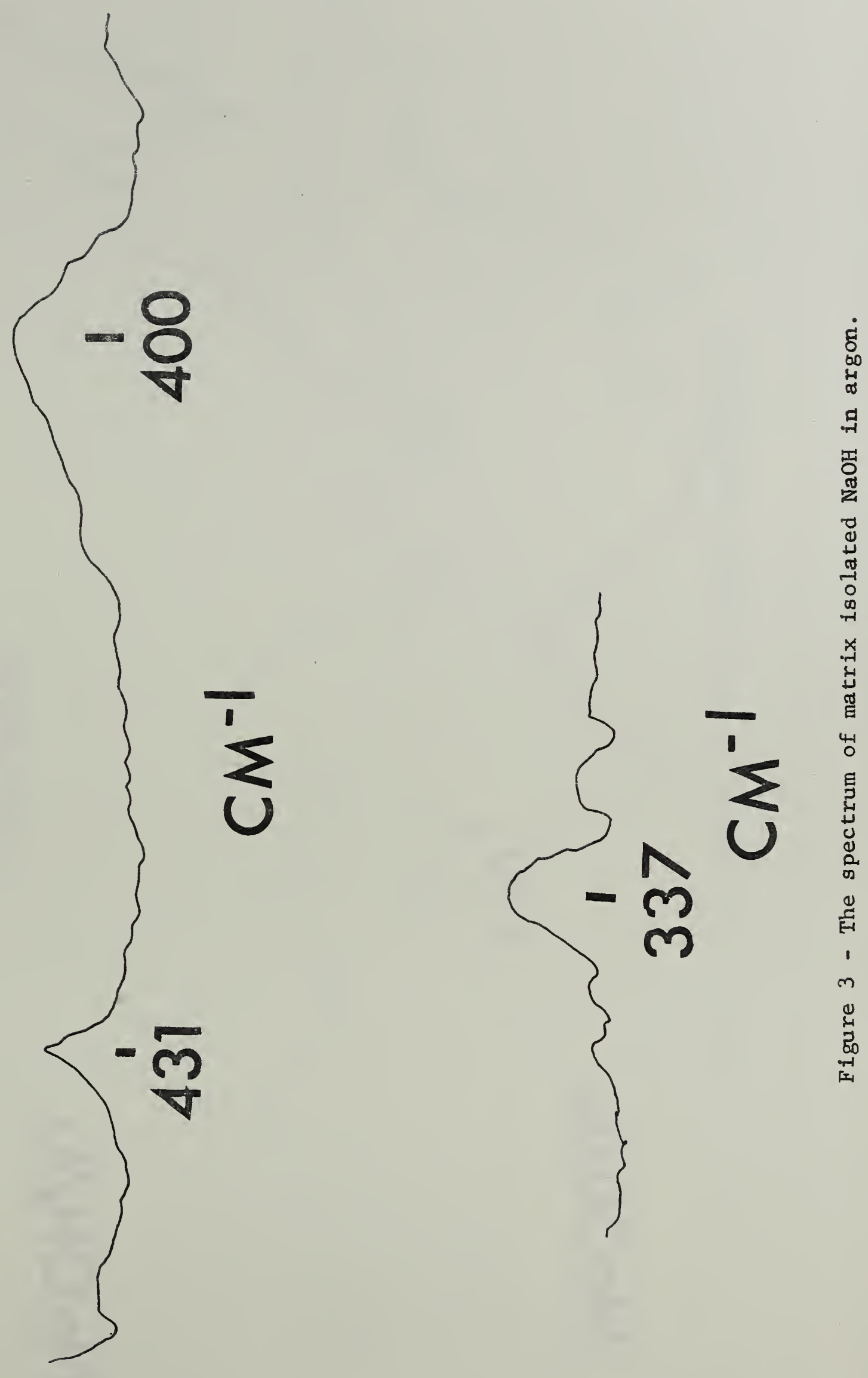


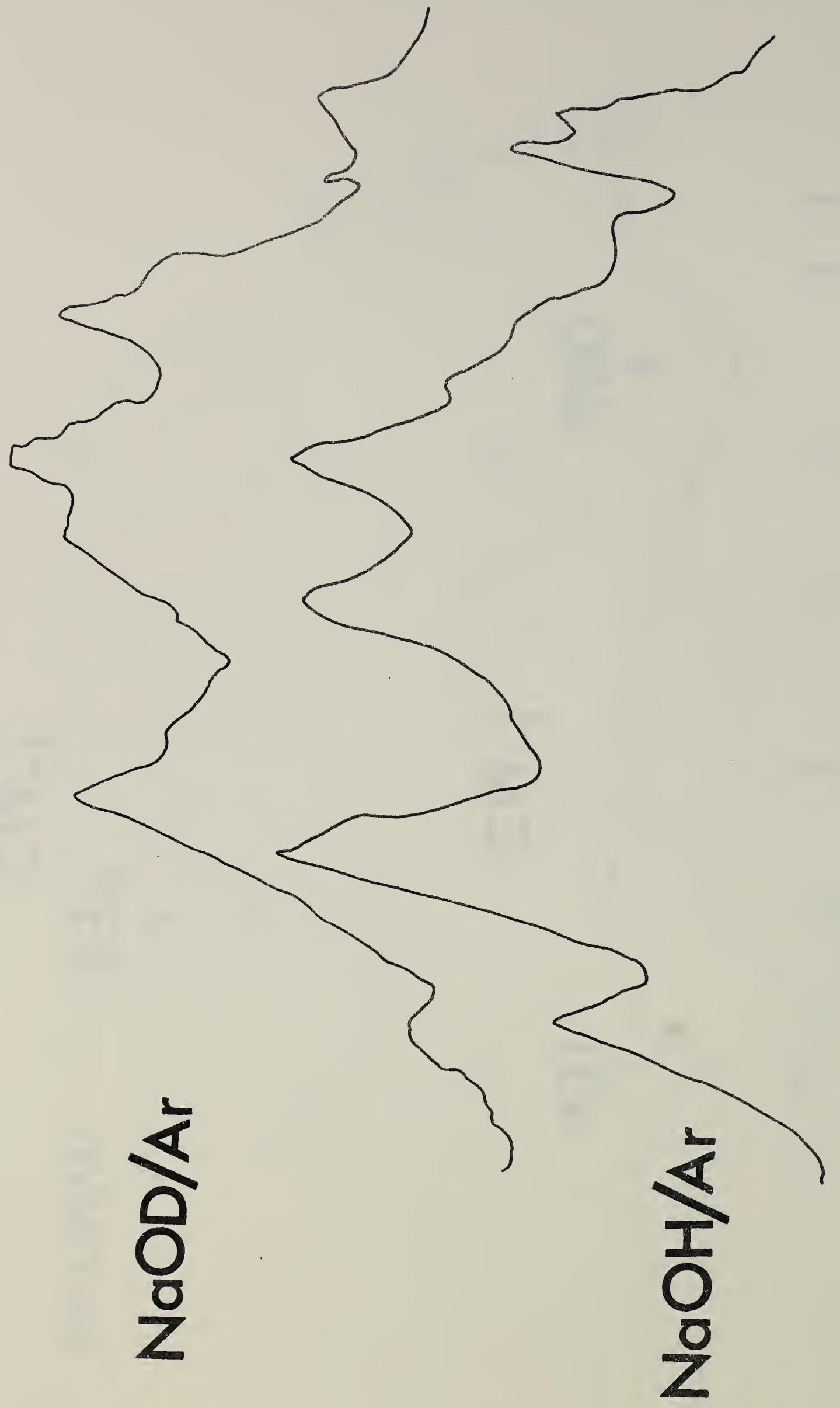

100

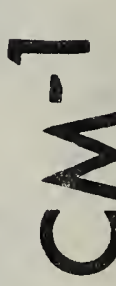

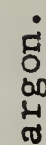

묘

四

ป

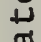

$-1$ 

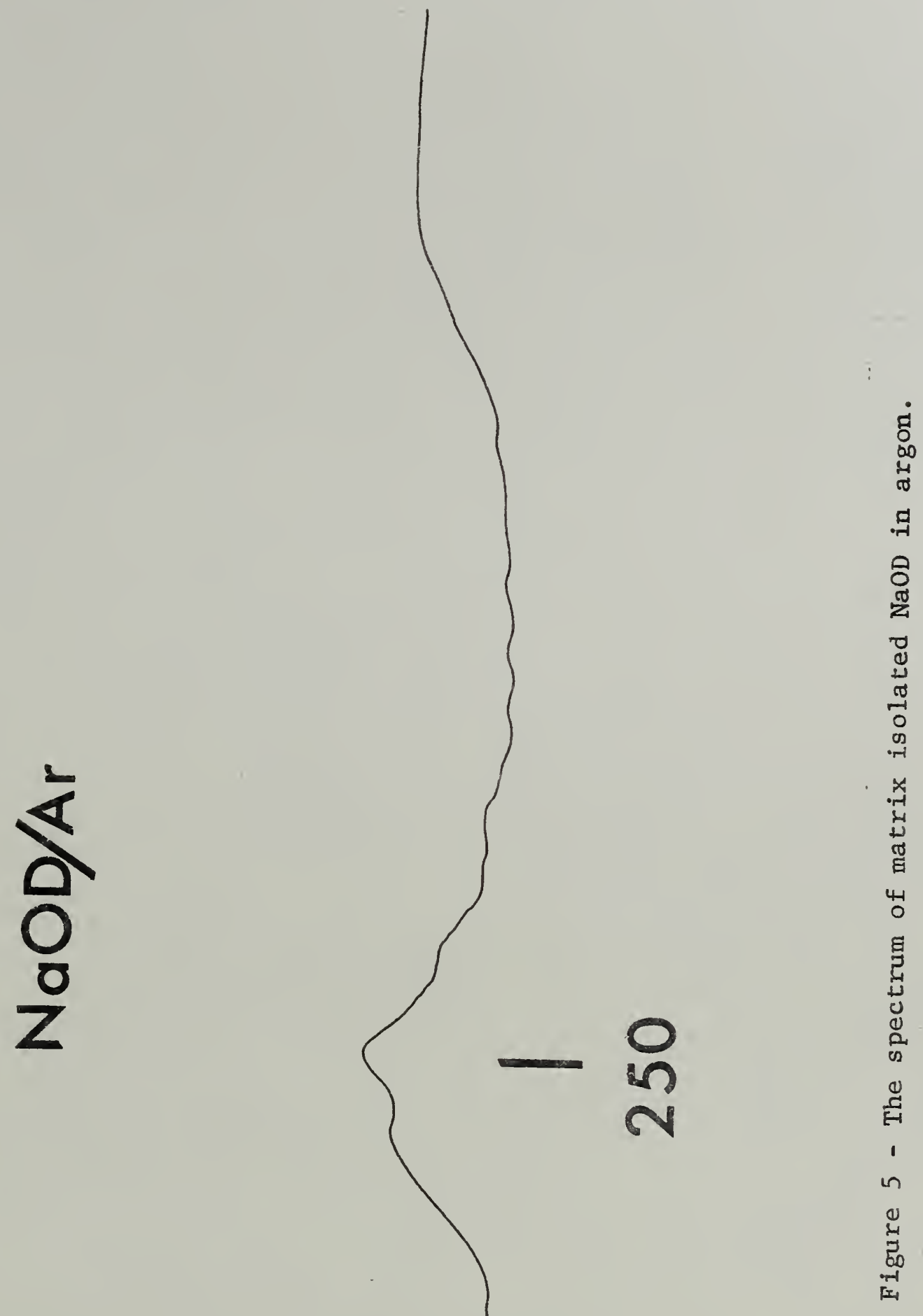



\section{.}


(i) 